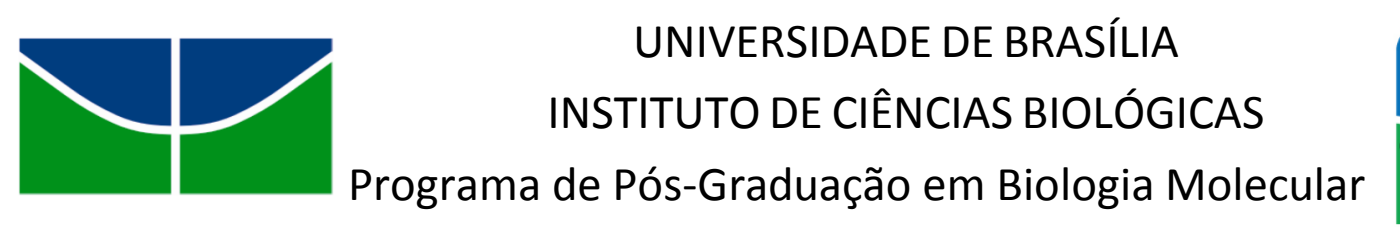

Departamento de Ciências Fisiológicas

Laboratório de Toxinologia

Caroline Barbosa Farias Mourão

\title{
NOVA CLASSE DE INIBIDOR DE SERINOPEPTIDASE PRESENTE NA PEÇONHA DO ESCORPIÃO Tityus obscurus
}

Brasília 


\title{
NOVA CLASSE DE INIBIDOR DE SERINOPEPTIDASE PRESENTE NA PEÇONHA DO ESCORPIÃO Tityus obscurus
}

\begin{abstract}
Tese apresentada ao Programa de PósGraduação em Biologia Molecular do Instituto de Ciências Biológicas da Universidade de Brasília como requisito parcial à obtenção do título de Doutora em Biologia Molecular.
\end{abstract}

Orientadora: Dra. Elisabeth Ferroni Schwartz

Brasília 


\section{BANCA EXAMINADORA}

Profa. Dra. Elisabeth Ferroni Schwartz - Presidente da banca examinadora Universidade de Brasília

Prof. Dr. Ricardo Bentes de Azevedo - membro interno Universidade de Brasília

Prof. Dr. João Alexandre R. G. Barbosa - membro interno Universidade de Brasília

Profa. Dra. Ana Marisa Chudzinski Tavassi - membro externo Instituto Butantan

Prof. Dr. Paulo Cezar Vieira - membro externo Universidade Federal de São Carlos

Profa. Dra. Márcia Renata Mortari - membro suplente Universidade de Brasília 
Dedico essa tese

à minha mãe, Jaqueline Barbosa, ao meu aconchego, Lucas Caridade, à minha mentora, Elisabeth Ferroni, e a todas as pessoas incriveis que me inspiraram nessa trajetória. 


\section{Agradecimentos}

Agradeço imensamente à minha querida mãe, Jaqueline, por ser minha referência de força e independência, pelo amor, suporte e por ter sempre apoiado minhas escolhas acadêmicas. À minha família, pelo carinho, diversão e por estarem sempre na torcida.

Ao Lucas Caridade, pelo amor, companheirismo e motivação. Obrigada por me ajudar a superar muitas dificuldades ao longo desse caminho, tornando tudo mais leve. À sua família, que me adotou tão bem e fez a torcida ainda maior.

À Dra. Elisabeth Ferroni, pela orientação, incentivo, sugestões, inspirações e pela confiança depositada em mim, sempre estimulando minhas ideias e me dando todo o espaço científico que eu pude ter. Obrigada por me ensinar tanto nesses nove anos de colaboração, pela companhia nos congressos nos pontos mais extremos desse planeta, pela oportunidade de conhecer novos pesquisadores e pelos aprendizados que carregarei para a vida.

Ao Dr. Carlos Bloch Jr., do Laboratório de Espectrometria de Massa - EMBRAPA Recursos Genéticos e Biotecnologia - Brasília, por permitir livre acesso ao laboratório e auxiliar nos processos envolvendo espectrometria de massa e análises químicas. A ele devo a afeição pela química de proteínas, sempre ensinada de forma muito entusiástica e rica em detalhes. À Dra. Maura Prates pelo auxílio com a síntese química e cromatografias e pelos eventuais lanchinhos e chocolates. Ao Dr. Thiago Mattos e ao Marcelo Ramada pela ajuda com a montagem e uso do espectropolarímetro de dicroísmo circular. A todos os alunos, pesquisadores e funcionários do Laboratório de Espectrometria de Massa, pela amizade e colaboração em diversos momentos. Tive o prazer de tê-los como "segundo laboratório" e poder realizar várias etapas da minha pesquisa em colaboração.

Ao Dr. Guilherme Brand, do Departamento de Química Orgânica da Universidade de Brasília - UnB, pelo acompanhamento nos experimentos de Ressonância Plasmônica de Superfície (SPR), pela ajuda com os experimentos, análises e pelas significativas conversas sobre cinética enzimática e termodinâmica.

À Dra. Sônia Freitas, do Laboratório de Biofísica Molecular, no Departamento de Biologia Celular - UnB, pelo auxílio nos experimentos com espectroscopia de dicroísmo circular.

Ao Dr. Ricardo Bentes de Azevedo, do Departamento de Genética e Morfologia, IB - UnB, por permitir o uso de seu laboratório e por ceder as células usadas nos ensaios antitumorais. À Dra. Graziella Joanitti, pelo acompanhamento durante a realização dos 
ensaios antitumorais in vitro e por me ensinar os primeiros passos com ensaios enzimáticos.

Ao Dr. Lourival Possani, do Instituto de Biotecnologia da Universidad Nacional Autónoma de México (UNAM), pela colaboração e por me receber tão gentilmente em seu laboratório. À Dra. Rita Restano-Cassulini, pela amizade, carinho, e pelo auxílio na realização dos ensaios eletrofisiológicos em sistema patch clamp. A todos los amigos do laboratório, que tornaram minha estada mais divertida e calorosa.

À Dra. Márcia Mortari, sempre tão querida e disposta a ajudar, e aos alunos do Laboratório de Farmacologia - UnB, em especial à Juliana de Castro e à Flávia Medeiros, pela ajuda na realização do ensaio em camundongos.

Ao Dr. João Alexandre Barbosa, à Dra. Cristiane Ano Bom e ao Dr. Francisco Gomes-Neto, pela colaboração com os experimentos de caracterização estrutural, ainda em andamento. À Dra. Simone Fonseca pelos experimentos de atividade antirretroviral, também em fase de realização.

À Brenda Camargo, pela assistência com os cálculos de velocidade enzimática. Ao Dr. Daniel Ardisson e ao César Prías, pela ajuda com o microscópio e processamento de imagens. Ao Daniel Machado, por inúmeras vezes me ajudar a sanar minhas dúvidas quanto à escrita do manuscrito.

Aos demais professores que influenciaram direta ou indiretamente esse projeto, em especial ao Prof. Carlos Schwartz pelos ensinamentos e carinho. À equipe de técnicos do LTx, em especial ao Adolfo Souza, pela ajuda e amizade. A todos os amigos do LTx, que juntos me deram uma família magnífica com a qual tive o prazer de estar ao lado por todos esses anos. Vocês são incríveis!

Aos meus queridos estagiários e alunos de Iniciação Científica Alessa Bembom, Luísa Coelho e Diogo Tibery, pela amizade, companhia, por estarem sempre dispostos e me ajudarem em diversas etapas. Vocês me permitiram estar em mais de um lugar ao mesmo tempo e sou eternamente grata por essa extensão corporal.

A todos meus estimados amigos que torceram tanto para a conclusão desse trabalho, em especial a Luiza Prado e o clube da Lulu, Bárbara, Humberto, Carol Carrijo, Dani e muitos outros queridos. Obrigada pela força, incentivo e pelo carinho.

Às agências de fomento CNPq e FAPDF pela concessão de apoio financeiro para a realização desse projeto.

À Empresa Brasileira de Pesquisa Agropecuária (EMBRAPA) - Recursos Genéticos e Biotecnologia, por permitir o uso de suas instalações.

À Universidade de Brasília e ao Programa de Pós-Graduação em Biologia Molecular, por possibilitarem a execução desse projeto. 


\section{Sumário}

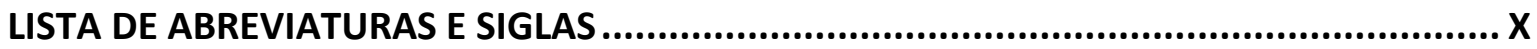

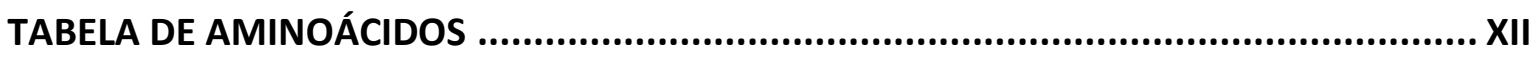

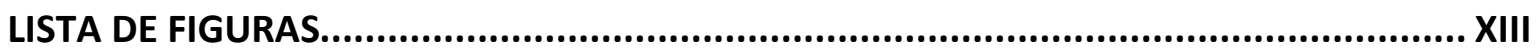

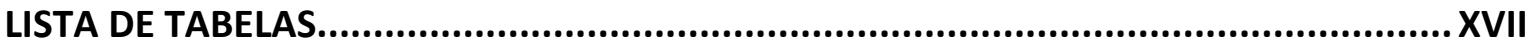

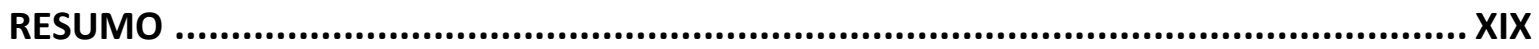

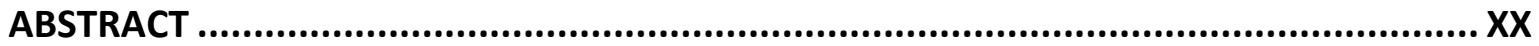

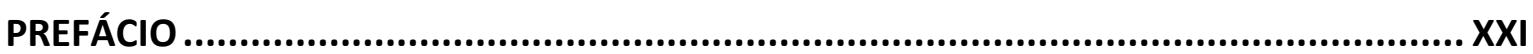

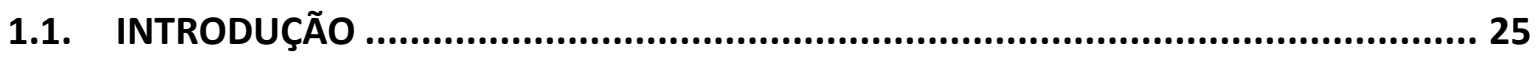

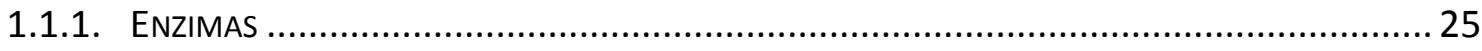

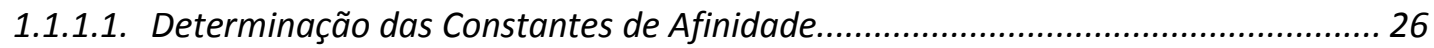

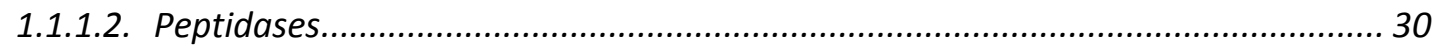

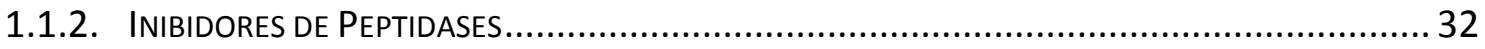

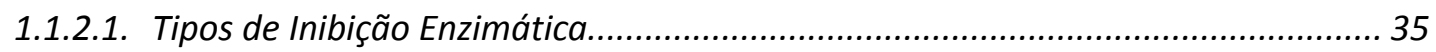

1.1.2.2. Inibidores de Peptidase de Venenos e Peçonhas Animais ..................................... 38

1.1.2.3. Câncer, Peptidases e Inibidores de Peptidases..................................................... 41

1.1.2.4. Inibidores de Peptidase com Ação em Canais de Potássio ...................................... 46

1.1.3. EsCoRPIÃo TITYUS OBSCURUS E ESTUdOS COM SUA PEÇONHA ..........................................53

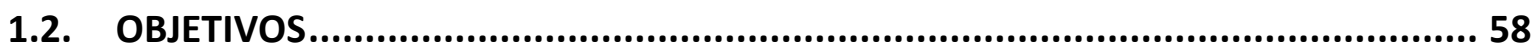

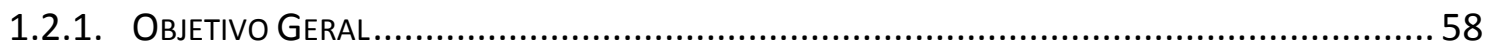

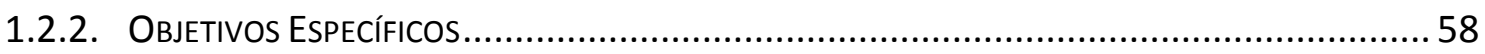

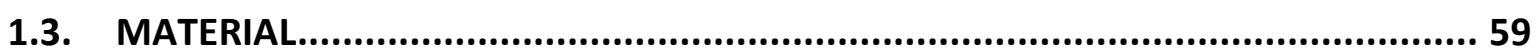

1.3.1. Solventes para Cromatografia LíQuida (HPLC E UFLC).......................................59

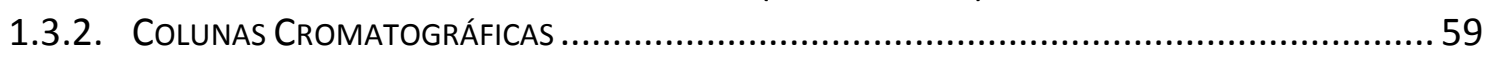

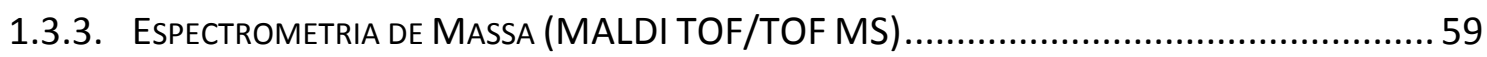

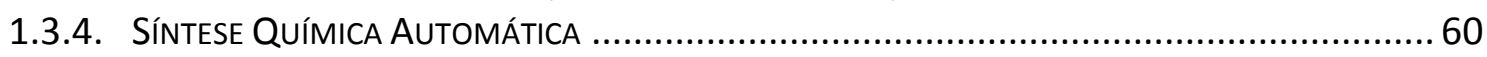

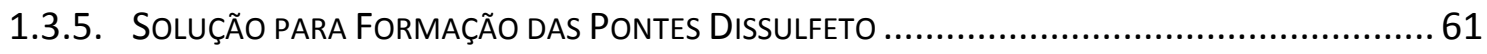

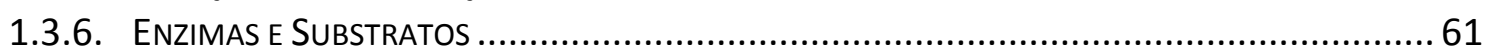

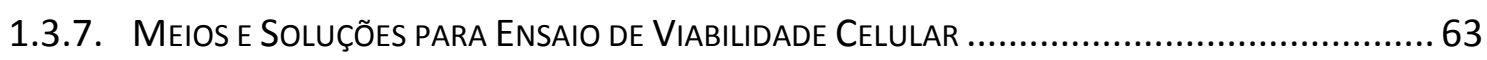

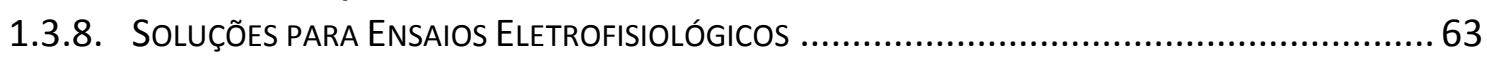

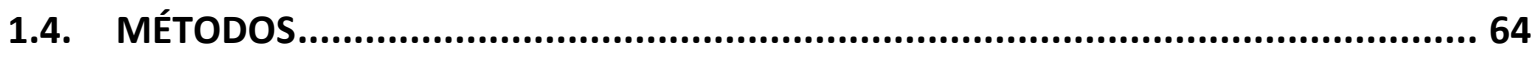

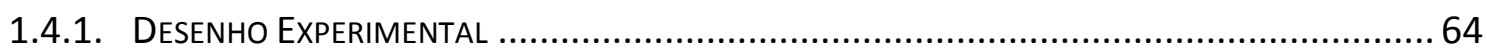

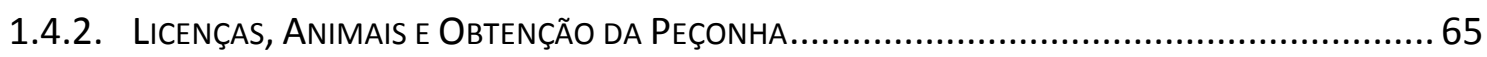

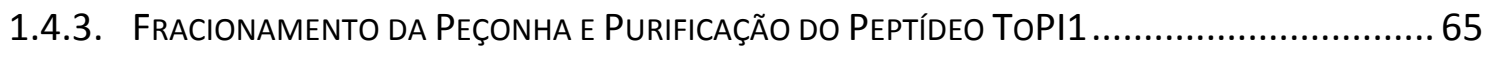

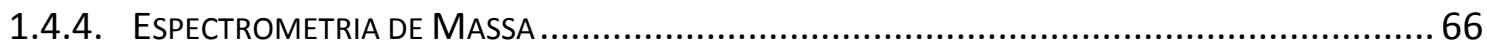

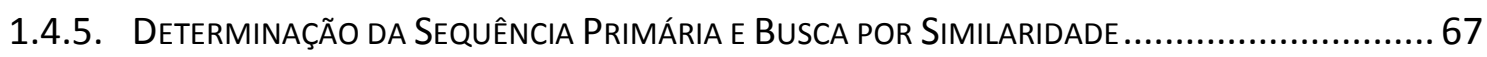

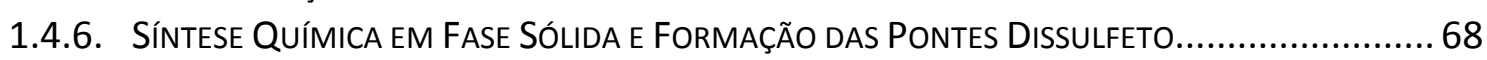

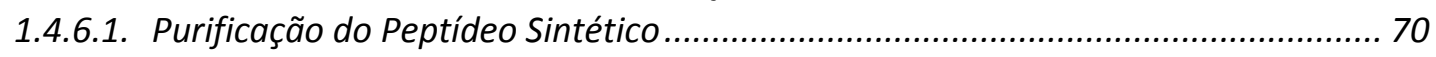




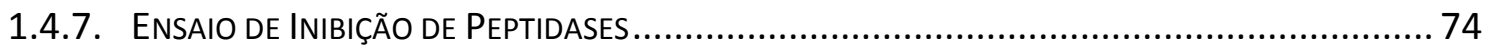

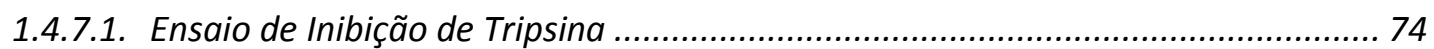

1.4.7.2. Mecanismo de Ação e Constante de Afinidade para Tripsina ............................... 76

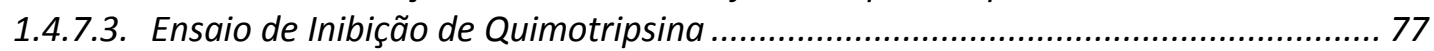

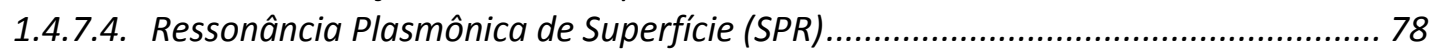

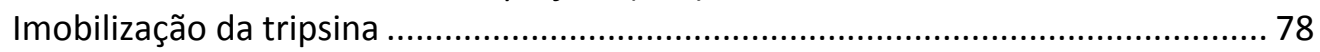

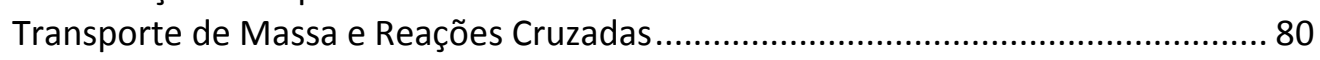

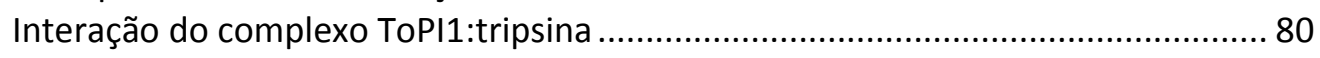

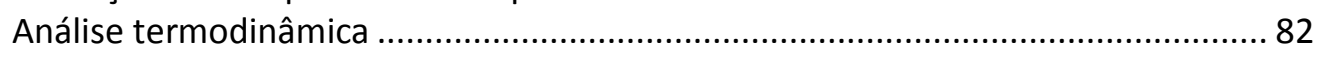

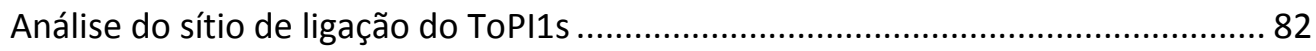

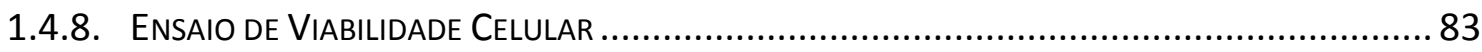

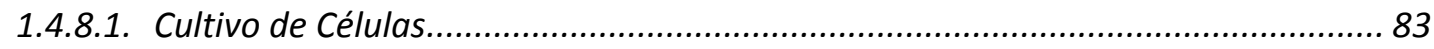

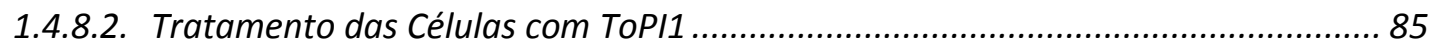

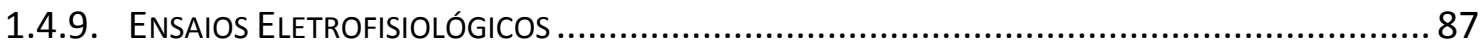

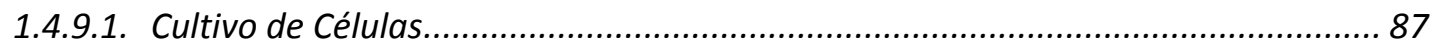

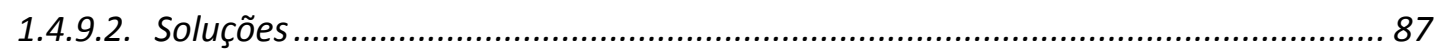

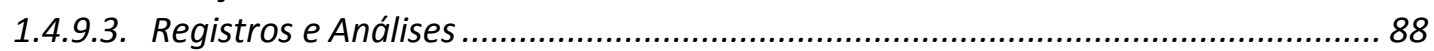

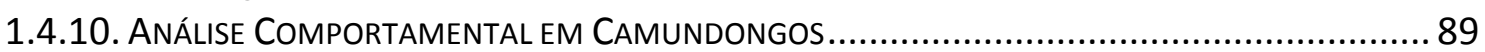

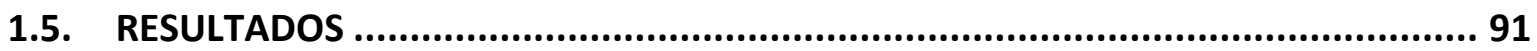

1.5.1. Fracionamento da Peçonha Bruta e Purificação do ToPi1 Nativo ........................ 91

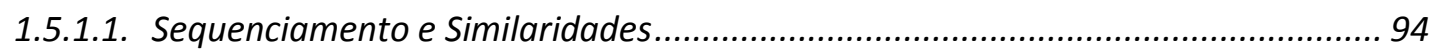

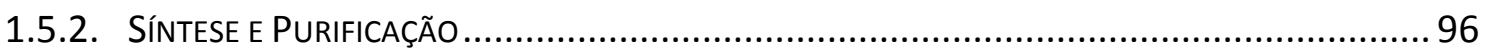

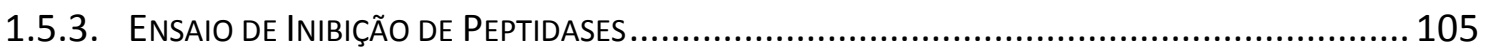

1.5.3.1. Ensaios Cromogênicos com ToPI1s, ToPl1s-Met* e ToPI1s reduzido .................... 106

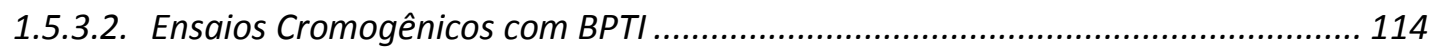

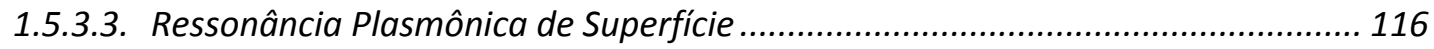

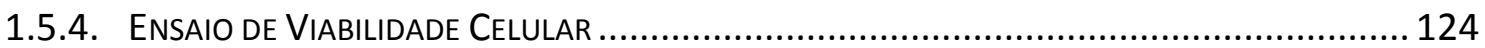

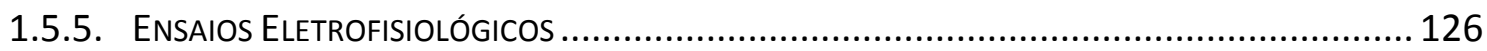

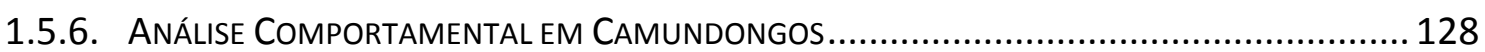

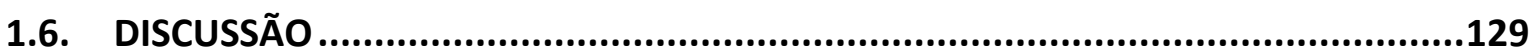

Caracterização da sequência primária do ToPI1 e similaridades............................ 130

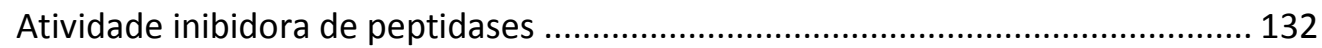

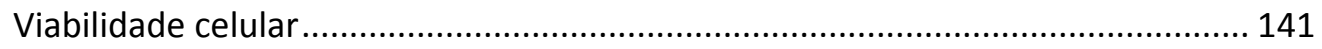

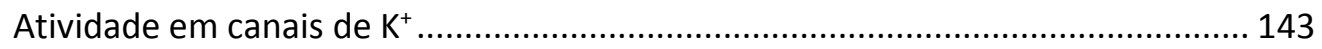

Análise comportamental em camundongos ..................................................... 146

Síntese química e oxidação do ToPI1 ..................................................................... 147

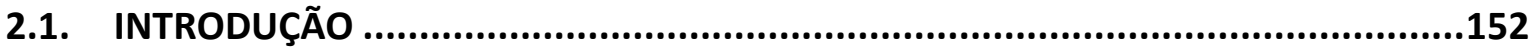

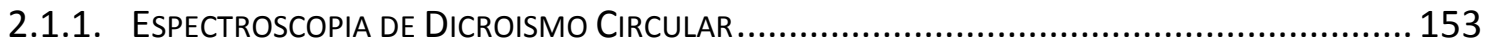

2.1.2. Motivos Estruturais de Inibidores de PePtidase de PeÇonhas Animais .................... 156

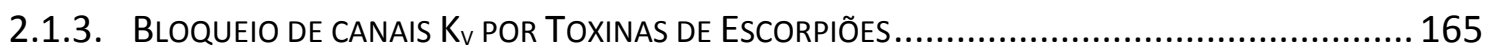

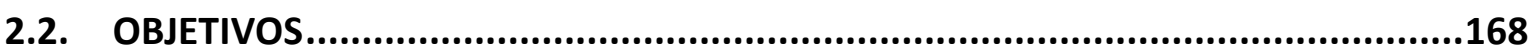

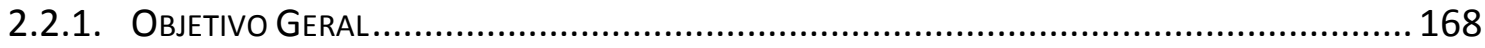

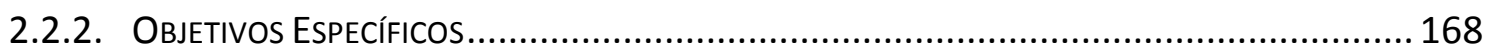

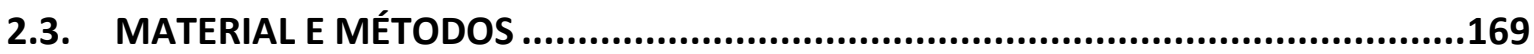


2.3.1. ESPECTROSCOPIA DE DICROISMO CIRCULAR 169

2.3.2. Síntese Química em Fase Sólida e Formação das Pontes Dissulfeto de DoIs ANÁlogos 170

2.3.3. PURIFICAÇÃo dos ANÁlogos SintÉtICOS 172

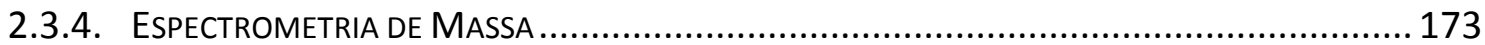

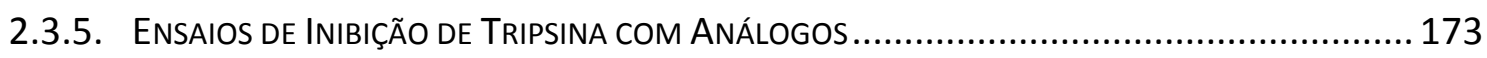

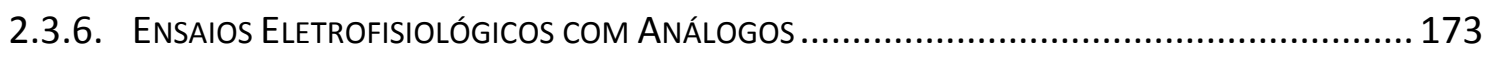

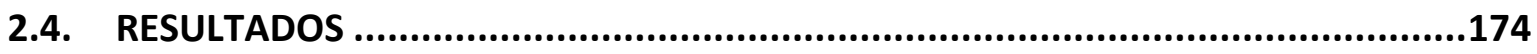

2.4.1. Estrutura SeCUndária e ESTABILIDAde Química e TÉRMICA do ToPI1S........................ 174

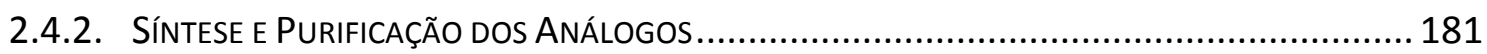

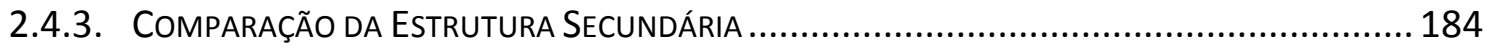

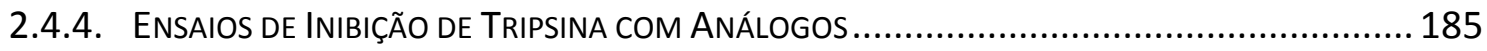

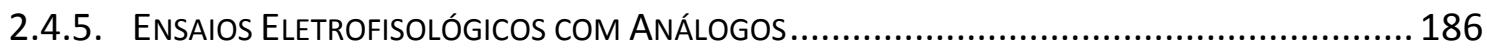

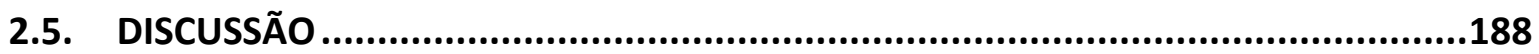

Caracterização estrutural e estabilidade do peptídeo ToPI1s ................................ 188

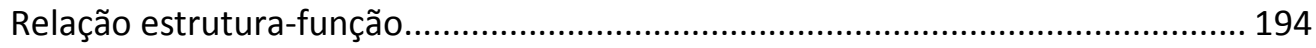

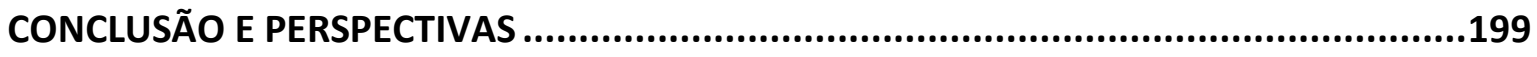

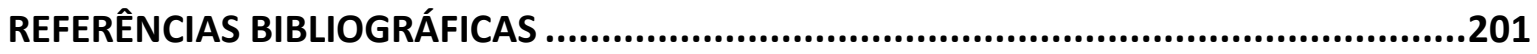

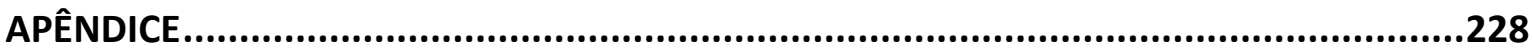




\section{LISTA DE ABREVIATURAS E SIGLAS}

$\begin{array}{ll}\text { Abs } & \text { absorbância } \\ \text { ACN } & \text { acetonitrila } \\ \text { ATCC } & \text { American Type Culture Collection } \\ \text { BBI } & \text { inibidor Bowman-Birk } \\ \text { BLAST } & \text { Basic Local Alignment Search Tool } \\ \text { CD } & \text { Circular Dichroism / dicroísmo circular } \\ C_{f} & \text { concentração final } \\ C_{p} & \text { calor específico sob pressão constante } \\ \text { CS- } \alpha / \beta & \text { Cysteine-Stabilized } \alpha / 6 \text { motif / motivo } \alpha / \beta \text { estabilizado por cisteína } \\ \text { DE } 50 & \text { dose efetiva média, capaz de produzir o efeito em } 50 \% \text { da população } \\ \text { E } & \text { enzima } \\ \text { ES } & \text { complexo enzima-substrato } \\ \text { E }_{\boldsymbol{t}} & \text { enzima total }\end{array}$

HPLC High-performance liquid chromatography / cromatografia líquida de alta eficiência

I inibidor

I/I máx amplitude da corrente em função da corrente máxima

IC intervalo de confiança

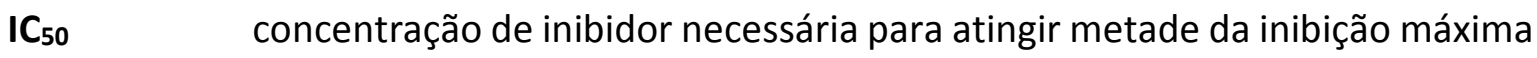

ISD

in-source decay / fragmentação na fonte

$K_{\mathrm{A}}$

constante de associação ou afinidade

$K_{\mathrm{D}} \quad$ constante de dissociação

$\boldsymbol{K}_{\mathbf{i}} \quad$ constante inibitória

$\boldsymbol{K}_{\mathbf{i}}^{\text {app }} \quad$ constante inibitória aparente

$\kappa_{1}$

constante de equilíbrio para a ligação do inibidor à enzima livre (E)

$\kappa^{\prime}$

constante de equilíbrio para a ligação do inibidor ao complexo ES

$K_{\mathrm{m}}$

constante de Michaelis, concentração de substrato para atingir $1 / 2 V_{\text {máx }}$ de acordo com o modelo cinético de Henri-Michaelis-Menten

KTI Kunitz-type inhibitor / inibidor do tipo Kunitz

KTx toxina com ação em canal de potássio

$\mathrm{K}_{\mathrm{v}}$

canal de potássio dependente de voltagem

$\boldsymbol{h} \quad$ coeficiente de Hill

$\mathbf{h K}_{\mathbf{v}} \quad$ canal de potássio dependente de voltagem isolado de humanos

$\mathbf{r K}_{\mathbf{v}} \quad$ canal de potássio dependente de voltagem isolado de ratos

$\boldsymbol{k}_{1}$ ou $\boldsymbol{k}_{\mathrm{a}} \quad$ constante de velocidade para as reações de formação do complexo ES

$\boldsymbol{k}_{\text {-1 }}$ ou $\boldsymbol{k}_{\mathbf{d}} \quad$ constante de velocidade para as reações de dissociação do complexo ES

MALDI Matrix Assisted Laser Desorption/Ionization / dessorção/ionização a laser auxiliada por matriz 


\begin{tabular}{|c|c|}
\hline MM & massa molecular \\
\hline MRW & Mean Residue Weight / massa residual média \\
\hline MS & Mass Spectrometry / espectrometria de massa \\
\hline MS/MS & Tandem Mass Spectrometry / espectrometria de massas sequencial \\
\hline$m / z$ & relação massa/carga \\
\hline NaScTx & toxina de escorpião com ação em canal de sódio / $\mathrm{Na}^{+}$-scorpion toxin \\
\hline $\mathbf{P}$ & produto \\
\hline PDB & Protein Data Bank \\
\hline $\mathbf{R}^{2}$ & coeficiente de determinação \\
\hline RMN & Ressonância Magnética Nuclear \\
\hline $\mathbf{R P}$ & Reversed-phase / fase reversa \\
\hline $\mathbf{R}_{\mathbf{T}}$ & Retention time / tempo de retenção \\
\hline $\mathbf{S}$ & substrato \\
\hline SPR & Surface Plasmon Ressonance / Ressonância Plasmônica de Superfície \\
\hline $\mathbf{T}$ & temperatura \\
\hline TFA & ácido trifluoroacético \\
\hline$T_{m}$ & temperatura de desnaturação \\
\hline TOF & Time of flight / tempo de voo \\
\hline ToPI1 & Tityus obscurus peptidase inhibitor 1 \\
\hline ToPI1s & ToPI1 sintético \\
\hline UFLC & Ultra fast liquid chromatography / cromatografia líquida ultra rápida \\
\hline$v_{0}$ & velocidade inicial \\
\hline $\boldsymbol{v}_{\mathbf{i}}$ & velocidade inicial na presença do inibidor \\
\hline$V_{\text {máx }}$ & velocidade máxima \\
\hline$\Delta \mathbf{G}$ & energia livre de Gibbs \\
\hline$\Delta \mathbf{H}$ & variação de entalpia \\
\hline$\Delta \mathbf{S}$ & variação de entropia \\
\hline \multicolumn{2}{|c|}{$\Delta \mathbf{G} \boldsymbol{t}_{\mathrm{a}}$ ou $\Delta \mathbf{G} \boldsymbol{t}_{\mathbf{d}}$ energia de Gibbs de ativação na fase de associação (a) ou dissociação (d) } \\
\hline \multicolumn{2}{|c|}{$\Delta \mathbf{H} \boldsymbol{\dagger}_{\mathrm{a}}$ ou $\Delta \mathbf{H} \boldsymbol{\dagger}_{\mathbf{d}}$ entalpia de ativação na fase de associação (a) ou dissociação (d) } \\
\hline Act ou & 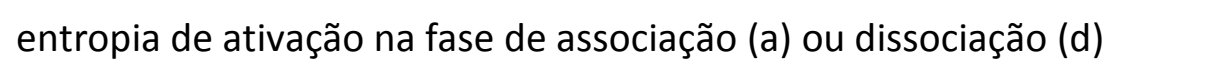 \\
\hline
\end{tabular}




\section{TABELA DE AMINOÁCIDOS}

\begin{tabular}{cccc}
\hline Aminoácido & Símbolo de uma letra & Símbolo de três letras & Massa monoisotópica \\
\hline Ácido aspártico & D & Asp & 115,026 \\
Ácido glutâmico & E & Glu & 129,042 \\
Alanina & A & Ala & 71,0371 \\
Arginina & R & Arg & 156,101 \\
Asparagina & N & Asp & 114,042 \\
Cisteína & C & Cys & 103,009 \\
Fenilalanina & F & Phe & 147,068 \\
Glicina & G & Gli & 57,0214 \\
Glutamina & Q & Gln & 128,058 \\
Histidina & H & His & 137,058 \\
Isoleucina & I & Iso & 113,084 \\
Leucina & L & Leu & 113,084 \\
Lisina & K & Lys & 128,094 \\
Metionina & M & Met & 131,040 \\
Prolina & P & Pro & 97,052 \\
Serina & S & Ser & 87,032 \\
Tirosina & Y & Tyr & 163,063 \\
Treonina & T & Thr & 101,047 \\
Triptofano & W & Trp & 186,079 \\
Valina & V & Val & 99,0684 \\
\hline
\end{tabular}




\section{LISTA DE FIGURAS}

Figura 1.1. Representação esquemática de um biossensor baseado em Ressonância Plasmônica de Superfície (SPR).

Figura 1.2. Sensorgrama típico de um ciclo de ligação............................................................... 29

Figura 1.3. Representação esquemática de um substrato proteico ligado a uma peptidase...... 30

Figura 1.4. Exemplos clássicos de três tipos de inibição reversível. ............................................ 37

Figura 1.5. Estrutura geral de um canal de $\mathrm{K}^{+}$dependente de voltagem................................... 47

Figura 1.6. Poro de condução iônica de um canal de potássio KcsA e alinhamento de sequências

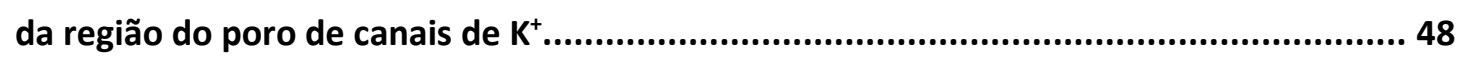

Figura 1.7. Alinhamento de sequências das toxinas representativas com motivo estrutural tipo Kunitz e atividade bloqueadora de canais de potássio.. ................................................. 52

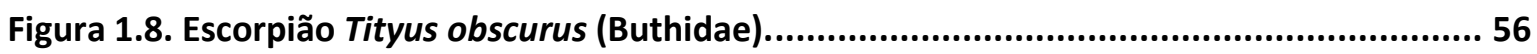

Figura 1.9. Esquema do desenho experimental geral desse estudo........................................ 64

Figura 1.10. Estratégia de purificação dos peptídeos oxidados ToPI1s e ToPI1s-Met* (azul) e do peptídeo ToPI1s reduzido (laranja).............................................................................. 71

Figura 1.11. Representação esquemática do acoplamento amina da tripsina à superfície do chip sensor.

Figura 1.12. Purificação do peptídeo ToPI1 nativo........................................................................ 92

Figura 1.13. Massa molecular do peptídeo ToPI1 nativo........................................................ 93

Figura 1.14. Sequenciamento parcial do peptídeo ToPI1 nativo por MALDI-TOF-ISD. ................994

Figura 1.15. Sequência de nucleotídeos e predição da sequência de aminoácidos do peptídeo ToPI1.

Figura 1.16. Alinhamento da sequência precursora do peptídeo ToPI1 com sequências precursoras de toxinas da peçonha de outros escorpiões da família Buthidae: pMEKTx7-1 a pMEKTx7-4 são de Mesobuthus eupeus, e $\alpha-K T x 17.1$ (ou BmKK4) é de Mesobuthus martensii..

Figura 1.17. Fracionamento do extrato de síntese do ToPI1s oxidado em coluna preparativa e semipreparativa C18.

Figura 1.18. Fracionamento em coluna analítica C18 do peptídeo ToPI1s com Met ${ }^{30}$ oxidada (ToPI1s-Met*) e sem Met $^{30}$ oxidada (ToPI1s). .100

Figura 1.19. Massa molecular dos peptídeos ToPI1s-Met* (superior) e ToPI1s (inferior)...........101

Figura 1.20. Purificação do peptídeo ToPI1s reduzido em coluna analítica C18. 102 
Figura 1.21. Massa molecular do ToPI1s reduzido obtido por MALDI-TOF/TOF MS UltraFlex III (Bruker Daltonics, Alemanha), operando em modo positivo refletido, com matriz saturada de ácido $\alpha$-ciano-4-hidroxicinâmico. .103

Figura 1.22. Comparação do perfil cromatográfico do peptídeo ToPI1s oxidado obtido a partir de diferentes sínteses e do ToPI1s reduzido. 104

Figura 1.23. Comparação da massa molecular do ToPI1s obtido na síntese S1 (preto) e S2 (azul).

Figura 1.24. Atividade inibidora de tripsina do peptídeo ToPI1s. .106

Figura 1.25. Efeito da concentração do substrato BAPNA nos valores de $I C_{50}$ para a inibição de tripsina pelo peptídeo ToPI1s. 107

Figura 1.26. Valores de IC 50 em função da concentração total de enzima tripsina para o inibidor ToPI1s.

Figura 1.27. Curvas de progresso da reação enzimática com tripsina na presença de diferentes concentrações de ToPI1s.

Figura 1.28. Inibição da tripsina pelo ToPI1s em diferentes concentrações de substrato. .........110

Figura 1.29. Atividade residual da quimotripsina em função da concentração de ToPI1s. .112

Figura 1.30. Atividade inibidora de tripsina do peptídeo ToPI1s-Met* em comparação com o ToPI1s.

Figura 1.31. Atividade inibidora de tripsina do peptídeo ToPI1s em sua forma reduzida.

Figura 1.32. Atividade inibidora de tripsina do peptídeo BPTI..

Figura 1.33. Teste de reação cruzada (A) e transporte de massa (B) para a interação do complexo ToPI1s:tripsina.

Figura 1.34. Cinética da interação do ToPI1s com tripsina imobilizada em superfície e dependência da temperatura por Ressonância Plasmônica de Superfície.

Figura 1.35. Energia livre de Gibbs da ligação do complexo ToPI1s:tripsina e dependência de temperatura das constantes de velocidade.

Figura 1.36. Perfil energético para as vias teóricas de reação de interação do complexo ToPI1s:tripsina em pH 7,4.

Figura 1.37. Avaliação do sítio de interação do ToPI1s com tripsina por Ressonância Plasmônica de Superfície.

Figura 1.38. Efeito do ToPI1s na taxa de viabilidade de diferentes linhagens celulares. 124

Figura 1.39. Fotomicrografias de células das linhagens tumorais B16F10 (de melanoma murino) e HeLa (de câncer cervical humano) e de fibroblasto murino não tumoral (NIH-3T3) 
Figura 1.40. Efeito do peptídeo ToPI1s na corrente de diferentes subtipos de canais de $\mathrm{K}^{+}$

(hK 1.1, hK 1.4 , hERG1, hERG2, hERG3, EAG1 e EAG2).

Figura 1.41. Efeito do ToPI1s em diferentes subtipos de canais de $K^{+}$dependentes de voltagem.

Figura 1.42. Alinhamento de sequências de toxinas escorpiônicas de diferentes famílias .132

Figura 1.43. Efeitos da concentração de substrato nos valores de $I C_{50}$ de inibição do tipo tightbinding dos modos: (A) competitiva (ćrculos sólidos), não-competitiva quando $\alpha=1$ (círculos abertos) e incompetitiva (quadrados sólidos); e (B) não-competitiva quando $\alpha<1$ (quadrados) e quando $\alpha>1$ (círculos). Retirado de Copeland (2000). 133

Figura 1.44. Oxidação de resíduos de Metionina. 149

Figura 2.1. Espectros de dicroísmo circular (CD) na região far-UV associados a diferentes tipos de estruturas secundárias.

Figura 2.2. Estruturas tridimensionais de polipeptídeos isolados de animais venenosos e que apresentam o motivo estrutural tipo Kunitz (A-D) e o complexo BTPI:tripsina (E).

Figura 2.3. Alinhamento representativo de inibidores de serinopeptidases tipo Kunitz de animais venenosos. 160

Figura 2.4. Estrutura tridimensional de inibidores do tipo Bowman-Birk. 163

Figura 2.5. Estrutura do complexo charybdotoxina-canal $K_{v}$ e exemplos de $\alpha$-KTxs escorpiônicas.

Figura 2.6. Sequência do ToPI1 e de seus dois peptídeos análogos a serem sintetizados. .170

Figura 2.7. Espectros dicroicos dos polipeptídeos ToPI1 nativo (linha contínua) e seu sintético ToPI1s (linha pontilhada).

Figura 2.8. Efeito do $\mathrm{pH}$ na estrutura secundária do peptídeo ToPI1s oxidado a $25^{\circ} \mathrm{C}$. 176

Figura 2.9. Espectro na região distante do UV do peptídeo ToPI1s em função da temperatura e $\mathrm{pH}$.

Figura 2.10. Efeito da temperatura na estrutura do peptídeo ToPI1s oxidado. .178

Figura 2.11. Espectros dicroicos do peptídeo ToPI1s reduzido (vermelho) e oxidado (preto) em $\mathrm{pH} 3,0$ e 9,0 . .179

Figura 2.12. Espectros na região distante do UV do peptídeo ToPI1s reduzido em função da temperatura e $\mathrm{pH}$. 180

Figura 2.13. Efeito da temperatura na estrutura do peptídeo ToPI1s reduzido. 181

Figura 2.14. Massa molecular dos análogos reduzidos .182

Figura 2.15. Fracionamento em coluna analítica C18 dos peptídeos análogos 183

Figura 2.16. Sobreposição dos espectros de massa molecular dos análogos. 184

Figura 2.17. Espectros dicroicos do polipeptídeo ToPI1s (preto) e dos análogos. .185 


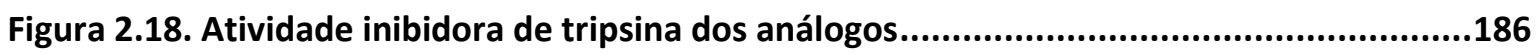

Figura 2.19. Efeito do ToPI1s e de seus dois análogos na corrente de canais hKv1.1...............187

Figura 2.20. Espectro de dicroísmo circular de inibidores tipo Kunitz de escorpião e do clássico inibidor BPTI.

Figura 2.21. Estrutura do peptídeo ToPI1 predita por modelagem molecular pela estratégia I-

Taser. .194

Figura 2.22. Comparação do peptídeo ToPI1 com inibidores de peptidase tipo Kunitz e toxinas de escorpiões bloqueadoras de canais de potássio, e sequência dos dois peptídeos análogos ao ToPI1.

Figura 2.23. Alinhamento da sequência do ToPI1 com a toxina Tc32, do escorpião Tityus obscurus. 


\section{LISTA DE TABELAS}

Tabela 1.1. Exemplos de inibidores de peptidases aprovados para o uso clínico.

Tabela 1.2. Inibidores de peptidase caracterizados da peçonha de escorpiões.

40

Tabela 1.3. Atividade bloqueadora de canais de potássio de peptídeos que apresentam o motivo estrutural tipo Kunitz obtidos de peçonhas e venenos de animais.

Tabela 1.4. Mistura de peptídeos e proteínas para calibração externa no MALDI-TOF/TOF MS. 60

Tabela 1.5. Reagentes utilizados para a síntese de ToPIs. 60

Tabela 1.6. Fmoc-aminoácidos utilizados para a síntese de ToPI1s. 61

Tabela 1.7. Etapas de fracionamento utilizadas para a purificação dos peptídeos oxidados ToPI1s e ToPI1s-Met*.

Tabela 1.8. Etapas de fracionamento utilizadas para a purificação do peptídeo ToPI1s reduzido.

Tabela 1.9. Dados obtidos pelo ajuste não-linear das respostas do ensaio de inibição de tripsina pelo peptídeo ToPI1s em diferentes concentrações de substrato.

Tabela 1.10. Valores de $K_{\mathrm{m}}$ e $\mathrm{V}_{\text {máx }}$ obtidos pelo ajuste não-linear das curvas de progresso da reação enzimática com tripsina na presença de diferentes concentrações de ToPI1s. .....109

Tabela 1.11. Valores das constantes inibitórias aparentes da inibição de tripsina por ToPI1s para diferentes concentrações de substrato BAPNA.

Tabela 1.12. Dados obtidos pelo ajuste não-linear das respostas do ensaio de inibição de tripsina a 100 nM pelo BPTI em diferentes concentrações de substrato.

Tabela 1.13. Dados obtidos pelo ajuste não-linear das respostas do ensaio de inibição de tripsina a $400 \mathrm{nM}$ pelo BPTI em diferentes concentrações de substrato.

Tabela 1.14. Parâmetros cinéticos em função da temperatura para o complexo ToPI1s:tripsina calculados pelo ajuste dos dados obtidos por SPR.

Tabela 1.15. Parâmetros termodinâmicos da formação do complexo ToPI1s:tripsina.

Tabela 1.16. Valores de parâmetros termodinâmicos para a ligação de inibidores à tripsina...138

Tabela 2.1. Reagentes utilizados para a síntese dos análogos

Tabela 2.2. Fmoc-aminoácidos utilizados para a síntese dos análogos.

Tabela 2.3. Gradientes de soluções utilizados nas etapas de fracionamento para a purificação dos peptídeos oxidados 172

Tabela 2.4. Porcentagem das estruturas secundárias (\%) do ToPI1 nativo e seu sintético ToPI1s. 
Tabela 2.6. Porcentagem das estruturas secundárias (\%) do ToPI1s reduzido.

. .179

Tabela 2.7. Diversidade de toxinas com ação em canais de potássio da peçonha de escorpiões

(KTxs).

190 


\section{RESUMO}

O interesse na caracterização de novos inibidores de peptidases (PIs) tem aumentado nas últimas décadas devido a seu potencial uso na prevenção e tratamento de diversas doenças humanas. Muitos Pls já foram caracterizados de animais venenosos e peçonhentos, como anêmonas, serpentes, anuros e, mais recentemente, escorpiões e aranhas. Nesse estudo apresentamos uma nova classe de inibidor de serinopeptidase isolado da peçonha do escorpião Tityus obscurus (Buthidae), responsável por muitos casos de envenenamento na região Amazônica. Denominado ToPI1, ele foi purificado da peçonha bruta por RP-HPLC, e sua sequência foi determinada por MALDI-ISD e pela análise de seu precursor, obtido da biblioteca de cDNA da glândula de peçonha do T. obscurus. O ToPI1 compartilha menos de $45 \%$ de similaridade com outros peptídeos descritos em bancos de dados públicos. Ainda assim, todas eles são bloqueadores ou possíveis bloqueadores de canais de $\mathrm{K}^{+}$, não havendo similaridade com nenhum $\mathrm{PI}$ descrito até o momento. $\mathrm{O}$ peptídeo sintético oxidado (ToPl1s), obtido usando a estratégia Fmoc/t-butila, foi ativo contra tripsina em ensaios cromogênicos, mostrando-se do tipo tight-binding, e também por Ressonância Plasmônica de Superfície (SPR), em um biossensor Biacore 3000, onde apresentou afinidade picomolar por tripsina imobilizada. Os resultados indicaram que a formação do complexo ToPI1:tripsina é espontânea, endotérmica e favorecida por um aumento de entropia. Experimentos em SPR indicaram que o ToPI1s se liga ao sítio ativo da tripsina, semelhante aos inibidores canônicos. O ToPI1s não inibiu quimotripsina mesmo em concentrações elevadas. Também não reduziu a viabilidade de células tumorais HeLa (de câncer cervical humano) e B16F10 (de melanoma murino) nem de fibroblastos murinos não tumorais (NIH-3T3). Seu efeito foi mínimo ou nulo nas correntes de diferentes subtipos de canais de $\mathrm{K}^{+}$. O ToPI1s não causou alterações comportamentais e/ou fisiológicas visíveis em camundongos. A potente atividade inibidora de tripsina do ToPI1s em conjunto com esses resultados negativos o tornam um candidato atrativo para futuras aplicações terapêuticas. Análises por dicroísmo circular (190-260 nm) sugerem ausência de diferenças de estrutura secundária entre o ToPI1 nativo e o ToPI1s, com predominância de estruturas do tipo $\beta$ (folhas- $\beta$ e voltas- $\beta$ ) e desordenadas, e menor quantidade de $\alpha$-hélice. O ToPI1s mostrou-se bastante estável, não desnaturando na faixa de pH 3,0-9,0 mesmo a $95^{\circ} \mathrm{C}$. Dois análogos do ToPI1 foram sintetizados, os quais estão sob processo de proteção à propriedade intelectual.

Palavras-chave: inibidor de tripsina; tight-binding; peçonha de escorpião; Tityus obscurus; SPR. 


\begin{abstract}
The interest in the characterization of new peptidase inhibitors (PIs) has increased in recent decades due to their potential use in the prevention and treatment of several human diseases. Many PIs from poisonous and venomous animals such as sea anemones, snakes, anurans and, more recently, scorpions and spiders have been characterized. In the present study we present a new class of serinopeptidase inhibitor isolated from Tityus obscurus scorpion venom. This species (Buthidae) is responsible for many cases of envenomation in the Amazon region.

Named ToPI1, it was purified from the crude venom by RP-HPLC and its sequence was determined by MALDI-ISD and by the analysis of its precursor, obtained from the cDNA library of $T$. obscurus venom gland. ToPI1 shares less than $45 \%$ sequence similarity with other peptides described in public databases. Still, they are all blockers or potential blockers of $\mathrm{K}^{+}$channels, with no similarity to any PI described so far. The oxidized synthetic peptide (ToPI1s), obtained by using the Fmoc/t-butyl strategy, was active against trypsin in chromogenic assays, displaying tight-binding inhibition, and also by Surface Plasmon Resonance (SPR) in a Biacore 3000 biosensor, where it showed picomolar affinity to immobilized trypsin. The results indicated that the formation of the bimolecular complex ToPI1:trypsin is spontaneous, endothermic and favored by an entropy increase.

SPR experiments indicated that ToPI1s binds to the active site of trypsin, similar to the canonical inhibitors. ToPI1s did not inhibit chymotrypsin even at high doses. In addition, it reduced neither the viability of the tumor cells HeLa (from human cervical cancer) and B16F10 (from murine melanoma) nor of non-tumor murine fibroblasts (NIH-3T3). It showed minimal or null effect on the currents of different subtypes of $\mathrm{K}^{+}$channels. The ToPI1s did not cause any visible behavioral and/or physiological changes in mice. The potent trypsin inhibitory activity of ToPI1s together with these negative results make it an attractive candidate for future therapeutic purposes. Analysis by circular dichroism (190-260 nm) suggests the absence of differences in secondary structures between ToPI1s and the native ToPI1, with predominance of $\beta$-type structures ( $\beta$-sheets and $\beta$-turns) and randon coil, and a smaller amount of $\alpha$-helix. The ToPI1s proved to be very stable, non-denaturing at the range of $\mathrm{pH} 3.0$ to 9.0 even at $95{ }^{\circ} \mathrm{C}$. Two ToPI1 analogues were synthesized, which are under process of intellectual property protection.
\end{abstract}

Keywords: trypsin inhibitor; tight-binding; scorpion venom; Tityus obscurus; SPR. 


\section{PREFÁCIO}

A vida depende de uma série de reações catalíticas, as quais, no geral, ocorreriam tão lentamente por si só que inviabilizariam o processo vital. Nesse contexto, o poder catalítico das enzimas é fundamental, estando elas presentes em todos os organismos vivos e vírus. A primeira referência que se tem conhecimento do uso comercial de enzimas remonta ao Código de Hammurabi (Babilônia antiga, cerca de 1800 a.C.), relativa à produção de vinhos. Outras referências podem ser encontradas em textos de civilizações antigas, onde microorganismos eram usados como fonte de enzimas para a fermentação, produzindo vinagres, queijos, pães, bebidas alcóolicas e para a tenderização de carnes (Copeland, 2000). Atualmente, enzimas ainda são usadas para esses processos e para inúmeros outros produtos industrializados, além de serem fundamentais na indústria farmacêutica e pesquisas científicas, visto que muitas doenças estão relacionadas com alterações na atividade de enzimas ou na sua regulação.

Ainda que várias das enzimas envolvidas na fisiologia humana sejam bem conhecidas, muitas ainda não foram isoladas ou caracterizadas. Assim, quanto mais a respeito dessas enzimas for elucidado, mais novos inibidores se farão necessários para regular sua ação, satisfazendo as novas demandas médicas. Além disso, o estudo de inibidores enzimáticos tem ajudado a compreender os mecanismos enzimáticos e a definir algumas vias metabólicas.

Devido à grande variedade de compostos de alta especificidade nos venenos e peçonhas de animais, esses complexos coquetéis de moléculas bioativas têm sido alvo de estudos para isolamento e caracterização de novos inibidores de peptidases (PIs) há cerca de quatro décadas, sendo os inibidores de serpentes e anêmonas marinhas os mais estudados até então. Embora haja muitos estudos caracterizando a atividade de toxinas peptídicas isoladas da peçonha de escorpiões em canais iônicos, principalmente os de $\mathrm{K}^{+}$, $\mathrm{Na}^{+}$e $\mathrm{Ca}^{2+}$, pouco se sabe sobre PIs encontrados na peçonha dos mesmos, sendo que os primeiros trabalhos com a caracterização funcional destes datam do final de 2011 (ver revisão por Mourão \& Schwartz (2013)). Em estudos prévios realizados no Laboratório de Toxinologia da Universidade de Brasília (LTX-UnB) com a peçonha do escorpião Tityus obscurus, foi isolado um peptídeo que apresentou atividade inibidora de tripsina em 
ensaios preliminares (Mourão CBF, dados não publicados). Denominado ToPI1, esse peptídeo compartilha algumas características com toxinas de escorpiões específicas para canais de $\mathrm{K}^{+}(\mathrm{KTXs})$ e, diferente da maioria dos Pls obtidos de venenos e peçonhas animais, que possuem cerca de 60 resíduos de aminoácidos, o ToPI1 possui tamanho e sequência únicos.

Embora exista uma vasta literatura documentando a associação de peptidases com câncer, muitos aspectos ainda são desconhecidos, como: o papel das peptidases na progressão neoplásica; o papel de inibidores de peptidases, ativadores e receptores endógenos; principais substratos para essas peptidases; assim como quais peptidases seriam alvos terapêuticos efetivos nas lesões pré-malignas em comparação com os estágios terminais de câncer, ou entre dois tipos de câncer distintos, por exemplo (Moin et al., 2012; Sloane et al., 2006). Visto que Pls compõem a base para muitos estudos de atividade anticarcinogênica, e que o crescimento e invasão de alguns cânceres têm sido associados a alterações funcionais de canais iônicos, em especial canais de $\mathrm{K}^{+}$, um peptídeo com atividade inibidora de peptidase e bloqueadora de canais de $\mathrm{K}^{+}$pode ser um potencial agente anticarcinogênico.

Com base nessas considerações, o Capítulo 1 do presente trabalho apresenta a caracterização química e biológica do ToPI1, com uso de ferramentas proteômicas e transcritômicas para a caracterização de sua sequência primária. Apresenta também as estratégias de síntese e purificação do ToPI1 e todos os ensaios de caracterização da sua atividade biológica. Sua atividade inibidora de tripsina é testada por meio diferentes ensaios, a fim de compreender melhor seu mecanismo de ação e caracterizar suas constantes de afinidade e termodinâmica de formação do complexo bimolecular enzima:inibidor. Além disso, foram realizados ensaios de viabilidade com células tumorais e não-tumorais, ensaios eletrofisiológicos com diferentes subtipos de canais de $\mathrm{K}^{+}$e ensaios de alteração comportamental em camundongos. Esses experimentos de caracterização do ToPI1 são essenciais para avaliar seu potencial como possível agente terapêutico, uma vez que, embora muitos PIs sejam frequentemente descritos, poucos se tornam agentes terapêuticos, devido a diversos requisitos que vão além da inbição do alvo molecular, relacionados também à solubilidade, permeabilidade, ligação proteica, seletividade, metabolismo e perfil de toxicidade. 
Um dos critérios para se estabelecer uma nova família de inibidores de serinopeptidases é a homologia de sequência entre os membros, de forma que a localização do sítio reativo e o alinhamento das pontes dissulfeto são essenciais (Laskowski \& Kato, 1980). Apesar disso, em membros de uma mesma família, já foi mostrada a possibilidade de compostos com diferentes tamanhos ou quantidades de pontes dissulfeto. Nessas variantes, porém, o sítio reativo permanece inalterado (Mourão \& Schwartz, 2013). Atualmente, o motivo estrutural para os representantes da maioria dessas famílias de PIs já é conhecido, diferindo bastante de uma família para outra (Krowarsch et al., 2003).

Uma vez que a identificação da família de PIs a que o ToPI1 pertence por meio da homologia de sequência primária é dificultada pela sua sequência única - o que por si só já poderia sugerir que ele represente uma nova família -, a caracterização de sua conformação estrutural pode fornecer novas informações para essa classificação. Assim, o Capítulo 2 versa sobre a caracterização estrutural do ToPI1 e sua estabilidade frente a alterações de $\mathrm{pH}$ e temperaturas, e apresenta um breve estudo da relação estruturafunção.

Visando identificar os resíduos de aminoácidos essenciais para a atividade inibidora de tripsina do ToPI1, presentes no denominado sítio reativo do inibidor, optou-se pela síntese de dois análogos com mutações pontuais de resíduos de aminoácidos e pela realização de estudos comparativos em relação ao peptídeo selvagem. Dessa forma, com base em alinhamentos de sequências - ainda que com baixo grau de identidade - com outros inibidores de peptidase e bloqueadores de canais de $\mathrm{K}^{+}$, e com experimentos realizados com os análogos mutados, o Capítulo 2 visa identificar também os principais resíduos essenciais às atividades em questão. Espera-se que nessa breve análise de estrutura-função do ToPI1 consigamos compreender melhor não somente os sítios de interação do peptídeo ToPI1 com peptidases, mas fornecer novos dados para a compreensão dessas proteínas receptoras frente a uma possível nova classe de molécula. Além disso, uma das vantagens dos estudos da relação estrutura-função é poder identificar o núcleo ativo da molécula e reduzir seu tamanho, simplificando-a para uma estrutura mínima de alta afinidade, o que torna mais viável sua produção caso venha a se tornar um agente terapêutico. 
Capítulo 1

Caracterização química e biológica de um polipeptídeo inibidor de serinopeptidase isolado da peçonha do escorpião Tityus obscurus 


\subsection{INTRODUÇÃO}

\subsubsection{ENZIMAS}

Com exceção de um pequeno grupo de moléculas de RNA com propriedades catalíticas, todas as enzimas são proteínas, sendo sua conformação nativa essencial para a atividade catalítica. Enzimas catalisam a transformação química de uma molécula, o substrato $(\mathrm{S})$, em um composto molecular distinto, o produto $(\mathrm{P})$, sem serem consumidas na reação, e atuam aumentando a velocidade da reação pela diminuição da energia de ativação. Elas são altamente específicas, tanto para o substrato como para o tipo de reação efetuada sobre o substrato. A especificidade inerente das enzimas reside em uma cavidade favorável à ligação ao substrato, denominada sítio ativo, o qual consiste em um arranjo de certos resíduos de aminoácidos da enzima que interagem com o substrato e catalisam sua transformação química. Muitas vezes, os resíduos de aminoácidos que formam o sítio ativo ficam em regiões distantes na sequência primária, mas próximos no sítio ativo, devido ao enovelamento de cadeia polipeptídica (Copeland, 2000; Nelson \& Cox, 2006).

Ainda que os grupos funcionais catalíticos de uma enzima possam realizar uma ligação covalente transitória com o substrato (para ativá-lo para a reação ou para transferir um grupo transitoriamente do substrato para a enzima), a maioria das interações entre enzima e substrato requeridas para reduzir a energia de ativação são interações fracas, não-covalentes. A energia de ligação, resultante dessa interação, é a principal fonte de energia livre usada para diminuir a energia de ativação (Nelson \& Cox, 2006).

A atividade de uma enzima é sensível a diferentes condições, como concentração do substrato, concentração e tipo de ativadores e inibidores, pH e temperatura da solução enzimática (Copeland, 2000). Até certo ponto, quanto maior a concentração de substrato disponível, maior é a velocidade de colisão e ligação entre as moléculas da enzima e substrato. $\mathrm{O}$ pH da solução atua nos grupos ionizáveis, podendo alterar a conformação enzimática e, portanto, sua atividade. Quanto à temperatura, no princípio, seu aumento resulta no aumento da velocidade de reação, por aumentar a energia cinética das moléculas do sistema; porém, aumentos elevados levam à desnaturação térmica da enzima, inativando-a. 


\subsubsection{Determinação das Constantes de Afinidade}

Constantes de afinidade são representações quantitativas da força com que duas moléculas interagem. Assim, elas fornecem dados essenciais no estudo de reações enzimáticas. A interação mais fundamental na Biologia é a reação de interação bimolecular (Goodrich \& Kugel, 2007):

$$
\mathrm{A}+\mathrm{B} \underset{k_{d}}{\stackrel{k_{a}}{\rightleftarrows}} \mathrm{AB}
$$

onde $A$ e $B$ representam duas moléculas distintas que interagem e $A B$ representa $O$ complexo resultante. A seta superior representa a associação entre A e B, a qual é regida pela constante cinética de associação $k_{\mathrm{a}}$, enquanto a seta inferior representa a dissociação do complexo $\mathrm{AB}$, a qual é regida pela constante cinética de dissociação $k_{\mathrm{d}}$. As constantes $k_{\mathrm{a}}$ e $k_{\mathrm{d}}$ são frequentemente referidas por $k_{1}$ e $k_{-1}$, respectivamente. A afinidade entre as duas moléculas pode ser descrita pela constante de associação $K_{\mathrm{A}}$ ou pela constante de dissociação $K_{\mathrm{D}}$, as quais são inversamente relacionadas:

$$
K_{\mathrm{D}}=\frac{k_{\mathrm{d}}}{k_{\mathrm{a}}}=\frac{[\mathrm{A}][\mathrm{B}]}{[\mathrm{AB}]}=\frac{1}{K_{\mathrm{A}}}
$$

sendo $[A],[B]$ e $[A B]$ as concentrações molares dos componentes $A, B$ ou $A B$ em equilíbrio.

Conforme essa relação, a afinidade relativa (por exemplo, força de ligação) de um complexo $\mathrm{AB}$ é inversamente proporcional a seus valores de $K_{\mathrm{D}}$ - interações de maior afinidade terão menores valores de $K_{\mathrm{D}}$, estando o equilíbrio favorável à formação do complexo AB. Por outro lado, quando $K_{\mathrm{D}}$ é numericamente grande, o equilíbrio está a favor das formas A e B livres (baixa afinidade) (Nelson \& Cox, 2006). Em relação às constantes cinéticas, uma interação com baixo $K_{\mathrm{D}}$ terá $k_{\mathrm{a}}$ elevada e $k_{\mathrm{d}}$ reduzida, ou seja, A e B irão se associar rapidamente e o complexo $A B$ terá lenta dissociação. O contrário ocorre para valores altos de $K_{\mathrm{D}}$, ou seja, uma reação com $k_{\mathrm{a}}$ baixa e $k_{\mathrm{d}}$ alta, de forma que A e B irão se associar lentamente e o complexo AB terá rápida dissociação (Goodrich \& Kugel, 2007). No caso particular da interação enzima-inibidor, a constante de dissociação é geralmente referida como constante inibitória $\left(K_{\mathrm{i}}\right)$.

As constantes de velocidade $\left(k_{\mathrm{d}}\right.$ e $\left.k_{\mathrm{a}}\right)$ e de equilíbrio $\left(K_{\mathrm{D}}\right.$ e $\left.K_{\mathrm{A}}\right)$ podem ser determinadas experimentalmente de diversas formas, como métodos espectroscópicos e 
cromatográficos, e, mais recentemente, com a utilização de técnicas baseadas na tecnologia de Ressonância Plasmônica de Superfície (SPR), como o sistema Biacore (Cooper, 2002; Copeland, 2000; Jelesarov, 2010).

Os biossensores ópticos baseados em SPR, como o Biacore, se destacam na investigação de interações moleculares devido à alta seletividade e sensibilidade, e devido ao curto tempo de resposta de análise da amostra, sem necessidade de marcação das moléculas. O chip sensor consiste em uma lâmina de vidro revestida com um fino filme metálico, comumente de ouro, no qual uma matriz de dextrana está ligada covalentemente (Figura 1.1). Outras configurações diferentes da matriz de dextrana também são possíveis (Carvalho et al., 2003). Para que haja a interação, uma molécula alvo é imobilizada na matriz (ligante), e um fluxo constante de solução tampão contendo o analito solúvel é injetado na célula de fluxo em velocidade e temperatura definidas. Então, um feixe de luz plano-polarizada passa por um prisma ligado à superfície inferior do chip e é refletida para um detector (Cooper, 2002; Wilson, 2002). Em um determinado ângulo de incidência e comprimento de onda, os fótons de luz refletidos criam um campo elétrico na superfície de ouro, o qual interage com os elétrons livres oscilantes (plasma) do filme metálico. Dessa forma, os fótons de luz incidentes são convertidos em plasmons de superfície no filme de ouro, caracterizando o fenômeno de ressonância plasmônica de superfície (Carvalho et al., 2003; Markey, 1999). Em consequência, parte da energia da luz incidente é perdida para o filme metálico, resultando na redução da intensidade da luz refletida a ser detectada. Da mesma forma, plasmons na superfície do filme de ouro criam um campo elétrico que se estende para o meio voltado para a célula de fluxo. A velocidade desse campo depende das propriedades do meio, as quais, no caso de ondas de luz, estão relacionadas com o índice de refração do meio. Se o índice de refração imediatamente acima da superfície do metal sofre alguma alteração, devido à adsorção de moléculas, uma alteração no ângulo de incidência é requerida para que haja o fenômeno de SPR. Essa variação do ângulo no qual ocorre a ressonância, durante um processo de adsorção em função do tempo, é registrada em unidades de ressonância (RU). A associação leva a um aumento em RU, e a dissociação - obtida pela injeção de solução tampão na ausência de analito - leva a uma redução (Carvalho et al., 2003; Cooper, 2002). 


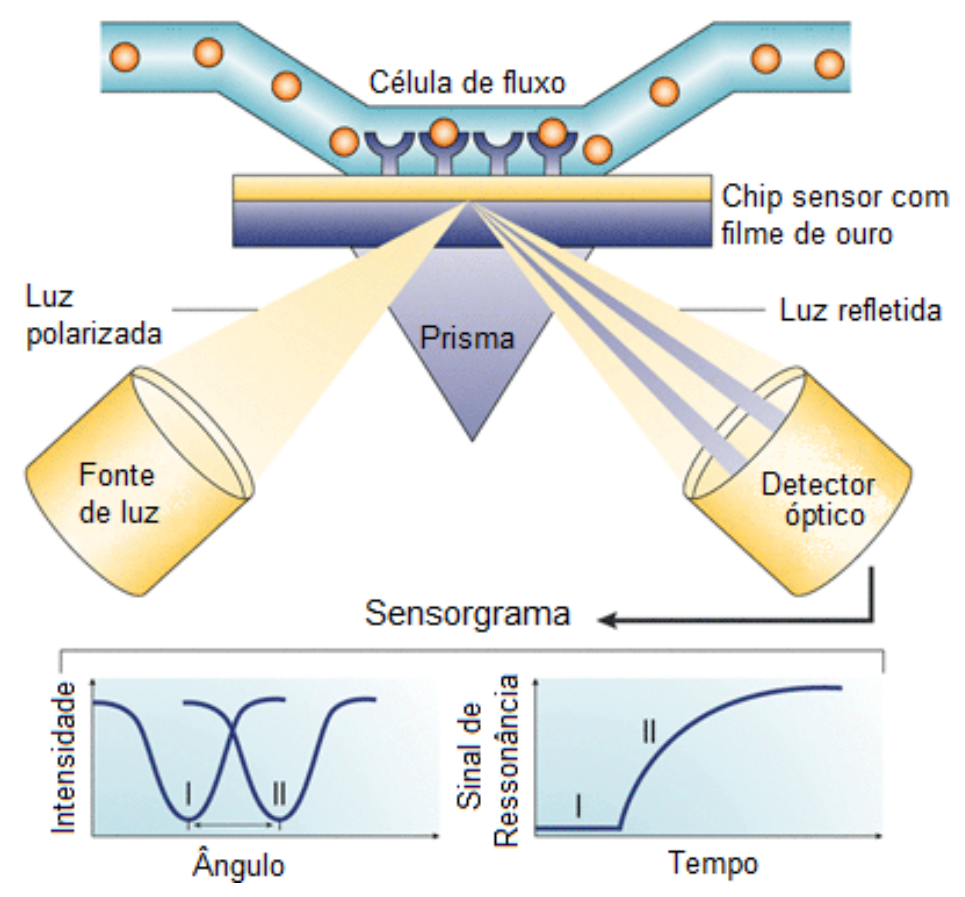

Figura 1.1. Representação esquemática de um biossensor baseado em Ressonância Plasmônica de Superfície (SPR). A tecnologia baseada em SPR detecta variações no índice de refração do meio nas imediações da camada de superfície do chip sensor. A SPR é observada como uma sombra na luz refletida do chip em um ângulo dependente da massa de material adsorvido na superfície. $O$ ângulo muda (de I para II, no diagrama inferior esquerdo) quando as moléculas se ligam à matriz e alteram a massa da superfície. Essa alteração no ângulo de ressonância pode ser monitorada em tempo real em um gráfico de sinal de ressonância (proporcional à variação da massa) em função do tempo (diagrama inferior direito). Adaptado de Cooper (2002).

Visto que a resposta SPR é dada em função do tempo, esse experimento permite obter informações cinéticas da interação analito:ligante (Figura 1.2). Medidas concomitantes em uma célula fluxo de referência (sem a presença do ligante) permitem a subtração da linha de base, e a verificação da especificidade da ligação (Borch \& Roepstorff, 2004). O ciclo de ligação, apresentado na Figura 1.2, é normalmente repetido várias vezes, em diferentes concentrações de analito, para gerar dados robustos para uma análise global e aplicação de um algorítimo de ligação apropriado (Cooper, 2002). A afinidade da interação é dada pela razão das constantes de velocidade, como apresentado pela equação 1.2 . 


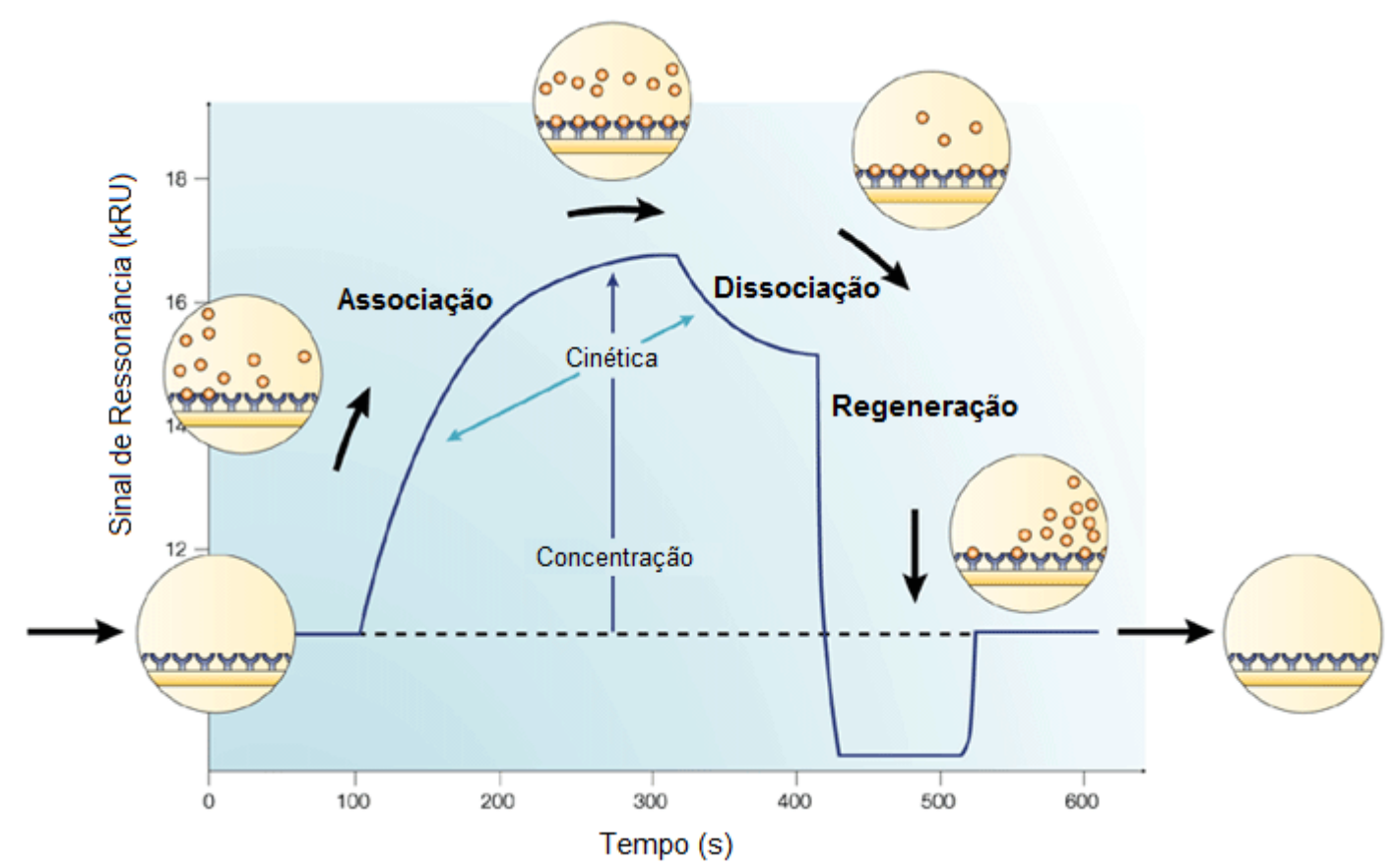

Figura 1.2. Sensorgrama típico de um ciclo de ligação. Estão apresentadas as fases de associação, dissociação e regeneração. No tempo $t=0 \mathrm{~s}$, o tampão entra em contato com o ligante na célula de fluxo. Em $t=100 \mathrm{~s}$, uma solução de analito solúvel no tampão passa pelo receptor. À medida que o analito se liga à superfície, o índice de refração do meio adjacente à superfície do chip sensor aumenta, levando a um aumento no sinal de ressonância. Sabendo-se a concentração do analito, a análise dessa parte da curva fornece a constante da taxa de associação $\left(k_{a}\right)$ da interação. No equilíbrio, por definição, a quantidade de analito em associação e dissociação com o receptor é a mesma. Em $t=320 \mathrm{~s}$, a solução com analito é substituída por apenas tampão, iniciando a etapa de dissociação do complexo ligante:analito. Análise dessa parte da curva fornece a constante da taxa de dissociação $\left(k_{d}\right)$ da interação. Em casos de dissociação lenta (maior tempo de meia-vida do complexo), é necessário aplicar um pulso de solução de regeneração (como alta concentração salina ou baixo $\mathrm{pH}$ ), em $t=420 \mathrm{~s}$, para romper o complexo e regenerar o ligante em seu estado livre. Adaptado de Cooper (2002).

Além de determinar as constantes de afinidades de interação e cinética enzimática, análises termodinâmicas de uma interação bimolecular também podem ser obtidas a partir de experimentos de SPR. Isso é realizado aplicando as relações de van't Hoff às constantes cinéticas de uma interação obtidas em diferentes temperaturas (Day et al., 2002; Jelesarov, 2010). Assim, dados podem ser obtidos sobre a energia livre de Gibbs ( $\Delta G)$ e seus componentes entálpicos $(\Delta \mathrm{H})$ e entrópicos $(\Delta S)$ da associação. Esses parâmetros são sensíveis a muitos fatores, como temperatura, pressão e composição química do sistema (concentração de prótons, sais e outras substâncias de baixa massa molecular). 


\subsubsection{Peptidases}

Enzimas proteolíticas, também conhecidas como peptidases ou proteases, são responsáveis pela hidrólise de proteínas e são uma das mais abundantes classes de enzimas, correspondendo a cerca de $2-4 \%$ dos genes em humanos e outros organismos (Abbenante \& Fairlie, 2005; Puente et al., 2005). Uma vez que peptidases controlam a ativação, síntese e degradação das proteínas, elas estão envolvidas em diversos processos biológicos, incluindo a progressão do ciclo celular, sinalização celular, proliferação e morte, tráfego de proteínas e respostas imunes, e são também essenciais para a replicação/transmissão de vírus, parasitas e bactérias patogênicas, e para a proliferação de pragas em plantações. Além disso, peptidases também estão envolvidas em muitas doenças humanas, desde doenças neurodegenerativas e inflamatórias a doenças infecciosas.

Peptidases interagem com seu substrato (ou inibidor) por meio de ligações de hidrogênio com a cadeia principal do substrato e por meio de interações hidrofóbicas e eletrostáticas entre as cadeias laterais dos resíduos de aminoácidos do substrato com bolsões bem definidos no sítio ativo da enzima. Assim, no sítio ativo da enzima encontramse os sítios designados S3, S2, S1, S1', S2', S3', os quais se ligam às cadeias laterais dos resíduos de aminoácidos correspondentes do substrato designados P3, P2, P1, P1', P2', P3'. Essas designações especificam resíduos das regiões amino- e carboxi-terminal do sítio de clivagem (P1-P1'), respectivamente (Figura 1.3) (Schechter \& Berger, 1967).

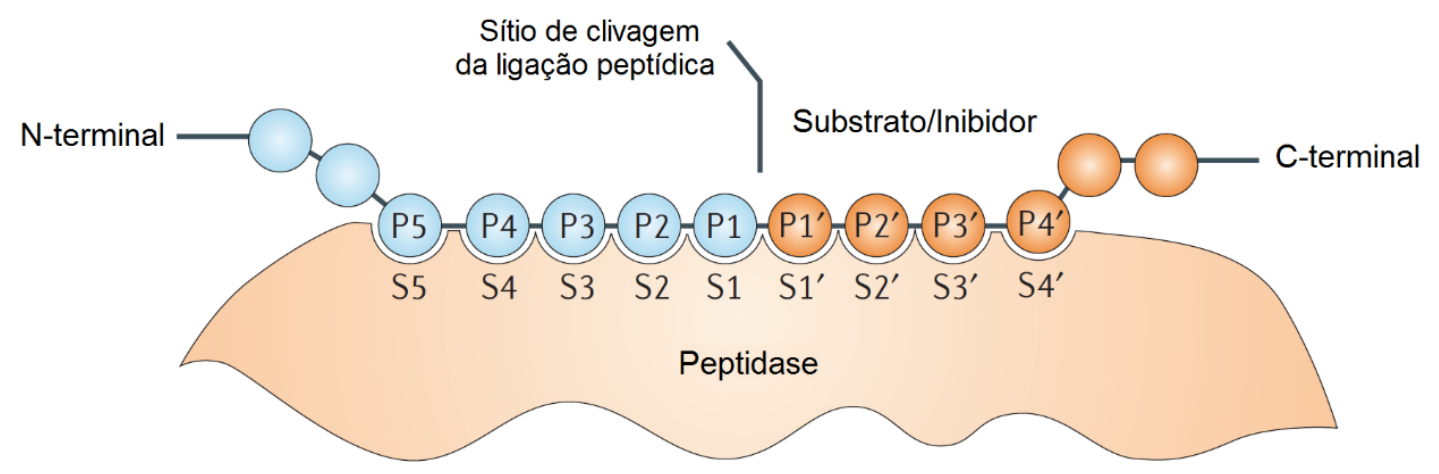

Figura 1.3. Representação esquemática de um substrato proteico ligado a uma peptidase. A superfície da peptidase que acomoda parte da cadeia polipeptídica de um substrato apresenta os sítios S1-Sn crescente para a região N-terminal do substrato e S1'-Sn', para a região C-terminal, começando do sítio de clivagem da ligação peptídica. Os resíduos do substrato são designados P1- 
$\mathrm{Pn}$ e $\mathrm{P1}$ '-Pn', respectivamente. Assim, a estrutura do sítio ativo da peptidase determina sua especificidade. Adaptado de Turk (2006).

De acordo com os resíduos de aminoácidos ou íon que catalisam a clivagem da ligação peptídica do substrato, as peptidases podem ser classificadas em sete classes distintas: aspártico, cisteíno, glutamato, metalo, serino, treonina e, mais recentemente caracterizada, a asparagine peptide lyase (Rawlings et al., 2011). Informações adicionais sobre essas enzimas podem ser encontradas no banco de dados MEROPS (http://merops.sanger.ac.uk/).

Cerca de um terço de todas as peptidases conhecidas pertencem à classe das serinopeptidases, constituindo o maior grupo e o com maior distribuição (Di Cera, 2009; Page \& Di Cera, 2008). Serinopeptidases são encontradas em todos os reinos de vida celular, assim como em genomas virais. A maioria delas são endopeptidases, nas quais a hidrólise ocorre no meio da cadeia polipeptídica. A classe é assim denominada devido ao resíduo Ser no sítio ativo da enzima, responsável pelo ataque nucleofílico à ligação peptídica do substrato. Esse mecanismo é dependente também de outros resíduos, que juntos formam a tríade catalítica, comumente formada por resíduos Asp, His e Ser (Asp ${ }^{102}$, $\mathrm{His}^{57}$ e Ser ${ }^{195}$ na quimotripsina), embora variações sejam possíveis (Hedstrom, 2002).

A família S1, das serinopeptidases tipo quimotripsina, inclui endopeptidases envolvidas em diversos processos fisiológicos, dentre os quais se destacam: digestão (quimotripsina, tripsina, elastase pancreática), resposta imunológica (triptase, fatores $\mathrm{B}, \mathrm{C}$ e D do sistema complemento, catepsina G, elastase neutrofílica), coagulação sanguínea (fatores de coagulação VIIa, IXa, Xa e XIla, trombina, proteína C), fibrinólise (uroquinase, ativador plasminogênico tecidual, plasmina, calicreína), reprodução (antígeno prostático específico, acroseína), ativação de hormônios, apoptose, transdução de sinal e homeostase (Hedstrom, 2002; Page \& Di Cera, 2008).

O sítio S1 das enzimas tipo quimotripsina é um bolsão adjacente à Ser ${ }^{195}$, formado pelos resíduos 189-192, 214-216 e 224-228. A especificidade geralmente é determinada pelos resíduos 189, 216 e 226 (Hedstrom, 2002). A quimotripsina, por exemplo, possui maior afinidade por resíduos hidrofóbicos grandes (Phe/Trp/Tyr/Leu) na posição P1, uma vez que a combinação dos resíduos $\operatorname{Ser}^{189}$, Gly ${ }^{216}$ e Gly ${ }^{226}$ cria um bolsão hidrofóbico 
profundo na enzima. Na tripsina, por sua vez, os resíduos Asp ${ }^{189}$ (S1), Gly $y^{216}$ e Gly ${ }^{226}$ criam uma carga negativa no sítio S1, o que acarreta em uma afinidade por substratos contendo resíduos básicos (Arg/Lys) na posição $\mathrm{P} 1$. A elastase tem maior afinidade para substratos com pequenos resíduos alifáticos na posição $\mathrm{P} 1$ (Ala/Val/Gly), pois, devido à presença dos resíduos $\mathrm{Val}^{216}$ e $\mathrm{Thr}^{226}$, seu sítio S1 é menor do que os sítios da tripsina e quimotripsina. Afinidade por substratos com os resíduos Met, Asn e His na posição P1 também já foi reportada para quimotripsina (Chang et al., 2001; Chen et al., 2001; Guo et al., 2013; Laskowski \& Kato, 1980; Scheidig et al., 1997).

\subsubsection{INIBIDORES DE PEPTIDASES}

Inibidores de peptidases (PIs, do inglês peptidase inhibitors) são compostos capazes de inibir a ação catalítica de enzimas proteolíticas e estão amplamente distribuídos em animais, microrganismos e plantas. Devido a seu papel regulador de peptidases que são moléculas-alvo para a indústria farmacêutica, tem-se aumentado o interesse na caracterização de novos PIs (Tabela 1.1) (Deu et al., 2012). Eles apresentam relevância biológica em diversos processos metabólicos, como o sistema de coagulação sanguínea, ciclo celular, apoptose, vias de processamento hormonal e cascata do sistema complemento. Assim, PIs possuem potencial uso para a melhor compreensão e/ou tratamento terapêutico de diversas condições patológicas, como câncer, artrite, inflamação, hemorragia, e doenças neurodegenerativas e cardiovasculares (Abbenante \& Fairlie, 2005; Kennedy, 1998; Turk, 2006). Além disso, PIs podem ser usados para o desenvolvimento de plantas mais resistentes a pragas (Dunaevsky et al., 2005; Gatehouse, 2011; Lingaraju \& Gowda, 2008). 
Tabela 1.1. Exemplos de inibidores de peptidases aprovados para o uso clínico. Adaptado de Turk (2006).

\begin{tabular}{|c|c|c|c|c|}
\hline Indicação & Composto & Companhia & Alvo & $\begin{array}{l}\text { Classe da } \\
\text { peptidase }\end{array}$ \\
\hline $\begin{array}{l}\text { Hipertensão, } \\
\text { infarto do } \\
\text { miocárdio }\end{array}$ & $\begin{array}{l}\text { Captopril } \\
\text { Enalapril } \\
\text { Lisinopril } \\
\text { Trandalapril } \\
\text { Zofenopril } \\
\text { Ramipril } \\
\text { Moexipril } \\
\text { Imidapril } \\
\text { Perindopril } \\
\text { Qinapril } \\
\text { Fosinopril } \\
\text { Benazepril } \\
\text { Cilazapril }\end{array}$ & $\begin{array}{l}\text { Bristol-Myers Squibb } \\
\text { Merk } \\
\text { AstraZeneca } \\
\text { Abbott } \\
\text { Menarini group } \\
\text { Aventis } \\
\text { Boehringer Mannheim } \\
\text { Trinity Pharmaceuticals } \\
\text { Daiichi Pharmaceutical, Servier/Solvay } \\
\text { Pfizer } \\
\text { Bristol-Myers Squibb } \\
\text { Novartis } \\
\text { Roche }\end{array}$ & ECA & Metalo \\
\hline Periodontite & Periostat & CollaGenex & MMP1, MMP2 & Metalo \\
\hline HIV & $\begin{array}{l}\text { Ritonavir } \\
\text { Amprenavir } \\
\text { Fosamprenavir } \\
\text { Atazanavir } \\
\text { Lopinavir } \\
\text { Indinavir } \\
\text { Saquinavir } \\
\text { Nelfinavir mesylate }\end{array}$ & $\begin{array}{l}\text { Abbott } \\
\text { Vertex Pharmaceuticals, Glaxo } \\
\text { SmithKline } \\
\text { Glaxo SmithKline } \\
\text { Bristol-Myers Squibb } \\
\text { Abbott } \\
\text { Merck } \\
\text { Hoffmann-La Roche } \\
\text { Pfizer }\end{array}$ & HIV peptidase & Aspártico \\
\hline Trombose & $\begin{array}{l}\text { Ximelagatran* } \\
\text { Argatroban } \\
\text { Lepirudin } \\
\text { Desirudin }\end{array}$ & $\begin{array}{l}\text { AstraZeneca } \\
\text { Mitsubishi-Pharma } \\
\text { Aventis (Hoechst Marion Roussel) } \\
\text { Novartis }\end{array}$ & Trombina & Serino \\
\hline & $\begin{array}{l}\text { Fondaparinux } \\
\text { sodium (indireto) }\end{array}$ & Sanofi Synthelabo & Fator Xa & Serino \\
\hline $\begin{array}{l}\text { Doença } \\
\text { respiratória }\end{array}$ & Sivelestat & Ono & $\begin{array}{l}\text { Elastase } \\
\text { neutrofílica } \\
\text { humana }\end{array}$ & Serino \\
\hline Pancreatite & Camostat mesylate & Ono & Tripsina-like & Serino \\
\hline $\begin{array}{l}\text { Pancreatite, } \\
\text { inflamação }\end{array}$ & $\begin{array}{l}\text { Nafamostat } \\
\text { mesilate }\end{array}$ & Japan Tobacco & Amplo espectro & Serino \\
\hline Câncer & Bortezomib & Millennium & Proteassoma & Treonina \\
\hline
\end{tabular}

*Retirado do mercado devido à hepatotoxicidade. ECA, enzima conversora de angiotensina; MMP, metaloproteinase de matriz.

Embora a maioria dos PIs pareça ser específica para uma única classe mecanicista de peptidases, existem exemplos de inibidores que inibem mais de uma classe, como cisteíno e aspártico, serino e metalo, serino e aspártico, dentre outros, devido à presença de sítios de ligação distintos e não sobrepostos (ver revisão por Krowarsch et al. (2003)). Dentre os inibidores de serinopeptidases, três grupos podem ser evidenciados (Krowarsch et al., 2003; Otlewski et al., 2005): 
(i) inibidores canônicos: possuem 3-21 kDa por domínio, são do tipo tight-binding, e interagem de forma não covalente com o sítio ativo da peptidase, assemelhandose ao substrato;

(ii) inibidores não-canônicos: possuem 6-8 kDa por domínio, são extremamente fortes e, até o momento, parecem possuir interação específica apenas com fator Xa e trombina; inibem o sítio ativo da enzima por meio de seu $\mathrm{N}$-terminal e também formam várias interações secundárias com a peptidase na região externa ao sítio ativo;

(iii) serpins: possuem $45-55 \mathrm{kDa}$, formam complexos acil-enzima covalentes irreversíveis, alteram a conformação do sítio ativo da peptidase.

Os inibidores canônicos formam o maior grupo de Pls, e podem ainda ser divididos em diferentes famílias, como Kunitz, Kazal, Bowman-Birk, STI, Ascaris, ecotin, dentre outras (Krowarsch et al., 2003; Laskowski \& Kato, 1980; Shewry, 1999). Algumas dessas famílias são abordadas no Capítulo 2. O segmento responsável pela inibição de peptidase, chamado peptidase-binding loop, é conservado entre os inibidores canônicos. Essa estrutura em alça convexa, estendida e exposta ao solvente é altamente complementar ao sítio ativo côncavo da enzima, formando uma folha- $\beta$ antiparalela com o mesmo. O mecanismo padrão de inibição envolve a presença de um sítio reativo $\mathrm{P} 1-\mathrm{P} 1$ ' localizado na região mais exposta da alça de ligação. Esse mecanismo é semelhante ao usado para a a clivagem da ligação peptídica de substratos por peptidases. A interação tripsina:inibidor, por exemplo, parece ser quase independente da natureza do resíduo básico na posição $\mathrm{P} 1$, sem alterações significantes nas energias de associação com tripsina após a mutação K15R no BPTI (inibidor básico pancreático de tripsina) (Navaneetham et al., 2010). Por outro lado, a inibição da calicreína favorece Arg em vez de Lys (Fiedler, 1987; Grzesiak et al., 2000b), enquanto a inibição de plasmina é aumentada pela presença da Lys na posição P1 (Van Nostrand et al., 1995). A posição $P 1^{\prime}$ de inibidores de tripsina/quimotripsina isolados de peçonhas e venenos animais é geralmente ocupada por um resíduo hidrofóbico (Ala, Gly e Phe), sendo Ala o mais comum (Mourão \& Schwartz, 2013).

O BPTI, também conhecido como aprotinina, é um dos inibidores canônicos de serinopeptidases mais estudados, pertencente ao motivo estrutural tipo Kunitz (mais detalhes no Capítulo 2). Ele consiste em 58 resíduos de aminoácidos, com três pontes 
dissulfeto, e possui afinidade por tripsina, quimotripsina, plasmina e calicreína (Grzesiak et al., 2000b; Stassen et al., 1995). Devido à baixa imunogenicidade em humanos - o que permite sua utilização na clínica como agente antifibrinolítico (Ascenzi et al., 2003; Hardy \& Desroches, 1992) - e a seu mecanismo de ação bem caracterizado, o BPTI tem sido um bom candidato para estudos com engenharia de proteínas que visam a melhor compreensão dos mecanismos de interação com peptidases (Czapinska et al., 2000; Grzesiak et al., 2000a; Grzesiak et al., 2000b). A interação entre o BPTI e a enzima é reversível e competitiva do tipo tight-binding, resultando em um complexo altamente estável (Castro \& Anderson, 1996).

\subsubsection{Tipos de Inibição Enzimática}

Estudos de mecanismo de ação são realizados para caracterizar a interação de um composto com seu alvo molecular, como no caso de um inibidor com uma peptidase. Existem duas grandes classes de inibidores enzimáticos, os reversíveis e os irreversíveis. Os inibidores irreversíveis ligam-se à enzima de forma covalente particularmente estável (Powers et al., 2002). Os inibidores reversíveis, por sua vez, podem ser classificados em competitivos, incompetitivos, não-competitivos e mistos.

$\mathrm{Na}$ inibição competitiva, os dois ligantes (substrato e inibidor) competem pela mesma forma estrutural da enzima (Figura 1.4 A), de forma que a enzima em sua forma livre liga-se a apenas uma molécula de inibidor ou uma de substrato, mas não aos dois simultaneamente. Na maioria dos casos, os inibidores competitivos ligam-se ao sítio ativo da enzima, formando um complexo com esta, porém sem levar à catálise. Para isso, é comum que esses inibidores se assemelhem estruturalmente ao substrato ou a um estado de transição da reação. Outra forma, embora menos comum, de um inibidor competitivo bloquear a ligação do substrato à enzima é observada quando o inibidor se liga a um sítio distinto do sítio ativo e induz mudanças conformacionais na enzima, as quais modificam o sítio de ligação do substrato (Copeland, 2000; Strelow et al., 2004). A porcentagem de inibição resultante na inibição competitiva depende, portanto, de basicamente dois fatores: as concentrações relativas de substrato e inibidor, e da afinidade diferencial da enzima por um ou outro. $O$ fator $\alpha$ reflete o efeito do inibidor na afinidade da enzima pelo 
seu substrato, assim como o efeito do substrato na afinidade da enzima pelo inibidor, sendo tipicamente descrito como a razão $K_{l}^{\prime} / K_{l}$ ( $K_{1}$ é a constante de equilíbrio para a ligação do inibidor à enzima livre e $K_{l}^{\prime}$ é a constante de equilíbrio para a ligação do inibidor ao complexo ES) (Copeland (2000)). Como o inibidor competitivo liga-se reversivelmente à enzima, em sua presença é necessária uma maior concentração de substrato para atingir a mesma velocidade atingida na ausência do inibidor. Dessa forma, enquanto a $K_{\mathrm{m}}$ aparente aumenta na presença do inibidor por um fator $\alpha, V_{\text {máx }}$ permanece igual, pois ainda pode ser atingida caso haja uma concentração suficiente de substrato (Figura 1.4 A') (Nelson \& Cox, 2006).

Um inibidor incompetitivo (uncompetitive) liga-se a um sítio distinto do sítio ativo do substrato, e, ao contrário do inibidor competitivo, liga-se apenas ao complexo ES (Figura 1.4 B). O efeito aparente desses inibidores é diminuir ambos $\mathrm{V}_{\text {máx }}$ e $K_{\mathrm{m}}$ aparente (Figura 1.4 $\left.B^{\prime}\right)$. Na prática, porém, apenas raramente esses inibidores não apresentam sequer algum grau de afinidade pela enzima livre. Assim, na inibição incompetitiva, o que ocorre normalmente é que $K_{\mathrm{l}}>K_{\mathrm{l}^{\prime}}(\alpha<<1)$ (Copeland, 2000).

Outra modalidade de inibição é a não-competitiva (noncompetitive), na qual o inibidor liga-se igualmente bem à E ou ao complexo ES, sem diferenças de afinidade $(\alpha=1)$ (Figura 1.4 C). Esses eventos de ligação ocorrem exclusivamente em um sítio distinto do sítio ativo da enzima ocupado pelo substrato. Como não há competição do inibidor com o substrato pelo sítio de ligação na enzima, a inibição não-competitiva não pode ser superada por concentrações crescentes de substrato. Assim, inibidores não-competitivos reduzem o valor de $V_{\text {máx }}$ sem alterar o valor de $K_{\mathrm{m}}$ aparente (Figura $1.4 \mathrm{C}^{\prime}$ ), de forma que o $K_{\mathrm{i}}$ do inibidor não muda em função da concentração do substrato (Nelson \& Cox, 2006). Em algumas circunstâncias, um composto pode apresentar afinidade desigual por E e ES ( $\alpha$ finito, porém diferente de 1), de forma que esse tipo de inibição é conhecido como inibição mista, e geralmente ambos $V_{\text {máx }}$ e $K_{m}$ são alterados. Na literatura enzimológica é comum que a terminologia "inibição não-competitva" seja considerada de forma mais ampla, sendo válida também para os casos inibição mista (Copeland, 2000; Copeland, 2005). 
A)

$$
\text { Inibição competitiva }
$$

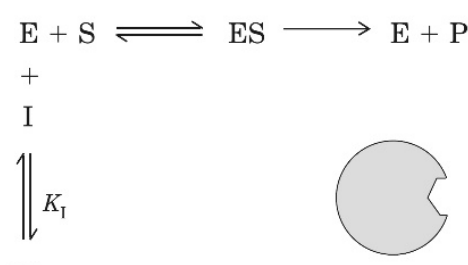

EI

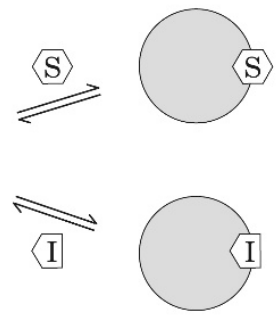

B)

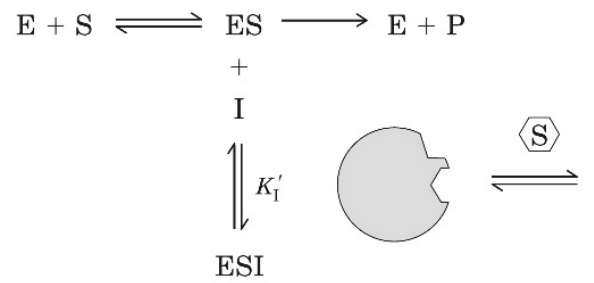

Inibição incompetitiva

ESI
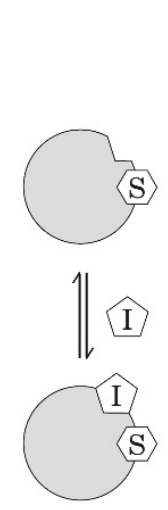

C)

Inibição não-competitiva

$\mathrm{E}+$
+
$\mathrm{I}$
$\|_{K_{\mathrm{I}}}$

$\mathrm{EI}+\mathrm{S}$

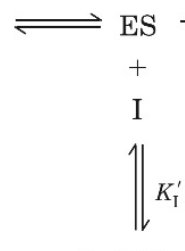

ESI

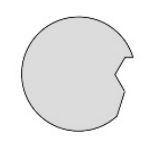

(I) 1

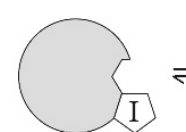

\section{S}

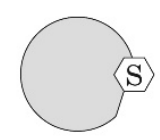

S)

B')

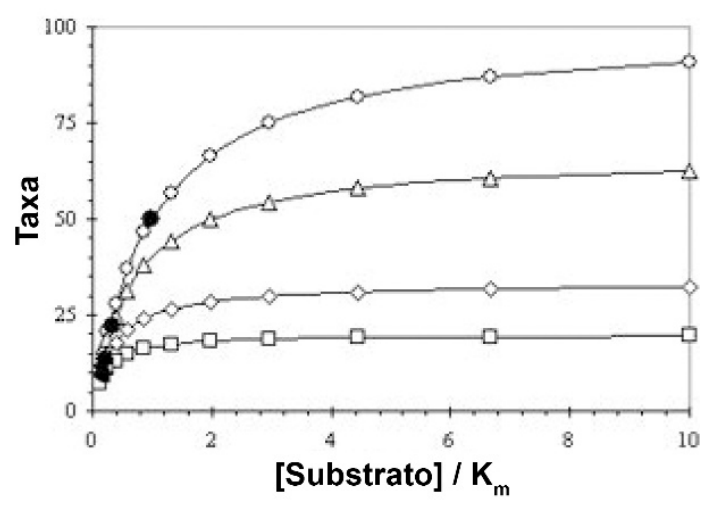

C')

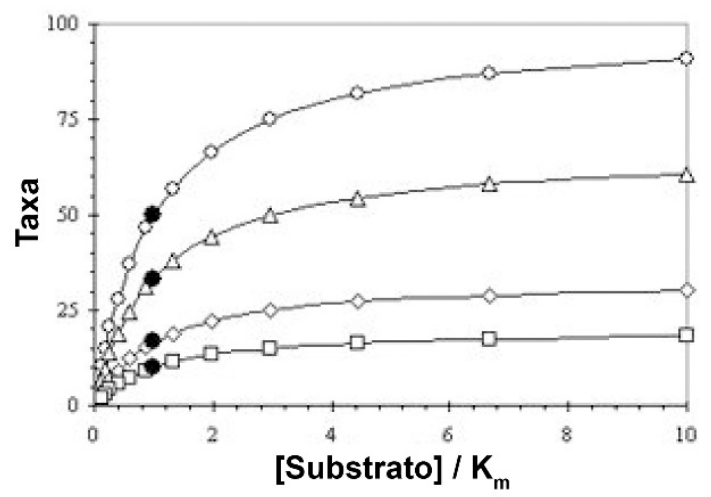

Figura 1.4. Exemplos clássicos de três tipos de inibição reversível. A, B e C são representações esquemáticas dos tipos de inibição competitiva, incompetitiva e não-competitiva, respectivamente, mostrando a enzima em cinza e os sítios de ligação do substrato $S$ e inibidor $I$. $K_{1}$ é a constante de equilíbrio para a ligação do inibidor a $\mathrm{E}$; $K_{\mathrm{l}^{\prime}}$ é a constante de equilíbrio para a ligação do inibidor ao complexo ES. A', B' e $\mathbf{C}^{\prime}$ são as representações desses tipos de inibição pelo modelo cinético de Henri-Michaelis-Menten. Os círculos representam as taxas obtidas na ausência de inibidor; triângulos, losangos e quadrados representam as taxas na presença de $0,5 . K_{\mathrm{i}}, 2,0 . K_{\mathrm{i}} \mathrm{e}$ $4,0 . K_{\mathrm{i}}$ de inibidor, respectivamente. Os círculos pretos mostram os valores de $\mathrm{K}_{\mathrm{m}}$ aparente de cada curva. Adaptado de Nelson \& Cox (2006) e Strelow et al. (2004). 
Além desses tipos clássicos de inibição, outros eventos potenciais incluem inibição do tipo tight-binding, alostérica, parcial e dependente de tempo. Nos limitaremos aqui à explicação do primeiro tipo, enquanto os demais podem ser vistos em Strelow et al. (2004) e Copeland (2000).

Inibidores do tipo tight-binding são aqueles que se ligam à enzima alvo com tanta afinidade que a população de inibidores livres é significativamente depletada pela formação do complexo enzima-inibidor ou enzima-substrato-inibidor (muito baixa taxa de dissociação). Para esses inibidores, as aproximações dos estados de transição feitas pelos métodos clássicos da cinética de Henri-Michaelis-Menten não mais são válidas, e propõese que sejam abandonadas sempre que o $K_{\mathrm{i}}$ de um inibidor for menos que 1000 vezes maior que a concentração total de enzima (Copeland, 2000). Um bom indicativo desse tipo de inibição é quando se obtém um valor de $I_{50}$ próximo à $[E]_{\text {total }}$ na reação. Além disso, inibidores do tipo tight-binding interagem com a enzima de forma bastante estequiométrica, então, a uma dada [S], quanto maior a [E], maior a [I] necessária para atingir metade da saturação máxima. Assim, espera-se que o valor de $I C_{50}$ de um inibidor do tipo tight-binding varie linearmente em função da [E] total (Myers, 1952; Williams \& Morrison, 1979). Muitos inibidores de enzimas terapêuticas contemporâneas são do tipo tight binding, tais como inibidores da diidrofolato redutase (DHFR) como fármacos antitumorais, inibidores da aspartil peptidase como fármacos anti-HIV, e inibidores de metalopeptidases como potenciais protetores de cartilagem (Chabner \& Allegra, 2011; Schimer et al., 2015). Vários inibidores enzimáticos de ocorrência natural que participam nos diversos processos de homeostase metabólica também pertencem a esse grupo (Copeland, 2000).

\subsubsection{Inibidores de Peptidase de Venenos e Peçonhas Animais}

Peptídeos inibidores de peptidase podem ser encontrados no veneno ou na peçonha de muitos organismos, tanto marinhos quanto terrestres. Embora a maioria dos PIs tenha sido isolada, até então, de anêmonas marinhas, serpentes e anuros, o interesse na caracterização de novos Pls de escorpiões, aranhas e himenópteros tem aumentado na comunidade científica, enquanto os inibidores de gastrópodes do gênero Conus 
permanecem pouco estudados. A maioria desses inibidores foram testados contra serinopeptidases, e mostraram diferentes afinidades por peptidases tais como tripsina, quimotripsina, elastase, plasmina e outras. Nesta seção, daremos ênfase aos inibidores de peptidase caracterizados da peçonha de escorpiões (Tabela 1.2), porém, mais informações sobre os inibidores dos demais organismos foram compiladas no artigo de revisão Protease inhibitors from marine venomous animals and their counterparts in terrestrial venomous animals (Mourão \& Schwartz, 2013), disponibilizado como Apêndice I.

O primeiro relato de um inibidor de peptidase obtido da peçonha de escorpiões parece ter sido em 1981, quando Chhatwal e Habermann (1981) descreveram um polipeptídeo inibidor de tripsina com aproximadamente $8500 \mathrm{Da}$ isolado da peçonha do escorpião Mesobuthus tamulus (Tabela 1.2). O peptídeo inibiu trispina e calicreína, porém exibiu pouca ou nenhuma atividade contra quimotripsina, e foi inativo para plasmina e trombina. No entanto, sua sequência não foi elucidada.

Em seguida, Schwartz e colaboradores (2007), utilizando estratégia transcritômica, reportaram pela primeira vez a presença de um inibidor de peptidase putativo do tipo Kunitz em escorpiões. O peptídeo maduro, denominado $\mathrm{Hg1}$, do escorpião mexicano Hadrurus gertschi, não foi encontrado na peçonha, e sua atividade permanecia desconhecida, até ser posteriormente expresso heterologamente em células Escherichia coli BL21(DE3), purificado e testado (Chen et al., 2012a). Junto com Hg1, outros seis polipeptídeos recombinantes da peçonha de escorpiões (LmKTT-1a, LmKTT-1b, LmKTT-1c, BmKTT-1, BmKTT-2 \& BmKTT-3) também foram caracterizados como inibidores de tripsina (Tabela 1.2) (Chen et al., 2012a). Desses, o LmKTT-1b (ou SdPI), de Lychas mucronatus, foi o primeiro inibidor do tipo Kunitz funcionalmente caracterizado de escorpiões (Zhao et al., 2011). Todos esses peptídeos recombinantes parecem ter estruturas secundárias semelhantes à do BPTI, conforme analisado por espectroscopia de dicroísmo circular. Além disso, alguns deles mostraram também atividade bloqueadora de canais de potássio (Chen et al., 2012a). Embora Chen e colaboradores (2012a) tenham apresentado que esses sete inibidores não tiveram atividade contra quimotripsina ou elastase mesmo em concentrações elevadas, um estudo mais recente mostrou que a toxina BmKTT-2 inibe, além de tripsina, também quimotripsina, elastase e plasmina (Tabela 1.2), sendo a afinidade por elastase menor (Ding et al., 2015). 
Outro inibidor tipo Kunitz foi identificado na biblioteca de cDNA da glândula de peçonha de M. martensii, o BmKPI (Tabela 1.2). Com 64 resíduos e quatro pontes dissulfeto, o BmKPI recombinante inibiu quimotripsina e elastase em concentrações nanomolares, e tripsina em doses maiores (Chen et al., 2013a).

Tabela 1.2. Inibidores de peptidase caracterizados da peçonha de escorpiões. Letras maiúsculas se referem às peptidases inibidas: $T$, tripsina; $Q$, quimotripsina; $P$, plasmina; $C$, calicreína; $E$, elastase. As classes estruturais estão indicadas por símbolos: inibidores de peptidase tipo Kunitz; $\diamond$ motivo tipo Ascaris. As toxinas cujo nome está precedido pela letra " $r$ " foram obtidas a partir de expressão heteróloga (toxina recombinante), e não a partir da peçonha. Versão adaptada e atualizada de Mourão \& Schwartz (2013).

\begin{tabular}{|c|c|c|c|c|c|c|}
\hline Espécie & Toxina & $\begin{array}{l}\text { UniProt } \\
\text { KB }\end{array}$ & $\mathbf{A A}^{\mathrm{a}}$ & Peptidase inibida & $\begin{array}{c}\text { Atividade } \\
\text { inibitória b, c }\end{array}$ & Referência \\
\hline $\begin{array}{l}\text { Mesobuthus } \\
\text { tamulus }\end{array}$ & Fração IX-1-a & - & - & $\begin{array}{l}\text { Tripsina*, } \\
\text { calicreína }\end{array}$ & $\begin{array}{l}19,2 \mathrm{lU} / \mathrm{mg}(\mathrm{T}) \\
87 \mathrm{IU} / \mathrm{mg}(\mathrm{C})^{\mathrm{b}}\end{array}$ & $\begin{array}{c}\text { (Chhatwal \& } \\
\text { Habermann, 1981) }\end{array}$ \\
\hline $\begin{array}{l}\text { Hadrurus } \\
\text { gertschi }\end{array}$ & $\diamond \mathrm{rHg} 1$ & P0C8W3 & $67^{111}$ & Tripsina & $107^{c}$ & $\begin{array}{c}\text { (Chen et al., 2012a; } \\
\text { Schwartz et al., } \\
\text { 2007) }\end{array}$ \\
\hline \multirow{4}{*}{$\begin{array}{l}\text { Lychas } \\
\text { mucronatus }\end{array}$} & $\diamond$ rLmKTT-1a & P0DJ46 & $59^{111}$ & Tripsina & $140^{c}$ & $\begin{array}{l}\text { (Chen et al., 2012a; } \\
\text { Zhao et al., 2011) }\end{array}$ \\
\hline & $\begin{array}{l}\text { rLmKTT-1b } \\
\text { ou SdPI }\end{array}$ & P0DJ45 & $59^{111}$ & Tripsina & $160^{c}$ & $\begin{array}{c}\text { (Chen et al., 2012a; } \\
\text { Zhao et al., 2011) }\end{array}$ \\
\hline & rLmKTT-1c & P0DJ48 & $59^{111}$ & Tripsina & $124^{c}$ & (Chen et al., 2012a) \\
\hline & $\Delta \mathrm{rLmAPI}$ & - & $60^{v}$ & Quimotripsina & $15,5^{c}$ & (Liu et al., 2015) \\
\hline \multirow{4}{*}{$\begin{array}{l}\text { Mesobuthus } \\
\text { martensii }\end{array}$} & $\checkmark \mathrm{rBmKTT-1}$ & P0DJ49 & $59^{111}$ & Tripsina & $136^{c}$ & (Chen et al., 2012a) \\
\hline & $\diamond \mathrm{rBmKTT}-2$ & PODJ50 & $58^{\mathrm{IV}}$ & $\begin{array}{l}\text { Tripsina, } \\
\text { plasmina }\end{array}$ & $\begin{array}{l}420(T) \\
8,75(P)^{c}\end{array}$ & $\begin{array}{c}\text { (Chen et al., 2012a; } \\
\text { Ding et al., 2015) }\end{array}$ \\
\hline & rBmKTT-3 & P0DJ47 & $70^{111}$ & Tripsina & $760^{c}$ & (Chen et al., 2012a) \\
\hline & $\bullet \mathrm{rBmKPI}$ & - & $64^{\mathrm{IV}}$ & $\begin{array}{c}\text { Quimotripsina*, } \\
\text { tripsina, } \\
\text { elastase }\end{array}$ & $\begin{array}{c}32(\mathrm{Q}), \\
1800(\mathrm{~T}) \\
160(\mathrm{E})^{c}\end{array}$ & (Chen et al., 2013a) \\
\hline \multirow{2}{*}{$\begin{array}{l}\text { Scorpiops } \\
\text { jendeki }\end{array}$} & $\diamond \mathrm{rSjAPI}$ & P0DM55 & $64^{v}$ & $\begin{array}{c}\text { Quimotripsina*, } \\
\text { elastase }\end{array}$ & $\begin{array}{l}97,1(Q), \\
3700(E)^{c}\end{array}$ & (Chen et al., 2013c) \\
\hline & $\diamond \mathrm{rSj} 7170$ & - & $62^{\mathrm{V}}$ & Quimotripsina & $100^{c}$ & (Song et al., 2014) \\
\hline
\end{tabular}

* Peptidase contra a qual o inibidor apresentou atividade mais potente. ${ }^{a}$ Número de resíduos de aminoácidos e pontes dissulfeto (sobrescrito) do peptídeo maduro. ${ }^{b}$ Valor medido em termos de unidades inibitórias (IU)/mg, onde 1 IU é a quantidade de proteína que inibe uma unidade de enzima. ${ }^{c}$ Valor medido para a constante $K_{\mathrm{D}}$ ou $K_{\mathrm{i}}(\mathrm{nM})$.

Também por meio de estratégia transcritômica, através de bibliotecas de cDNA construídas separadamente das glândulas de peçonha de três espécies de escorpiões, quatro inibidores de peptidase putativos pertencentes ao motivo estrutural tipo Ascaris foram identificados: SjAPI (Scorpiops jendeki Ascaris-type protease inhibitor), SjAPI-2 (Scorpiops jendeki Ascaris-type protease inhibitor 2), CtAPI (Chaerilus tricostatus Ascaris- 
type protease inhibitor), e BmAPI (Buthus martensii Ascaris-type protease inhibitor) (Chen et al., 2013c). Membros da família tipo Ascaris são caracterizados pela presença de cinco pontes dissulfeto (Grasberger et al., 1994). O polipeptídeo recombinante SjAPI (Tabela 1.2) inibiu tanto $\alpha$-quimotripsina quanto elastase, sem efeito aparente contra tripsina (Chen et al., 2013c). O SjAPI-2 teve baixa atividade contra quimotripsina $\left(\mathrm{IC}_{50} \sim 4,0 \mu \mathrm{M}\right)$ e não inibiu tripsina ou elastase. Além disso, assim como demonstrado anteriormente para Pls tipo Kunitz, o inibidor tipo Ascaris SjAPI-2 apresentou atividade em diferentes subtipos de canais de $\mathrm{K}^{+}$(Chen et al., 2015a). Também da biblioteca de cDNA de S. jendeki foi obtido o precursor do peptídeo denominado Sj7170 (Tabela 1.2), cujo peptídeo maduro inibiu quimotripsina, sem atividade contra tripsina e elastase (Song et al., 2014).

Posteriormente, quatro novos peptídeos com motivo estrutural tipo Ascaris foram descritos de bibliotecas de cDNA obtidas da glândula de peçonha de diferentes escorpiões: LmAPI (Lychas mucronatus Ascaris-type protease inhibitor), PcAPI (Pandinus cavimanus Ascaris-type protease inhibitor), PcAPI-2 (Pandinus cavimanus Ascaris-type protease inhibitor 2), e HjAPI (Hottentotta judaicus Ascaris-type protease inhibitor). O LmAPI recombinante inibiu quimotripsina com alta afinidade (Tabela 1.2), com pouco efeito contra elastase e sem efeitos contra tripsina (Liu et al., 2015).

Além desses inibidores, um inibidor de plasmina denominado discreplasminin foi isolado da peçonha do escorpião Tityus discrepans. Ele possui um mecanismo antifibrinolítico semelhante à aprotinina (BPTI) e provavelmente interage com os sítios ativos da plasmina e tPA, um ativador de plasminogênio tecidual (Brazón et al., 2009).

\subsubsection{Câncer, Peptidases e Inibidores de Peptidases}

Inibidores de peptidases têm sido apresentados como ferramentas terapêuticas em potencial para o tratamento de diversos tipos de câncer, uma vez que peptidases desempenham um papel essencial em inúmeros processos das células tumorais (Koblinski et al., 2000; Sloane et al., 2006; Uhland, 2006). Câncer é o nome dado a um conjunto de doenças que têm em comum a proliferação desordenada de células que invadem os tecidos e órgãos, podendo espalhar-se para outras regiões do corpo (metástase) (Ruddon, 2007). Estatísticas apontam a ocorrência de 14,1 milhões de novos casos e 8,2 milhões de óbitos 
devido ao câncer em 2012, o que representa cerca de $12 \%$ de todas as causas de morte no mundo (GLOBOCAN, 2012). As causas do câncer são variadas, podendo ser externas ou internas ao organismo, de forma que ambas estão inter-relacionadas (INCA, 2016). De todos os casos, 80 a 90\% dos cânceres têm início com a exposição a fatores ambientais e/ou hábitos comportamentais, dentre os quais destacam-se o consumo de tabaco e álcool, obesidade e sedentarismo, dieta rica em produtos industrialmente processados, e exposição a vírus oncogênicos, à radiação, à poluição e a produtos químicos, como agrotóxicos (Irigaray et al., 2007).

Estando atrás apenas do câncer de mama e do colorretal, o câncer cervical é o terceiro mais frequente na população feminina e a quarta causa de morte de mulheres por câncer no Brasil, contabilizando aproximadamente 5.430 mortes em 2013. Estimam-se 16.340 novos casos no ano 2016 no Brasil (INCA, 2016). Células HeLa constituem a primeira linhagem celular imortalizada de câncer humano, sendo obtidas de um câncer cervical glandular agressivo há cerca de 65 anos. Embora milhares de linhagens celulares de praticamente todo tipo de câncer têm sido estabelecidas desde então, as células HeLa continuam sendo uma das linhagens celulares de câncer humano mais amplamente usadas (Masters, 2002).

O câncer de pele é o mais frequente no Brasil, correspondendo a $25 \%$ de todos os tumores malignos registrados no país. Seu desenvolvimento depende do tipo de célula mutada. Mutações nas células produtoras de melanina, os melanócitos, levam ao desenvolvimento de melanoma. Apesar de ser bastante agressivo, devido à alta possibilidade de metástase, sua incidência é baixa, representando apenas $4 \%$ das neoplasias malignas do órgão. O número estimado de novos casos de melanoma no Brasil para 2016 é de 3.000 homens e 2.670 mulheres (INCA, 2016). Visto que o melanoma metastático já apresenta resistência a muitas terapias atuais e que está associado a um pobre prognóstico, é crucial a busca por novas moléculas-alvo em potencial (NIH, 2010; Paluncic et al., 2016).

Hanahan \& Weinberg (2011) descreveram um conjunto de características que permitem o crescimento tumoral e a disseminação metastática, auxiliando a compreensão desses processos que são fundamentais para a biologia do câncer. Em resumo, essas características compreendem: 
1. Proliferação descontrolada e insensibilidade a sinais supressores: enquanto tecidos normais têm um controle delicado da produção e liberação de moléculas sinalizadoras que regulam a entrada e progressão no ciclo celular, permitindo a homeostase celular, células tumorais possuem vias de sinalização intracelular alteradas, e utilizam diferentes mecanismos para garantir sua proliferação anormal, como produção de sinais de proliferação, estimulação para que células normais do estroma as forneçam fatores de crescimento, e insensibilidade às moléculas supressoras de crescimento;

2. Resistência à morte celular: células tumorais possuem várias estratégias para alterar a sinalização da apoptose, como o bloqueio da via de sinalização da proteína P53, o aumento na expressão de reguladores antiapoptóticos ou de sinais de sobrevivência, ou a regulação negativa de fatores pró-apoptóticos;

3. Indução da angiogênese: a fim de receber nitrogênio e oxigênio e descartar restos metabólicos e gás carbônico, e devido ao seu crescimento acelerado, tumores sinalizam para a formação contínua de novos vasos sanguíneos, os quais, no geral, possuem morfologia aberrante, com excesso de ramificações, fluxo sanguíneo errático, micro-hemorragias e níveis anormais de proliferação de células endoteliais;

4. Potencial replicativo ilimitado: a extensão dos telômeros nas extremidades dos cromossomos está associada ao número de divisões das células, de forma que seu encurtamento leva às fases de senescência e morte celular; nas células tumorais imortalizadas, diferentemente das normais, a expressão da enzima telomerase (que polimeriza o telômero) está aumentada, promovendo ilimitadas divisões celulares.

5. Invasão e metástase: essa característica depende de uma sucessão de eventos, a começar pela invasão local das células tumorais para os vasos sanguíneos e/ou linfáticos próximos (intravasamento), e seu deslocamento por esses vasos até que escapem para o parênquima de outro tecido distante (extravasamento), onde formam pequenos nódulos que irão se desenvolver em tumores macroscópicos (colonização). A invasão das células tumorais está relacionada à redução da expressão de moléculas de adesão a outras células e também à matriz extracelular e/ou aumento da expressão de moléculas de adesão que normalmente estão 
associadas às migrações celulares que ocorrem durante a embriogênese ou inflamação.

Além dessas características, outras são descritas como emergentes, por ainda não estarem completamente elucidadas (ver revisão por Hanahan \& Weinberg (2011)). Os tratamentos terapêuticos para câncer se desenvolvem à medida que essas características tidas como fundamentais para a progressão tumoral são melhor compreendidas. Nesse contexto, diferentes classes de peptidases têm sido estudadas devido a seus distintos papeis em células tumorais. Peptidases extracelulares medeiam a degradação da matriz extracelular e de estruturas de coesão intercelulares, permitindo a migração celular, e também atuam na ativação de fatores angiogênicos e fatores de crescimento. Essas peptidases derivam não somente das células tumorais, mas também de outras células presentes no microambiente do tumor: células do estroma (como fibroblastos), células inflamatórias (como macrófagos, mastócitos e neutrófilos) e células de vasos sanguíneos (como células endoteliais) (Hanahan \& Weinberg, 2011; Sloane et al., 2006).

Metalopeptidases (MMPs), serinopeptidases e cisteinopeptidases são usadas por células tumorais para a clivagem da matriz extracelular durante a migração invasiva, degradando estruturas de colágeno, laminina, vitronecticna e fibronectina (Fonovic \& Turk, 2014; Friedl \& Wolf, 2008). Além disso, MMPs contribuem para a angiogênese por meio da degradação de lâminas basais, o que permite a invasão das células endoteliais, e também por meio da clivagem de fatores que aumentam ou mantêm o fenótipo angiogênico (Cathcart et al., 2015; Moro et al., 2014). Dentre as cisteinopeptidases, as que parecem estar mais envolvidas com câncer são as catepsinas B, L, S, K e X (ver revisão por Löser \& Pietzsch (2015)). De forma geral, elas atuam facilitando a progressão tumoral, crescimento, invasão e metástase.

Dentre as serinopeptidases, a peptidase transmembrana tipo tripsina denominada matriptase encontra-se superexpressa em diversos tipos de câncer. Seu papel tem sido associado não apenas à invasão celular, mas também à ativação de vias oncogênicas. Seus substratos naturais parecem ser o zimogênio do ativador de plasminogênio tipo uroquinase (pro-uPA) e a forma precursora inativa do fator de crescimento de hepatócito (proHGF/SF), os quais estão envolvidos no processo de invasão metastática. Além disso, mostrou-se que uma forma secretada da matriptase é capaz de clivar fibronectina e 
laminina, ambos componentes da matriz extracelular e que medeiam a adesão e migração celular, além de ativar o PAR-2 (receptor 2 ativado por peptidase), um receptor acoplado à proteína $\mathrm{G}$ que tem papel essencial na adesão celular e nos processos inflamatórios iniciais (Uhland, 2006). O aumento de expressão de outras enzimas pertencentes à família tipo tripsina, como hepsina e HGFA (ativador de fator de crescimento de hepatócito) (Han et al., 2014), assim como de algumas calicreínas (Borgono \& Diamandis, 2004), também têm sido associado a cânceres. Além dessas, a serinopeptidase RBBP9 (proteína 9 ligante de retinoblastoma) apresentou atividade hidrolítica $40 \%$ mais elevada nos tumores analisados, embora sua expressão seja a mesma em células normais ou tumorais (Shields et al., 2010).

Além dessas classes de peptidases, os proteassomas - membros protótipos da classe das treonina-peptidases - são bastante estudados como moléculas-alvo no tratamento de diversos tipos de câncer, em especial de mieloma múltiplo e linfoma de células do manto (Johnson, 2015). Proteínas destinadas para degradação pelo sistema ubiquitina-proteassoma incluem proteínas danificadas, dobradas inadequadamente ou aquelas com curtos tempos de meia-vida nas células (Ciechanover, 2005). Dessa forma, inibidores de proteassomas promovem o acúmulo de proteínas que apresentam efeitos deletérios para a sobrevivência das células, representanto promissores agentes antitumorais (Ding et al., 2014; Johnson, 2015).

Assim sendo, inibidores de diferentes classes de peptidases têm sido sugeridos como potenciais agentes antitumorais. Alguns deles estão em fase clínica (Abbenante \& Fairlie, 2005; Johnson, 2015; Kobayashi, 2013; Koltai, 2015; Kumar et al., 2015) e outros já são utilizados para o tratamento terapêutico de determinados tipos de câncer, como os inibidores de proteassoma bortezomib e carfilzomib (Herndon et al., 2013; Johnson, 2015). Devido à heterogeneidade do microambiente tumoral, deve-se atentar para a possibilidade de múltiplas interações entre diferentes peptidases e as moléculas com as quais interagem, o que pode acarretar em diversos efeitos colaterais decorrentes da inibição de uma ou outra via (Koblinski et al., 2000; Lopez-Otin \& Matrisian, 2007). Apesar do intenso avanço nas pesquisas sobre o envolvimento das peptidases no câncer, o uso de inibidores como agentes terapêuticos ainda é uma área relativamente recente e que requer mais estudos para sanar inúmeros questionamentos, ajudando a desenvolver inibidores mais potentes e 
específicos. Além de sua aplicação direta como agentes terapêuticos, inibidores de peptidases específicos têm sido utilizados como sondas para identificação e localização de enzimas associadas a diversos tumores, permitindo monitorar sua dinâmica de regulação e estudar a interação com fármacos em modelos experimentais in vitro e in vivo (Edgington \& Bogyo, 2013; Nomura et al., 2010).

\subsubsection{Inibidores de Peptidase com Ação em Canais de Potássio}

Canais de potássio representam o maior e mais diverso subgrupo de canais iônicos, podendo ser ativados por um ligante, como um íon, uma pequena molécula orgânica ou mesmo uma proteína, ou podem ser ativados por uma diferença de potencial eletroquímico (voltagem) (Choe, 2002; Gati et al., 2012; Jenkinson, 2006; MacKinnon, 2003). Esses canais pertencem ao grupo dos canais tetraméricos, sendo cada monômero arranjado em segmentos transmembrânicos helicoidais que podem variar em número de acordo com a família do canal. Nos canais de potássio dependentes de voltagem (canais $\mathrm{K}_{\mathrm{v}}$ ), cada subunidade é arranjada em seis segmentos transmembrânicos helicoidais, denominados S1 a S6 (Figura 1.5).

Os segmentos S5-S6 das quatro subunidades formam em conjunto um único domínio do poro $(P)$, que é via de permeabilidade iônica pela membrana, e inclui o filtro de seletividade (P-loop). As hélices S1-S4 formam os domínios sensores de voltagem devido à presença de resíduos de aminoácidos positivamente carregados em S4, que se movem em resposta a uma despolarização da membrana, permitindo a ativação do canal e a geração da corrente de gating. O domínio T1 é uma porção altamente conservada da região Nterminal citoplasmática, e é responsável por mediar a multimerização do canal, sendo conhecida como domínio de tetramerização (Birnbaum et al., 2004; Chen et al., 2010). 
A

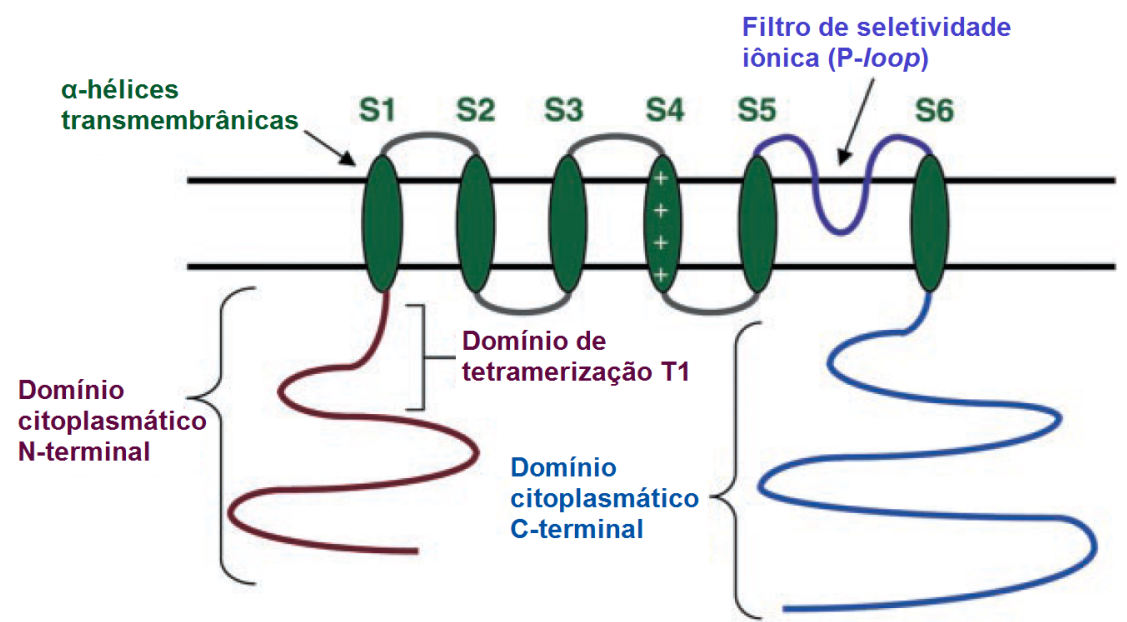

B

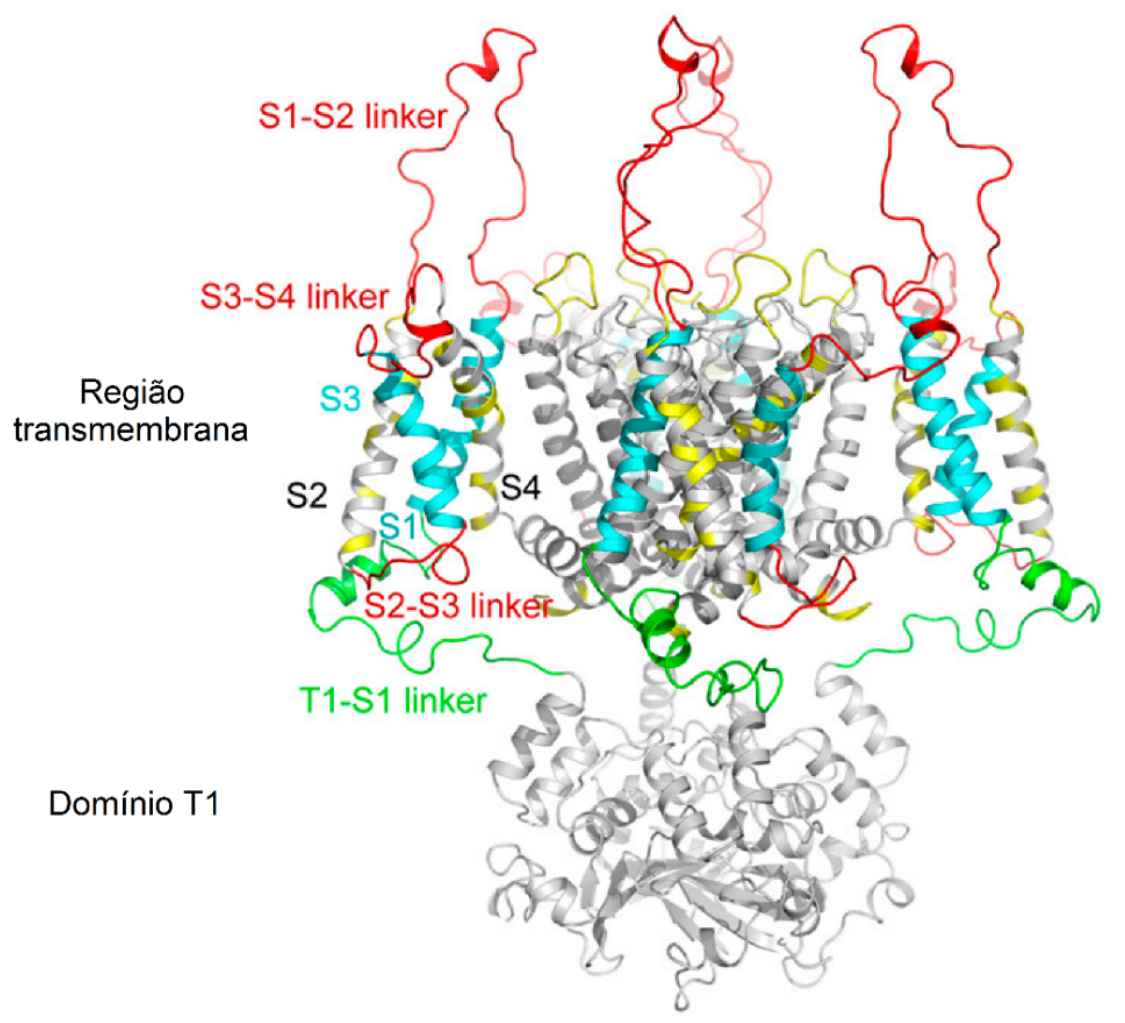

Figura 1.5. Estrutura geral de um canal de $\mathrm{K}^{+}$dependente de voltagem. (A) Representação esquemática de uma única subunidade, com elementos presentes na maioria dos canais de $\mathrm{K}^{+}$: domínio citoplasmático N-terminal, domínio T1, seis segmentos transmembrânicos S1-S6, sensor de voltagem S4, domínio do poro (constituído pelos segmentos S5 e S6), filtro de seletividade iônica e domínio citoplasmático C-terminal. (B) Estrutura do canal $\mathrm{K}_{\mathrm{v}} 1.2$ de Rattus norvegicus (PDB ID código 2A79). Adaptado de Birnbaum et al. (2004) (A) e Chen et al. (2010) (B).

Em um potencial de ação, canais $K_{v}$ permitem que o potássio passe do lado intracelular para o extracelular, retornando o potencial de membrana para seu estado polarizado. $\mathrm{O}$ filtro de seletividade de um canal $\mathrm{K}_{\mathrm{v}}$ se encontra na porção mais estreita do poro e possui $\sim 12$ Å de comprimento e 2,5 Å de diâmetro (Figura 1.6 A e B). Seu papel é assegurar que virtualmente apenas íons $\mathrm{K}^{+}$possam passar, o que é alcançado pela presença 
de átomos de oxigênio providos pelos grupos carbonilas da cadeia principal dos resíduos de aminoácidos Thr-Val-Gly-Tyr-Gly (TVGYG). Essa sequência está presente em todas as subunidades e é altamente conservada entre canais de $\mathrm{K}^{+}$(Figura 1.6 C), embora variações sejam observadas em alguns casos (MacKinnon, 2003). Esses átomos de oxigênio mimetizam a coordenação de íons $\mathrm{K}^{+}$em água, e, portanto, servem como sítios de ligação para os íons brevemente desidratados. Os átomos de oxigênio formam quatro sítios adjacentes ao longo do filtro (S1-S4), permitindo que mais de um íon $\mathrm{K}^{+}$se ligue e passe de um lado da membrana para o outro sem que haja reidratação. Essa desidratação transiente foi sugerida ser muito menos termodinamicamente favorável para íons $\mathrm{Na}^{+}$, o que favoreceria a seletividade do canal.

A

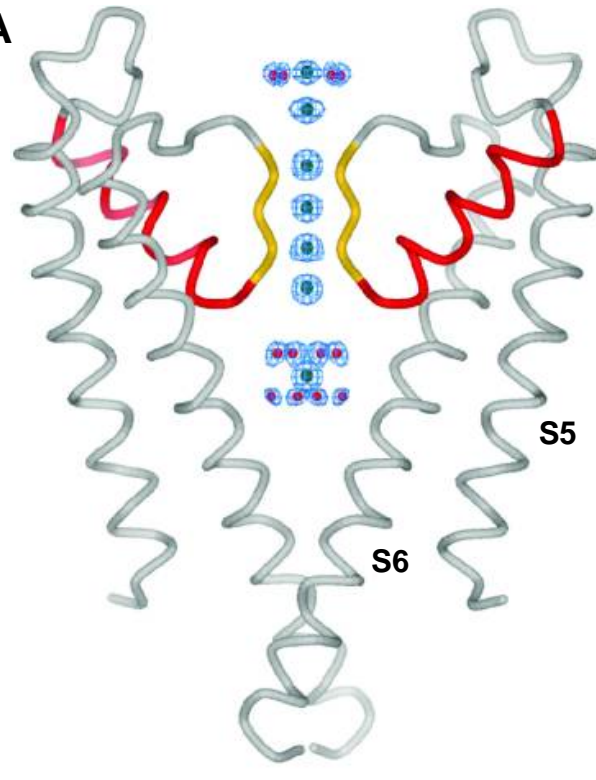

B
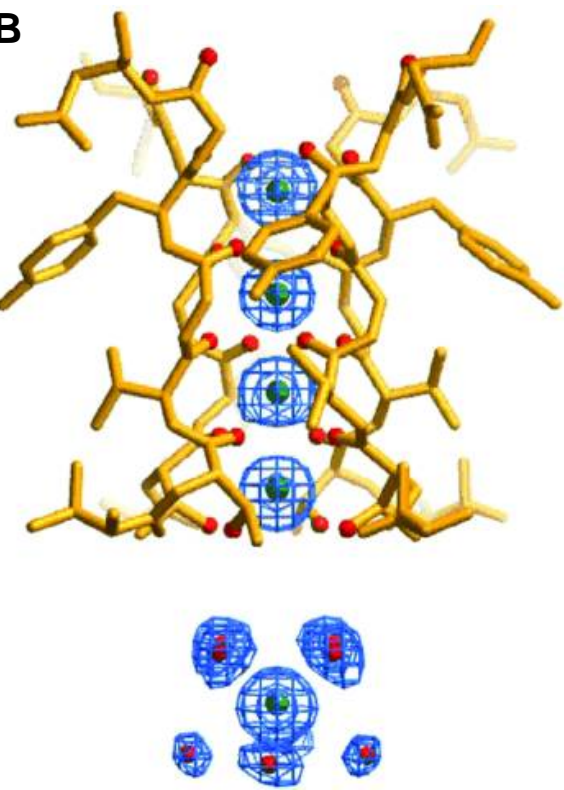

C

chimera: MRELGLLIFFLFIGVILFSSAVYFAEADERDSQFPSIPDAFWWAVVSMTTVGYGDMPTTIGGKIVGSLCAIAGVLTIALPVPVIVSNFNYFYHRET :417

Kv2.1 : YNELGLLILFLAMGIMIFSSLVFFAEKDEDDTKFKSIPASFWWATITMTTVGYGDIYPKTLLGKIVGGLCCIAGVLVIALPIPIIVNNFSEFYKEQK :420

Kv1.2 : MRELGLLIFFLFIGVILFSSAVYFAEADERDSQFPSIPDAFWWAVVSMTTVGYGDMVPTTIGGKIVGSLCAIAGVLTIALPVPVIVSNFNYFYHRET : 421

Kv1.1 : MRELGLLIFFLFIGVILFSSAVYFAEAEEAESHFSSIPDAFWWAVVSMTTVGYGDMYPVTIGGKIVGSLCAIAGVLTIALPVPVIVSNFNYFYHRET : 419

Kv1.3 : MRELGLLIFFLFIGVILFSSAVYFAFADDPSSGFNSI PDAFWWAVVTMTTVGYGDMHPVTIGGKIVGSLCAIAGVLTIALPVPVIVSNFNYFYHRET : 444

Kv1.5 : MRELGLLIFFLFIGVILFSSAVYFAEADNQGTHFSSIPDAFWWAVVTMTTVGYGDMRPITVGGKIVGSLCAIAGVLTIALPVPVIVSNFNYFYHRET :527

Shaker : MRELGLLIFFLFIGVVLFSSAVYFAEAGSENSFFKSIPDAFWWAVVTMTTVGYGDMTPVGVWGKIVGSLCAIAGVLTIALPVPVIVSNFNYFYHRET : 489

KCSA : WRAAGAATVLLVIVLLAGSYLAVLAERGAPGAQLITYPRALWWSVETATTVGYGDLYPVTLWGRCVAVVVMVAGITSFGLVTAALATWFVGREQERR : 122

Figura 1.6. Poro de condução iônica de um canal de potássio KcsA e alinhamento de sequências da região do poro de canais de $\mathrm{K}^{+}$. (A) Duas das quatro subunidades do canal KcsA estão representadas com o lado extracelular na parte superior. Cada subunidade contém uma hélice externa e uma interna próxima ao poro, uma hélice formadora de poro (vermelho) e um filtro de seletividade (amarelo). A malha azul mostra a densidade eletrônica de íons $\mathrm{K}^{+}$(verde) e moléculas de água (vemelho) ao longo do poro. (B) Aumento da região do filtro de seletividade com os íons 
$\mathrm{K}^{+}$desidratados nas posições 1 a 4 (externo para interno) e um íon $\mathrm{K}^{+}$hidratado na cavidade central abaixo do filtro. (C) Alinhamento de sequências da região do poro de canais membros da família

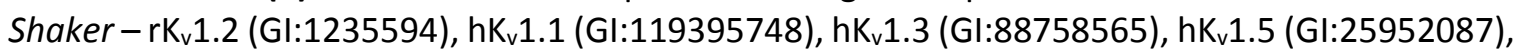
Shaker $\mathrm{K}_{\mathrm{v}}$ (GI:13432103) -, rKv2.1 (GI:24418849), KcsA (GI:61226909) e uma quimera do KcsA. A sequência do filtro de seletividade está mostrada em amarelo. Adaptado de MacKinnon (2003) (A e B) e Banerjee et al. (2013) (C).

Canais de potássio desempenham um papel essencial em processos de sinalização celular, regulando a liberação de neurotransmissores, frequência cardíaca, secreção de hormônios, excitabilidade neuronal, transporte de eletrólitos, contração do músculo liso e regulação do volume celular. Assim, toxinas modificadoras de correntes de $\mathrm{K}^{+}$emergem como moléculas promissoras para a melhor compreensão das propriedades funcionais desses canais e também para o desenvolvimento de novos fármacos para o tratamento de diversas doenças, dentre as quais doenças autoimunes, asma, arritmia cardíaca, inflamação, hipertensão, e doenças do Sistema Nervoso Central (SNC), como esclerose múltipla, doenças de Parkinson e Alzheimer, esquizofrenia e epilepsia (Bergeron \& Bingham, 2012; Gati et al., 2012; Wulff \& Zhorov, 2008).

Além disso, alterações nos níveis de expressão de canais de $\mathrm{K}^{+}-$como aumento da expressão por hormônios ou fatores de crescimento, ou redução causada por aberrações cromossômicas - podem ter efeitos substanciais nos processos celulares como morte celular, proliferação, migração, adesão e controle do volume celular, processos esses que podem influenciar a progressão de um tumor. De forma geral, muitos tumores apresentam expressão aumentada de diferentes subtipos de canais de $\mathrm{K}^{+}$(dentre os quais se destacam

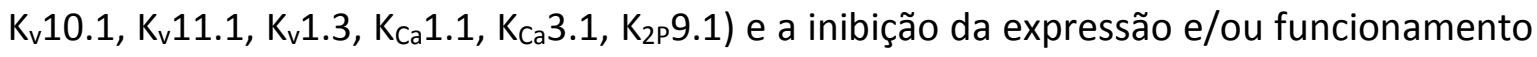
desses canais tem mostrado redução da progressão tumoral em diversos experimentos in vivo e in vitro (ver revisões por Pardo \& Stuhmer (2014), Urrego et al. (2014), Arcangeli \& Becchetti (2015)).

Peçonhas de artrópodes constituem uma rica fonte de toxinas peptídicas inibidoras de canais de $\mathrm{K}^{+}$(KTxs). As KTxs podem ser classificadas em bloqueadoras de canais de $\mathrm{K}^{+}$, ligando-se ao vestíbulo externo do canal e, então, bloqueando a condutância iônica pelo poro do canal, ou podem ser modificadoras de gating, deslocando a abertura do canal para potenciais mais positivos. Toxinas escorpiônicas, como a charybdotoxina, estão classificadas no primeiro grupo enquanto algumas toxinas de aranhas agem como 
modificadoras de gating (Banerjee et al., 2013; Wee et al., 2007). Alguns detalhes sobre os mecanismos de bloqueio desses canais por KTxs escorpiônicas estão apresentados no Capítulo 2.

A presença de peptídeos com dupla atividade, que inibem peptidases e bloqueiam canais de $\mathrm{K}^{+}$, já foi demonstrada por diversos autores na peçonha de serpentes, escorpiões, aranhas e no extrato corpóreo de anêmonas marinhas (para informações adicionais, ver revisão por Mourão \& Schwartz (2013) no Apêndice I). Visto que a produção de peptídeos exige uma alta demanda energética para o organismo, a dupla funcionalidade de um composto pode ser vista como uma maneira eficiente de economizar energia com máxima utilização farmacológica (Peigneur et al., 2011).

Sugere-se que moléculas que apresentam o motivo estrutural de inibidores de peptidase do tipo Kunitz tenham evoluído em três estágios prováveis: moléculas de função remota, moléculas bi-funcionais, e toxinas com nova função (Yuan et al., 2008). Assim, alguns inibidores de protease teriam adquirido uma função de neurotoxina, tornando-se bi-funcionais, enquanto outras teriam inclusive perdido a função inibidora de peptidase, agindo apenas em canais iônicos dependentes de voltagem (Yuan et al., 2008; Zupunski et al., 2003).

Bloqueadores de canais de $\mathrm{K}^{+}$altamente específicos e potentes apresentando o motivo estrutural tipo Kunitz, mas com pouca ou nenhuma atividade inibidora de peptidase, são particularmente bem desenvolvidos em serpentes. Por outro lado, essas moléculas não foram, até o momento, caracterizadas das secreções de anêmonas marinhas, escorpiões e aranhas, os quais possuem apenas inibidores efetivos de peptidase ou moléculas bi-funcionais, sendo que muitas destas apresentam baixa atividade bloqueadora de canais de $\mathrm{K}^{+}$. Yuan e colaboradores (2008) propuseram que essa diferença pode ser devido à pressão seletiva, que pode ter atuado de forma a manter as moléculas bi-funcionais com baixa potência em canais de $\mathrm{K}^{+}$em anêmonas, escorpiões e aranhas, uma vez que esses animais já possuem em sua peçonha ou extrato corpóreo outras neurotoxinas potentes. Diferentemente, em serpentes, apenas bloqueadores de canais de $\mathrm{K}^{+}$com motivo estrutural do tipo Kunitz foram caracterizados de sua peçonha até o momento. 
As dendrotoxinas (DTXs) de serpentes, por exemplo, são potentes bloqueadores de canais de $\mathrm{K}^{+}, \mathrm{e}$, apesar de compartilharem estrutura primária e terciária com inibidores do tipo Kunitz, possuem pouca ou nenhuma atividade inibidora de peptidase (Harvey, 2001; Harvey \& Robertson, 2004; Skarzynski, 1992). Essas toxinas bloqueiam diferentes subtipos de canais de $\mathrm{K}^{+}$, dentre os quais $\mathrm{K}_{\mathrm{v}} 1.1, \mathrm{~K}_{\mathrm{v}} 1.2$ e $\mathrm{K}_{\mathrm{v}} 1.6$, em concentrações nano ou picomolares (Tabela 1.3).

Tabela 1.3. Atividade bloqueadora de canais de potássio de peptídeos que apresentam o motivo estrutural tipo Kunitz obtidos de peçonhas e venenos de animais. Peptídeos mutados de escorpiões e aranhas não foram considerados. Adaptado de Mourão \& Schwartz (2013).

\begin{tabular}{|c|c|c|c|c|}
\hline Organismo & Peptídeo & $\mathrm{IC}_{50}(\mathrm{nM})$ & Alvo & Referência \\
\hline \multirow{5}{*}{$\begin{array}{l}\text { Anêmona } \\
\text { marinha }\end{array}$} & APEKTx1* & $0,9 \pm 0,1$ & $\mathrm{~K}_{\mathrm{v}} 1.1$ & (Peigneur et al., 2011) \\
\hline & AsKC1* & 2800 & $\mathrm{~K}_{\mathrm{v}} 1.2$ & (Schweitz et al., 1995) \\
\hline & AsKC2* & 1100 & $\mathrm{~K}_{\mathrm{v}} 1.2$ & (Schweitz et al., 1995) \\
\hline & AsKC3* & 1300 & $\mathrm{~K}_{\mathrm{v}} 1.2$ & (Schweitz et al., 1995) \\
\hline & SHTX-3* & 650 & $\operatorname{Sinap}^{a}$ & (Honma et al., 2008) \\
\hline Conus & Conk-S1 & $1,33 \pm 0,5$ & Shaker & (Bayrhuber et al., 2006) \\
\hline \multirow{7}{*}{ Serpente } & $\alpha-D T X$ & $0,4-150$ & $\mathrm{~K}_{\mathrm{v}} 1.1, \mathrm{~K}_{\mathrm{v}} 1.2, \mathrm{~K}_{\mathrm{v}} 1.6$ & (Harvey, 2001) \\
\hline & DTX-I & $0,13-50$ & $\mathrm{~K}_{\mathrm{v}} 1.1, \mathrm{~K}_{\mathrm{v}} 1.2, \mathrm{~K}_{\mathrm{v}} 1.6$ & (Harvey, 2001) \\
\hline & DTX-K & 0,03 & Kv1.1 & (Owen et al., 1997) \\
\hline & $\delta$-DTX & $0,029-1,8$ & $\mathrm{~K}_{\mathrm{v}} 1.1$ & (Hopkins, 1998; Owen et al., 1997) \\
\hline & $\mathrm{DaE}$ & 300 & $\mathrm{~K}_{\mathrm{v}} 1.1$ & (Tytgat et al., 2001) \\
\hline & Taicatoxin* & $1,45 \pm 0,22$ & $\mathrm{SK}_{\mathrm{Ca}}{ }^{\mathrm{a}}$ & (Doorty et al., 1997) \\
\hline & BF9* & $120,0 \pm 42,2$ & $\mathrm{~K}_{\mathrm{v}} 1.3$ & (Yang et al., 2014) \\
\hline \multirow{7}{*}{ Escorpião } & Hg1* & $6,2 \pm 1,2$ & $\mathrm{~K}_{\mathrm{v}} 1.3$ & (Chen et al., 2012a) \\
\hline & LmKTT-1a* & 1580 & $\mathrm{~K}_{\mathrm{v}} 1.3$ & (Chen et al., 2013b; Chen et al., 2012a) \\
\hline & LmKTT-1b* & $>1000$ & $\mathrm{~K}_{\mathrm{v}} 1.3$ & (Chen et al., 2012a) \\
\hline & LmKTT-1c* & $>1000$ & $\mathrm{~K}_{\mathrm{v}} 1.3$ & (Chen et al., 2012a) \\
\hline & BmKTT-1* & $129,7 \pm 31,331.3$ & $\mathrm{~K}_{\mathrm{v}} 1.3$ & (Chen et al., 2012a) \\
\hline & BmKTT-2* & $371,3 \pm 82,1$ & $\mathrm{~K}_{\mathrm{v}} 1.3$ & (Chen et al., 2012a) \\
\hline & BmKTT-3* & $>1000$ & $\mathrm{~K}_{\mathrm{v}} 1.3$ & (Chen et al., 2012a) \\
\hline Aranha & HWTX-XI* & 2570 & $\mathrm{~K}_{\mathrm{v}} 1.1$ & (Yuan et al., 2008) \\
\hline
\end{tabular}

${ }^{a}$ Atividade obtida por ensaios de ligação a sinaptossomas.

* Peptídeos que também possuem atividade inibidora de peptidases.

Estudos com engenharia genética e mutações químicas nas sequências primárias das dendrotoxinas permitiram a identificação dos resíduos de aminoácidos essenciais para a interação com canais de $\mathrm{K}^{+}$(Harvey, 2001; Harvey \& Robertson, 2004). Nessas moléculas longas, a Lys ${ }^{5}$ parece ser o resíduo determinante para a afinidade de ligação da $\alpha$-DTX e DTX-I por canais de K+ (Figura 1.7) (Harvey, 1997; Harvey et al., 1997). Além dele, o resíduo 
hidrofóbico vizinho Leu $^{9}$ mostrou-se importante para a afinidade com canais de $\mathrm{K}^{+}$ (Gasparini et al., 1998). A Lys ${ }^{19}$, que se encontra próxima ao "sítio anti-peptidase" (destacado em amarelo na Figura 1.7), causou apenas uma pequena perda de atividade quando acetilada na DTX-I (Harvey et al., 1997) ou substituída por Ala na $\alpha$-DTX (Gasparini et al., 1998). Os resíduos de aminoácidos da região b-turn (resíduos 25-28 na dendrotoxina $\mathrm{K}$, em especial $\operatorname{Trp}^{25}$ e Lys $^{26}$ ) também mostraram-se responsáveis pela atividade em canais de potássio (Smith et al., 1997; Wang et al., 1999).

\begin{tabular}{|c|}
\hline P00980|a-DTX • \\
\hline P00979|DTX-I• \\
\hline P00981|DTX-K • \\
\hline P00982|ठ-DTX • \\
\hline P0C1X2|Conk-S1 • \\
\hline B7S4N9|Taicatoxin \\
\hline P25660|BF9 \\
\hline P86862|APEKTx1 \\
\hline B1B5I8|SHTX-3 \\
\hline P0C8W3|Hg1 \\
\hline P0DJ50|BmKTT-2 \\
\hline P0DJ49|BmKTT-1 • \\
\hline Q9TWG0|AsKC1 ৩ \\
\hline Q9TWF9|AsKC2 ৩ \\
\hline Q9TWF8|AsKC3 $\diamond$ \\
\hline P68425|HWTX-XI ৩ \\
\hline P0DJ47|BmKTT-3 $\diamond$ \\
\hline P0DJ46|LmKTT-1a $\diamond$ \\
\hline P0DJ45 | LmKTT-1b $\diamond$ \\
\hline P0DJ48|LmKTT-1c $\diamond$ \\
\hline Consenso/85\% \\
\hline
\end{tabular}

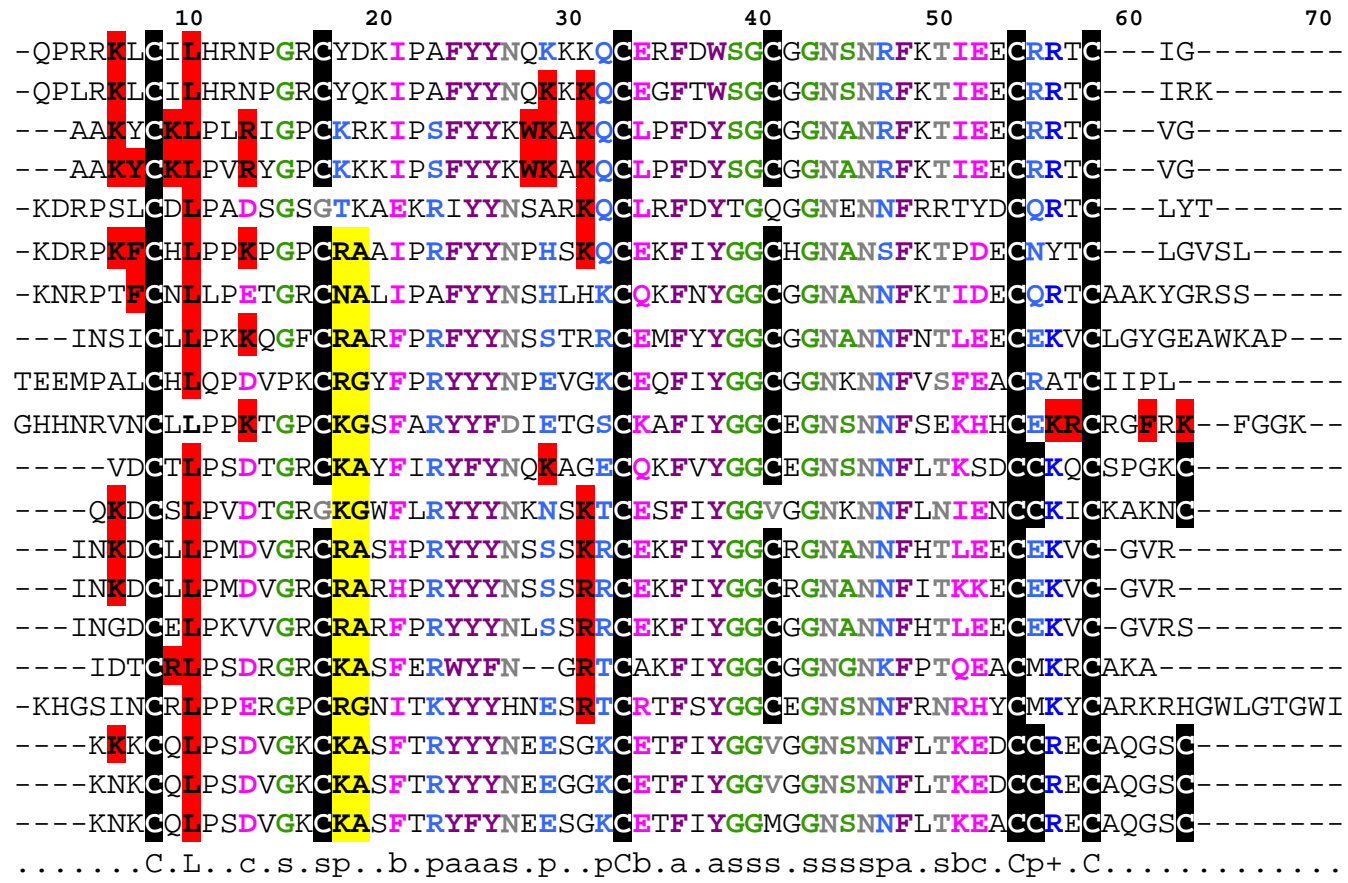

Figura 1.7. Alinhamento de sequências das toxinas representativas com motivo estrutural tipo Kunitz e atividade bloqueadora de canais de potássio. Diferentes grupos, segundo a classificação proposta por Yuan e colaboradores (2008), estão indicados pelos símbolos adjacentes aos nomes: -, bloqueadores de canais de $\mathrm{K}^{+}$sem atividade inibidora de peptidase ou ainda não testado contra as mesmas; e $\diamond$, toxinas bi-funcionais, onde denota toxinas com maior potência em canais de $\mathrm{K}^{+}$do que as indicadas por $\diamond$. Os inibidores de escorpiões encontram-se em negrito. $O$ alinhamento foi gerado por ClustalW (Larkin et al., 2007) e a sequência consenso foi colorida usando o software Chroma e por meio de edição manual (Goodstadt \& Ponting, 2001). Os resíduos essenciais (vistos por ensaios de mutação sítio-dirigida ou propostos com base em similaridade) para a atividade bloqueadora de canais de $\mathrm{K}^{+}$estão destacados em vermelho. Os resíduos essenciais à atividade inibidora de peptidase estão indicados em amarelo. Letras maiúsculas denotam resíduos de aminoácidos. Letras minúsculas ou símbolos denotam: p, polar; b, grande (big); a, aromático; +, positivo; s, pequeno (small); c, carregado (charged).

Sete inibidores de peptidase bi-funcionais caracterizados da peçonha de escorpiões até o momento apresentam o motivo estrutural tipo Kunitz e foram ativos em 
canais $\mathrm{K}_{\mathrm{v}} 1.3$ (Tabela 1.3 ). A toxina $\mathrm{rHg} 1$ foi a mais ativa em canais $\mathrm{K}_{\mathrm{v}} 1.3$, mesmo a concentrações de $100 \mathrm{nM}$. A $1 \mu \mathrm{M}$ ela também inibiu a corrente $(<50 \%)$ de canais $\mathrm{K}_{v} 1.1 \mathrm{e}$ $\mathrm{K}_{\mathrm{v}} 1.2$, com pouco efeito nas correntes de canais SKCa3 e BKCa (Chen et al., 2012a). SjAPI2, por sua vez, foi o primeiro inibidor de peptidase de escorpião com o motivo estrutural tipo Ascaris a apresentar atividade também como neurotoxina. Seu efeito foi verificado em diferentes subtipos de canais de $\mathrm{K}^{+}$, como $\mathrm{K}_{\mathrm{v}} 1.1, \mathrm{~K}_{\mathrm{v}} 1.2, \mathrm{~K}_{\mathrm{v}} 1.3$, SKCa2, SKCa3, IK $\mathrm{Ca}_{\mathrm{a}}$ e ${ }_{\mathrm{h}} \mathrm{KCNQ1}$, observando-se redução da corrente de forma mais expressiva em canais $\mathrm{K}_{\mathrm{v}} 1.3$ e ${ }_{\mathrm{h}} \mathrm{KCNQ} 1$ (Chen et al., 2015a). O canal KCNQ1 é importante na fase de repolarização do potencial de ação cardíaco e apresenta propriedades distintas dos demais canais de $\mathrm{K}^{+}$dependentes de voltagem (Cui, 2016).

Diferentes mutantes da Hg1 foram gerados pela estratégia de alanine-scanning e testados em canais $\mathrm{K}_{\mathrm{v}} 1.3$ (Chen et al., 2012a). Os resíduos $\mathrm{His}^{2}, \mathrm{His}^{3}, \mathrm{Asn}^{4}, \mathrm{Arg}^{5}$, Leu ${ }^{9}$ e Lys ${ }^{13}$ não mostraram efeito aparente na atividade farmacológica das toxinas. Visto que resíduos de aminoácidos básicos de toxinas animais estão comumente relacionados com a atividade bloqueadora de canais de potássio (Mouhat et al., 2005; Rodríguez de la Vega et al., 2003), novos mutantes foram gerados alterando-se o segundo grupo de resíduos básicos da Hg1, localizado no C-terminal do peptídeo. Verificou-se assim que a substituição dos resíduos Lys $^{56}$, Arg $^{57}$, Phe ${ }^{61}$ e Lys ${ }^{63}$ (Figura 1.7) por alanina reduziu significantemente a atividade em canais $K_{v} 1.3$. Os mutantes foram analisados por meio de dicroismo circular e não foram observadas alterações conformacionais dos mesmos em relação à Hg1 nativa. Assim, é esperado que a Hg1 use predominantemente seus resíduos C-terminais para inibir o canal $\mathrm{K}_{\mathrm{v}} 1.3$, sendo este um mecanismo distinto do usado pelas dendrotoxinas, as quais utilizam resíduos do N-terminal para bloquear canais de potássio (Jin \& Wu, 2011; Yuan et al., 2008). Um modelo estrutural computacional do complexo $\mathrm{Hg} 1-\mathrm{K}_{\mathrm{v}} 1.3$ suportou esses resultados, e mostrou que a $\mathrm{Lys}^{56}$ é o resíduo que bloqueia o poro do canal (Chen et al., 2012a).

\subsubsection{EsCorpião TitYus obsCURUS E EstUdos COM SUA PEÇONHA}

Escorpiões são predadores bem adaptados ao ambiente terrestre, com registros fósseis que datam de cerca de 450 milhões de anos atrás (período Siluriano), sendo geralmente aceito que a migração do ambiente marinho para o terrestre deu-se 325-350 
milhões de anos atrás (transição do período Devoniano para o Carbonífero) (Polis, 1990). Escorpiões pertencem ao reino Animalia, filo Arthropoda, subfilo Chelicerata, classe Arachnida e ordem Scorpiones, e apresentam ampla distribuição geográfica, sendo representados em todos os continentes, com exceção da Antártida, com maior concentração em áreas tropicais e subtropicais. Atualmente, constituem 18 famílias, 151 gêneros e aproximadamente 2000 espécies, dentre as quais cerca de trinta espécies são consideradas potencialmente perigosas para os seres humanos. Dentre estas, exceto por uma espécie da família Scorpionidae, as demais pertencem à família Buthidae, com destaque para os membros dos gêneros Centruroides (encontrados no México e sudoeste dos Estados Unidos), Tityus (América do Sul e Trinidad), Androctonus, Leiurus e Buthus (norte da África e Oriente Médio), Hemiscorpius e Mesobuthus (Irã, Iraque, Turquia e Afeganistão), Parabuthus (África do Sul e Arábia Saudita), e Hottenta (Marrocos e Índia) (Chippaux and Goyffon, 2008; Lourenço \& Von Eickstedt, 2009; Prendini, 2011).

No Brasil, as espécies responsáveis pelos casos de envenenamentos graves e até mesmo fatais pertencem ao gênero Tityus, com destaque para as espécies: $T$. serrulatus (encontrado nos estados $B A, C E, E S, D F, G O, M G, M T, P E, P I, P R, R J, R N, R O, R S, S C, S E, S P$ ), T. bahiensis (ES, GO, MG, PR, RJ, RS, SC, SP), T. stigmurus (AL, BA, CE, PB, PE, PI, RN, SE) e $T$. obscurus (AM, AP, MA, MT, PA). Além da espécie $T$. obscurus, as espécies $T$. metuendus e T. silvestres também são responsáveis por casos de envenenamentos na região Amazônica, porém com menor importância médica (MS, 2009; Pardal et al., 2014; Pardal et al., 2003; Pucca et al., 2014b).

O aparato de peçonha dos escorpiões consiste em uma vesícula com um par de glândulas, localizadas no último seguimento do pós-abdomen, ou télson. Essa vesícula está circundada por uma camada de músculo estriado responsável pela ejeção da peçonha (Chippaux \& Goyffon, 2008). A peçonha dos escorpiões é uma complexa mistura de diversos componentes, dentre os quais estão polipeptídeos, enzimas, nucleotídeos, lipídeos, sais, aminas biogênicas e mucopolissacarídeos. Os peptídeos da peçonha de escorpiões podem ser classificados em peptídeos que não possuem pontes dissulfeto (NDBP, do inglês non-disulfide-bridged peptides) - os quais exibem diversas funções biológicas, como potencialização de bradicinina, atividade antimicrobiana e hemolítica e modulação do sistema imune - e peptídeos que possuem pontes dissulfeto (DBP, do inglês 
disulfide-bridged peptides) (Zhijian et al., 2006). Os DBPs são os principais compostos responsáveis pelo efeito neurotóxico observado em casos de envenenamento com a peçonha de escorpiões, uma vez que afetam canais iônicos de células excitáveis e nãoexcitáveis de membranas biológicas, fator importante para que os escorpiões possam imobilizar suas presas e se defender. Os DBPs mais estudados são aqueles que atuam em canais de $\mathrm{Na}^{+}$ou $\mathrm{K}^{+}$, denominados $\mathrm{NaScT} x \mathrm{~s}$ (do inglês $\mathrm{Na}^{+}$-scorpion toxins) e KTxs ( $\mathrm{K}^{+}$toxins), respectivamente (Bartok et al., 2014; Gurevitz et al., 2014; Rodriguez de la Vega \& Possani, 2005). As NaScTxs possuem de 55-76 resíduos de aminoácidos e três ou quatro pontes dissulfeto, e são os principais responsáveis pelos efeitos neurotóxicos resultantes da picada de escorpiões.

O escorpião Tityus obscurus Gervais, 1843 - sinônimo sênior de T. paraensis Kraepelin, 1896 e T. cambridgei Pocock, 1897 (Lourenço \& Leguin, 2008) - (Figura 1.8), pertencente à família Buthidae, é responsável por muitos casos de envenenamento em humanos na região Amazônica brasileira (Pardal et al., 2014; Pardal et al., 2003). Quando adulto, $T$. obscurus é um escorpião grande, medindo de 8,5 a $10 \mathrm{~cm}$ de comprimento, e de coloração negra. Quando jovem, a coloração é matizada de preto com amarelo. A espécie apresenta dimorfismo sexual evidente, de forma que os machos apresentam os pedipalpos (pinças) bastante finos e alongados em relação às fêmeas. Além disso, os anéis da cauda são mais longos nos machos (Lourenço \& Leguin, 2008).

Esta espécie apresenta ampla distribuição, sendo comum na Guiana Francesa, Suriname e na região Norte do Brasil, principalmente nos estados do Pará e Amapá, com exemplares também encontrados na Amazônia, Maranhão e Mato Grosso (Benmosbah et al., 2013; Lourenço \& Leguin, 2008; MS, 2009; Pardal et al., 2014; Pucca et al., 2014b). 


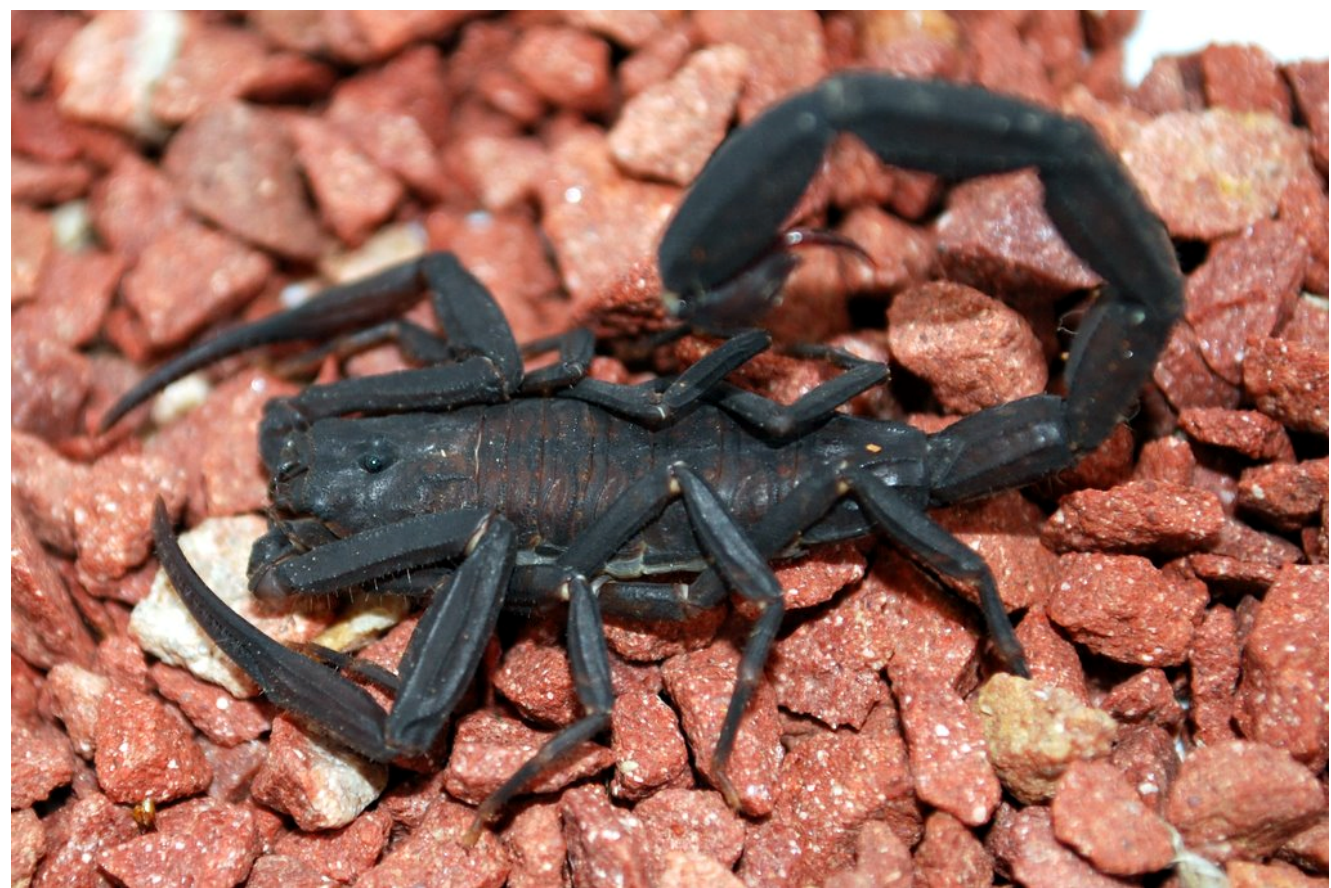

Figura 1.8. Escorpião Tityus obscurus (Buthidae). Foto por Solange C. Rego.

A manifestação clínica de sua picada é diversificada, dependendo da região de ocorrência. No Pará, manifestações neurológicas de mioclonia em que as vítimas referem como sensação de "choque elétrico" pelo corpo, disartria, dismetria e ataxia, entre outras foram descritos nos municípios de Santarém, Belterra e Prainha (Oeste do Estado do Pará), Altamira e Brasil-Novo (Sul), enquanto que nos acidentes ocorridos na região metropolitana de Belém (Leste do Estado do Pará) foram observadas em maior número sintomas locais (dor, edema, eritema) e tontura (Maestri Neto et al., 2008; Martins et al., 2002; Pardal, 2014; Pardal et al., 2003; Sperotto et al., 2001). Essas variações na sintomatologia podem estar diretamente relacionadas com a recente observação de uma diferenciação do padrão morfológico de $T$. obscurus coletado em diferentes regiões do Pará, sendo que as populações do Oeste são em média maiores do que as do Leste, e de alterações na composição de suas peçonhas. A análise cromatográfica da peçonha dessas duas populações mostrou maior número de frações cromatográficas na peçonha da população Oeste, principalmente nas faixas de tempo de retenção correspondentes às NaScTxs e KTxs, o que explicaria a maior gravidade dos sintomas de envenenamento na região Oeste do Pará (Pardal, 2014; Pardal et al., 2014). O autor sugere que essas variações sejam provenientes de uma especiação alopátrica devido à grande distância (cerca de 850 
km) e à presença de dois grandes rios (Xingu e Tocantins) entre as duas populações (Pardal, 2014). Essa diversificação na composição da peçonha em detrimento de variação geográfica, ou mesmo dieta, idade e sexo do animal, já foi relatada para outras espécies de escorpiões (Abdel-Rahman et al., 2009; De Sousa et al., 2010; Oliveira et al., 2013; Pucca et al., 2014a).

Em relação à composição da peçonha do escorpião $T$. obscurus, as primeiras análises mostraram a existência de no mínimo 102 componentes peptídicos distintos, dos quais cerca de $25 \%$ tiveram sua sequência $\mathrm{N}$-terminal determinada (Batista et al., 2004) e seis foram completamente sequenciados. Destes seis peptídeos, três possuem ação específica em canais de $K^{+}$(Tc1, Tc30 e Tc32 - ou $\alpha-K T x 13.1, \alpha-K T x 4.4$ e $\alpha-K T x 18.1$ respectivamente) (Batista et al., 2000; Batista et al., 2002a) e três em canais de $\mathrm{Na}^{+}$(Tc48a, Tc48b/Tc49a e Tc49b) (Batista et al., 2004; Batista et al., 2002b; Murgia et al., 2004).

Mais recentemente, a partir da construção da biblioteca de cDNA da glândula de peçonha de T. obscurus realizada por nosso grupo de pesquisa (Guerrero-Vargas et al., 2012), as sequências dos precursores dessas três toxinas que atuam em canais de $\mathrm{Na}^{+}$ foram caracterizadas, além de 12 novas sequências primárias identificadas como prováveis NaScTxs, denominadas To4 a To15. As sequências putativas de To5, To6 e To7 parecem ser equivalentes aos peptídeos Tc54, Tc43 e Tc50, respectivamente, os quais tinham sido isolados da peçonha e parcialmente sequenciados em trabalhos anteriores (Batista et al., 2004; Batista et al., 2002b). Além disso, neste trabalho mais recente por Guerrero-Vargas e colaboradores (2012), o peptídeo To5 foi purificado da peçonha e completamente sequenciado por técnicas de análise proteômica, e é semelhante a toxinas específicas para artrópodes, embora sua atividade ainda não tenha sido elucidada.

Nessa biblioteca de cDNA também foram caracterizados precursores de outras KTxs (Schwartz EF, dados não publicados) e a sequência precursora do peptídeo caracterizado neste trabalho, denominado ToPI1 devido a sua atividade inibidora de peptidase parcialmente caracterizada em trabalhos anteriores (Mourão CBF, dados não publicados). ToPI1 foi assim chamado por ser o primeiro inibidor de peptidase caracterizado da peçonha do escorpião T. obscurus (Tityus obscurus peptidase inhibitor 1). 


\subsection{OBJETIVOS}

\subsubsection{Objetivo Geral}

Caracterizar a sequência primária e a atividade biológica do polipeptídeo ToPI1, obtido inicialmente da peçonha do escorpião Tityus obscurus, dando ênfase em sua atividade inibidora de tripsina.

\subsubsection{ObJetivos Específicos}


1.3. MATERIAL 
MoURÃO, C. B. F. 
MoURÃO, C. B. F. 
MoURÃO, C. B. F. 
MoURÃO, C. B. F. 


\subsection{MÉTODOS}

1.4.1. DESENHO EXPERIMENTAL 
1.4.2. Licenças, ANimais e ObTenção da PeÇONHA

1.4.3. Fracionamento da Peçonha e Purificação do Peptídeo topi1 
1.4.4. ESPECTROMETRIA DE MASSA 
1.4.5. Determinação da SequênCia Primária e Busca por Similaridade 


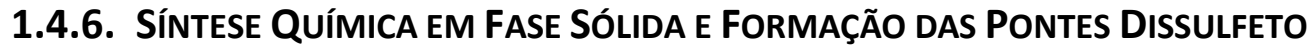


MoURÃO, C. B. F. 
1.4.6.1. Purificação do Peptídeo Sintético 
MoURÃO, C. B. F. 
MoURÃO, C. B. F. 
MoURÃO, C. B. F. 


\subsubsection{ENSAIO de INIBIÇÃo de PEPTIDASES}

1.4.7.1. Ensaio de Inibição de Tripsina 
MoURÃO, C. B. F. 
1.4.7.2. Mecanismo de Ação e Constante de Afinidade para Tripsina 
1.4.7.3. Ensaio de Inibição de Quimotripsina 
1.4.7.4. Ressonância Plasmônica de Superfície (SPR) 
MoURÃO, C. B. F. 
MoURÃO, C. B. F. 
MoURÃO, C. B. F. 
MoURÃO, C. B. F. 
1.4.8. Ensaio de Viabilidade Celular 
MoURÃO, C. B. F. 
MoURÃO, C. B. F. 
MoURÃO, C. B. F. 


\subsubsection{EnSAiOs Eletrofisiológicos}


MoURÃO, C. B. F. 
1.4.10. AnÁlise Comportamental em CAMundongos 
MoURÃO, C. B. F. 
MoURÃO, C. B. F.

2016

1.5. RESULTADOS 
MoURÃO, C. B. F. 
MoURÃO, C. B. F. 
MoURÃO, C. B. F. 
MoURÃO, C. B. F. 
MoURÃO, C. B. F. 
MoURÃO, C. B. F. 
MoURÃO, C. B. F. 
MoURÃO, C. B. F. 
MoURÃO, C. B. F. 
MoURÃO, C. B. F. 
MoURÃO, C. B. F. 
MoURÃO, C. B. F. 
MoURÃO, C. B. F. 
MoURÃO, C. B. F. 
MoURÃO, C. B. F. 
MoURÃO, C. B. F. 
MoURÃO, C. B. F. 
MoURÃO, C. B. F. 
MoURÃO, C. B. F. 
MoURÃO, C. B. F. 
MoURÃO, C. B. F. 
MoURÃO, C. B. F. 
MoURÃO, C. B. F. 
MoURÃO, C. B. F. 
MoURÃO, C. B. F. 
MoURÃO, C. B. F. 
MoURÃO, C. B. F. 
MoURÃO, C. B. F. 
MoURÃO, C. B. F. 
MoURÃO, C. B. F. 
MoURÃO, C. B. F. 
MoURÃO, C. B. F. 
MoURÃO, C. B. F. 
MoURÃO, C. B. F. 
MoURÃO, C. B. F. 
MourÃO, C. B. F. 
1.6. DISCUSSÃO 
MoURÃO, C. B. F. 
MourÃO, C. B. F. 
MourÃO, C. B. F. 
MoURÃO, C. B. F. 
MourÃO, C. B. F. 
MourÃO, C. B. F. 
MourÃO, C. B. F. 
MoURÃO, C. B. F. 
MourÃO, C. B. F. 
MoURÃO, C. B. F. 
MoURÃO, C. B. F. 
MourÃO, C. B. F. 
MoURÃO, C. B. F. 
MoURÃO, C. B. F. 
MoURÃO, C. B. F. 


\section{Capítulo 2}

Caracterização estrutural do polipeptídeo ToPI1 e estudo da relação estrutura-função 


\subsection{INTRODUÇÃO}

Nas últimas décadas tem se observado um importante aumento do número de sequências de peptídeos e proteínas depositadas em bancos de dados - resultante do avanço tecnológico das ferramentas para estudos proteômicos e também transcritômicos e genômicos -, e um crescente número de proteínas estruturalmente caracterizadas por métodos espectroscópicos, Ressonância Magnética Nuclear (RMN) e cristalografia de raios $\mathrm{X}$. Esses métodos têm providenciado uma riqueza de conhecimentos estruturais sobre as enzimas e seus inibidores.

Com isso e com o advento de técnicas da Bioquímica e Biologia Molecular, que permitem produzir peptídeos e proteínas mutados em determinados resíduos de aminoácidos de interesse, é crescente o conhecimento acerca os mecanismos de interação entre esses compostos e seu alvo molecular. Conhecendo-se melhor quais resíduos de aminoácidos do peptídeo interagem com a proteína alvo, como no caso de um substrato/inibidor com uma peptidase, ou uma toxina e determinado canal iônico, é possível desenvolver novos compostos e fármacos que ajam com maior afinidade, e que sejam específicos para o alvo de interesse.

Em relação a inibidores de peptidase, inúmeros estudos da correlação estruturafunção são apresentados na literatura. Um dos inibidores mais estudados é o BPTI, cuja estrutura tridimensional já foi obtida em diversos trabalhos tanto por RMN quanto por cristalografia em sua forma nativa, mutada, truncada, mono ou multimérica, livre ou em complexo com a tripsina ou outras peptidases (ver revisão por Ascenzi et al. (2003)), mostrando-se, assim, uma ferramenta molecular bastante atrativa para o estudo da conformação de proteínas, interação proteína/proteína e reconhecimento molecular. PIs de outras famílias estruturais também são usados amplamente como ferramentas moleculares para estudos de estrutura-função. Nesse contexto, modelos usando o pequeno loop reativo canônico dos inibidores tipo Bowman-Birk, baseados na estrutura do inibidor SFTI-1, têm chamado atenção (De Veer et al., 2015).

Já em relação a toxinas de escorpiões que agem em canais de $\mathrm{K}^{+}$, o primeiro estudo com mutações pontuais, envolvendo a técnica de alanine scanning (substituição de determinados resíduos por Ala), deu-se com a charybdotoxina, ou ChTx (UniProtKB 
P13487), isolada da peçonha do escorpião Leiurus quinquestriatus hebraeus (Park \& Miller, 1992). Esse estudo mostrou a importância de vários resíduos reativos expostos em sua superfície, em especial a $\mathrm{Lys}^{27}$, conforme veremos adiante. Depois disso, vários estudos foram publicados com análogos não-nativos, toxinas truncadas ou com mutações pontuais, compostos quiméricos, toxinas com marcadores fluorescentes, dentre outros (ver revisão por Bergeron e Bingham (2012)). Esses estudos têm demonstrado o papel fundamental da implementação de modelagem computacional para o mapeamento de interações bimoleculares (Chen \& Kuyucak, 2012; Pardo-Lopez et al., 2002; Yu et al., 2004). Além disso, têm contribuído bastante para o avanço do estudo de canais iônicos, servindo também como modelos de valor inestimável para o desenvolvimento de novas terapias moleculares (Bergeron \& Bingham, 2012).

Abordaremos na introdução desse capítulo os princípios da técnica de espectroscopia de dicroísmo circular, a qual é bastante utilizada para avaliar a estrutura secundária e a estabilidade química e térmica de peptídeos, sendo uma ferramenta útil e prática em estudos com mutações de aminoácidos. Além disso, serão apresentados os motivos estruturais das principais classes de inibidores de serinopeptidases, mostrando os resíduos-chave para a interação do complexo inibidor:tripsina, e os mecanismos de bloqueio de canais de potássio dependentes de voltagem $\left(\mathrm{K}_{\mathrm{v}}\right)$ por toxinas de escorpiões.

\subsubsection{ESPECTROSCOPIA DE DICROISMO CIRCULAR}

O dicroísmo circular ( $C D$, do inglês circular dichroism) tem sido cada vez mais reconhecido como uma técnica fundamental para a rápida caracterização estrutural de polipeptídeos e proteínas em solução. Resumidamente, o CD é definido como uma forma de espectroscopia que mede a absorção diferencial dos dois componentes circularmente polarizados, um que gira no sentido horário $(R)$ e outro no anti-horário (L), por uma molécula assimétrica. $\mathrm{O}$ sinal de $\mathrm{CD}$ será registrado na presença de um cromóforo quiral (oticamente ativo), o que inclui a maioria das moléculas biológicas. Essa quiralidade pode ser dada por: um átomo de C com quatro substituintes distintos; ângulos diedros (C-S-S-C) das pontes dissulfeto; ligação covalente a uma molécula quiral; estrutura tridimensional assimétrica adotada em solução (Kelly et al., 2005). Em proteínas, os cromóforos de 
interesse incluem as ligações peptídicas (absorção abaixo de $240 \mathrm{~nm}$ ), cadeia lateral de anéis aromáticos (absorção na faixa de 260 a $320 \mathrm{~nm}$ ) e pontes dissulfeto (bandas de baixa absorção próximo a $260 \mathrm{~nm}$ ).

A diferença da absorbância entre os componentes polarizados $\mathrm{R}$ e $\mathrm{L}$ geralmente é dada em termos de elipticidade $(\theta)$ em deg (graus), de forma que o espectro do CD é obtido pela medida da elipticidade em função do comprimento de onda. Para a apresentação gráfica, os dados são normalizados, considerando a concentração molar da molécula inteira ou das unidades repetitivas de um polímero, que no caso de proteínas é a ligação peptídica. A massa residual média (MRW, do inglês Mean Residue Weight) da ligação peptídica é calculada pela fórmula $\mathrm{MRW}=M /(N-1)$, onde $M$ é a massa molecular do polipeptídeo ou proteína (em $\mathrm{Da}$ ) e $N$ é o número de aminoácidos desse composto (o número de ligações peptídicas é igual a $N$-1). Para a maioria das proteínas, a MRW é $110 \pm 5$ Da (Kelly et al., 2005). Para a conversão da elipticidade observada em um dado comprimento de onda $\left([\theta]_{\mathrm{obs},}\right.$ em deg), para elipticidade média residual $\left([\theta]_{\mathrm{MRW}, \text {, em }} \mathrm{deg} \cdot \mathrm{cm}^{2} \cdot \mathrm{dmol}{ }^{-1}\right)$, usa-se a fórmula:

$$
[\Theta]_{M R W}=M R W \times \Theta_{o b s} /(10 \times d \times c)
$$

onde $d$ é o caminho óptico $(\mathrm{cm})$ da cubeta e $c$ é a concentração da molécula de interesse $\left(\mathrm{g} / \mathrm{mL}\right.$, que é igual a $\left.\mathrm{g} / \mathrm{cm}^{3}\right)$.

O CD pode ser usado para obter diferentes tipos de informação, dentre as quais: avaliar os tipos de estrutura secundária que compõem uma proteína (porcentagem de hélices e folhas- $\beta$, por exemplo); avaliar alterações conformacionais de proteínas mutadas ou que receberam um ligante; acompanhar o dobramento de uma proteína obtida por biossíntese ou que foi desnaturada; avaliar a estabilidade estrutural da proteína em diferentes temperaturas e soluções (Kelly et al., 2005).

Espectros obtidos na região distante do ultravioleta (far-UV), geralmente de 190 a 260 nm, são mais comuns, e dão informações quanto aos diferentes tipos de estrutura secundária de proteínas. Diferentes elementos secundários possuem espectros CD característicos (Figura 2.1). Proteínas com estrutura em $\alpha$-hélice, por exemplo, possuem bandas negativas em 208 e 222 nm e positiva em 193 nm; proteínas com folhas- $\beta$ antiparalelas bem definidas possuem bandas negativas em $218 \mathrm{~nm}$ e positivas em $195 \mathrm{~nm}$; 
e proteínas com estrutura desordenada possuem baixa elipticidade acima de $210 \mathrm{~nm}$ e bandas negativas próximo a $195 \mathrm{~nm}$ (Greenfield, 2006). Diferentes algoritmos usam os dados do espectro far-UV para dar uma estimativa das porcentagens de estruturas secundárias de uma proteína. A maioria deles usa um banco de dados com os espectros CD de diferentes proteínas cujas estruturas já foram determinadas por cristalografia de raios X ou RMN (Sreerama \& Woody, 2000; Whitmore \& Wallace, 2004).

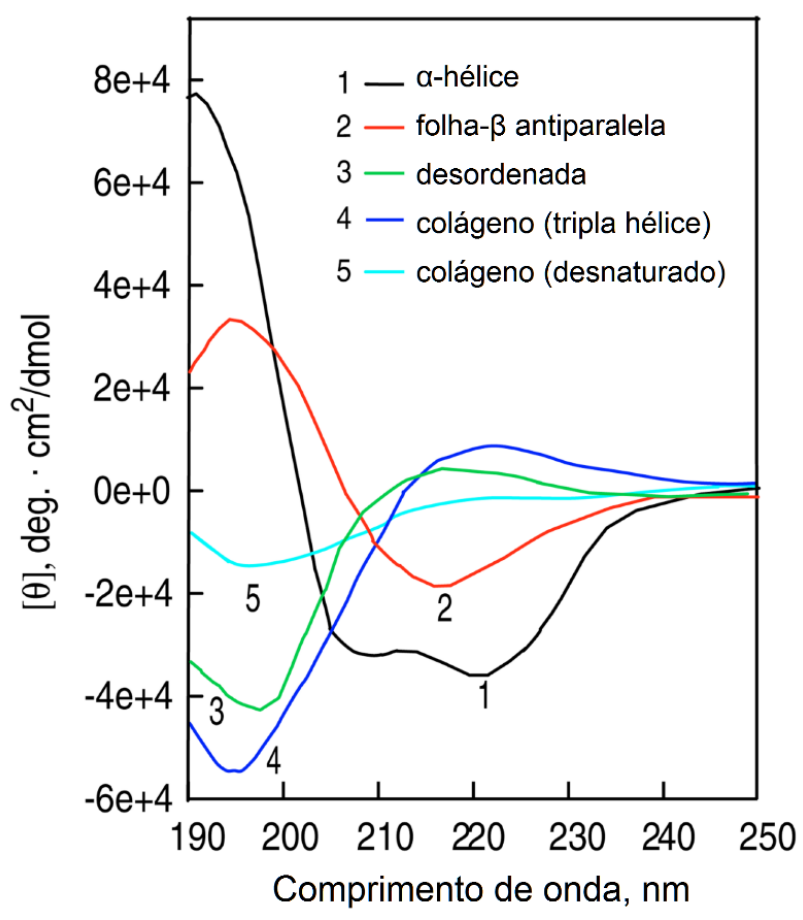

Figura 2.1. Espectros de dicroísmo circular (CD) na região far-UV associados a diferentes tipos de estruturas secundárias. Espectro da poli-L-lisina em pH 11,1 com estrutura em $\alpha$-hélice (1, preto) e folha- $\beta$ antiparalela ( 2 , vermelho), e em pH 5,7 na conformação desordenada ( 3 , verde); e colágeno placentário em sua conformação nativa em tripla hélice (4, azul) e desnaturada (5, ciano). Retirado de Greenfield (2006).

Espectros na região próxima do UV (near-UV), por sua vez, abrangem a região de 260 a 320 nm, proveniente da absorção por anéis aromáticos. Cada aminoácido possui um perfil característico de comprimento de onda: Trp apresenta um pico entre 290 e 305 nm; Tyr, entre 275 e $282 \mathrm{~nm}$; e Phe possui bandas mais fracas entre 255 e $270 \mathrm{~nm}$. O formato e intensidade das bandas nesse tipo de espectro depende do número e tipo de cada aminoácido na proteína, de sua mobilidade, da natureza de seu ambiente (interação com 
outros grupos químicos) e de sua disposição espacial na proteína (Kelly et al., 2005). Embora sua análise seja mais complexa, o espectro near-UV de uma proteína fornece uma impressão geral de sua estrutura terciária, a qual pode ser usada, por exemplo, para comparar as formas nativa e mutante de uma proteína (Gasymov et al., 2014; Sreerama et al., 1999).

Em relação às técnicas de $\mathrm{RMN}$ ou cristalografia de raios $\mathrm{X}$, as quais podem fornecer informações das proteínas com resolução em nível atômico, o CD é uma técnica de baixa resolução estrutural. Todavia, é uma técnica que requer uma quantidade muito menor de amostra, assim como demanda menos tempo de experimento e análise. Dessa forma, um espectro de qualidade satisfatória em CD pode ser obtido com $\leq 0,1 \mathrm{mg}$ (far-UV) ou 1,0 mg (near-UV e visível) de proteína em cerca de $30 \mathrm{~min}$, sendo ainda uma técnica não destrutiva, ou seja, permite recuperar a amostra ao final do experimento. Por sua vez, a cristalografia de raios $X$ requer a obtenção de cristais proteicos adequados para a difração dos raios $X$, de forma que a amostra utilizada não é recuperada após os experimentos; e a RMN requer altas concentrações de proteína (geralmente $0,5 \mathrm{mM}$ ) e é limitada a proteínas ou fragmentos de menor tamanho $(\leq 40 \mathrm{kDa})$. Além disso, o $\mathrm{CD}$ apresenta a versatilidade de se trabalhar com a proteína sob diferentes condições experimentais e pode ser usado para medir as taxas em que as alterações conformacionais ocorrem. O CD pode ser usado ainda como uma técnica aliada às demais, verificando a estrutura e estabilidade da proteína sob as condições usadas para a RMN (geralmente, $\mathrm{pH}$ levemente ácido e temperaturas elevadas, com maiores tempos de aquisição), ou para explorar a estrutura da proteína em condições próximas às usadas para a cristalização (Kelly et al., 2005).

\subsubsection{Motivos Estruturais de Inibidores de Peptidase de Peçonhas Animais}

Como abordado no Capítulo 1, a maioria dos PIs encontrados em peçonhas animais são inibidores de serinopeptidases. Com base em seus motivos estruturais conservados, esses inibidores podem ser divididos em muitas classes, sendo a classe dos inibidores do tipo Kunitz a mais abundante e bem caracterizada entre elas (Conlon \& Kim, 2000; Isaeva et al., 2012; Lingaraju \& Gowda, 2008; Yuan et al., 2008; Zhao et al., 2011). Essa família foi nomeada após a publicação do primeiro inibidor isolado em sua forma cristalina (Kunitz \& 
Northrop, 1936), assim como o primeiro a mostrarem a estequiometria 1:1 típica de complexos enzima:inibidor, o primeiro a ser sequenciado, e o primeiro cuja estrutura tridimensional foi determinada por cristalografia tanto para o inibidor livre quanto para sua forma em complexo com a tripsina, sendo esse inibidor atualmente designado BPTI (bovine pancreatic trypsin inhibitor) (ver revisão por Laskowski \& Kato (1980)). Os inibidores tipo Kunitz (KTI) consistem em uma cadeia polipeptídica de cerca de 60 resíduos de aminoácidos comumente estabilizada por três pontes dissulfeto $\left(C_{1}-C_{V I}, C_{\mid 1}-C_{I V}, C_{\mid I I}-C_{V}\right)$. Eles interagem com peptidases pelo mecanismo clássico tipo substrato (Krowarsch et al., 2003), majoritariamente pela interação P1-S1, de acordo com a nomenclatura de Schechter e Berger (1967). Para mais detalhes sobre os motivos estruturais particulares à cada grupo de animais venenosos, ver o artigo de revisão Peptidase inhibitors from marine venomous animals and their counterparts in terrestrial venomous animals (Mourão \& Schwartz, 2013) no Apêndice I.

A estrutura tridimensional do BPTI, determinada tanto por cristalografia quanto por RMN, mostra um motivo $\alpha / \beta / \alpha$ (Berndt et al., 1992; Deisenhofer \& Steigemann, 1975; Wagner et al., 1987). O BPTI contém 58 resíduos de aminoácidos, três pontes dissulfeto ( $C_{1-}$ $\left.C_{V I}, C_{\mid I}-C_{\mid V}, C_{I I I}-C_{V}\right)$ e um núcleo hidrofóbico, e sua estrutura é caracterizada por uma hélice$3_{10}$ em seu $\mathrm{N}$-terminal (resíduos 3 a 7), um grampo- $\beta$ dos resíduos 18 a 35, uma folha- $\beta$ antiparalela envolvendo o resíduo 45 em contato com o 21 , e uma $\alpha$-hélice formada plos resíduos 47-56 no C-terminal (Berndt et al., 1992). Estudos de estrutura-função do complexo BPTI:tripsina mostraram que a alça exposta ao solvente, formada pelos resíduos 8-19, é altamente complementar ao sítio ativo da enzima (bolsão S1), de forma que o resíduo na posição $\mathrm{P} 1$ (Lys ${ }^{15}$ no $\mathrm{BPTI}$ ) penetra profundamente o sítio ativo para interagir com o resíduo na posição S1 da tripsina (Asp ${ }^{189}$ ) (Kawamura et al., 2011; Otlewski et al., 2001; Prasad et al., 2004) (Figura 2.2). Estudos mostram alta afinidade do complexo BPTI:tripsina (PDB ID: 2FTL e 3OTJ), com $K_{\mathrm{D}}$ de $5 \times 10^{-14} \mathrm{M}$ (Castro \& Anderson, 1996) ou 6 x 10-14 M (Vincent \& Lazdunski (1972), citado por Ascenzi et al. (2003)). 
A

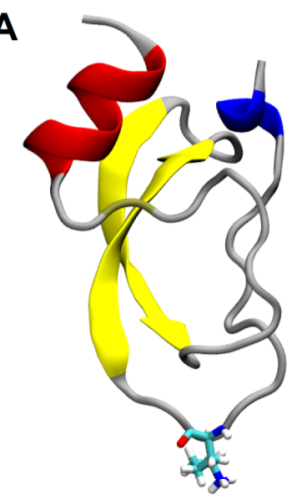

ShPI1 (1SHP)
B

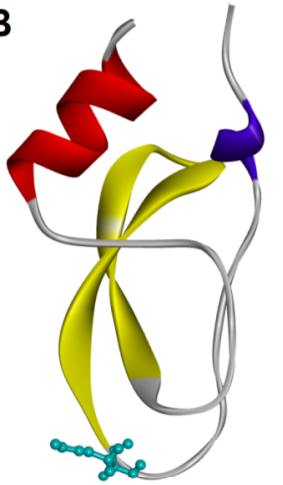

Conkunitzin-S1 (2CA7)
C

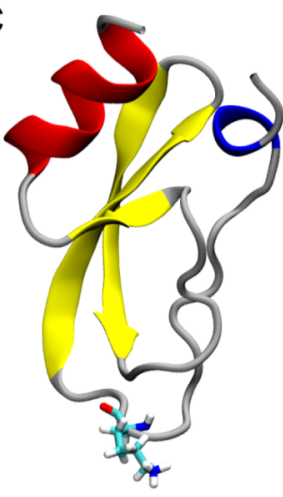

HWTX-XI (2JOT)

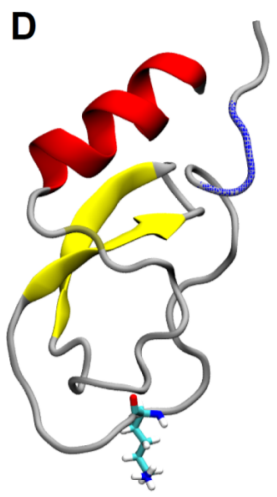

Anntoxin (2KCR)

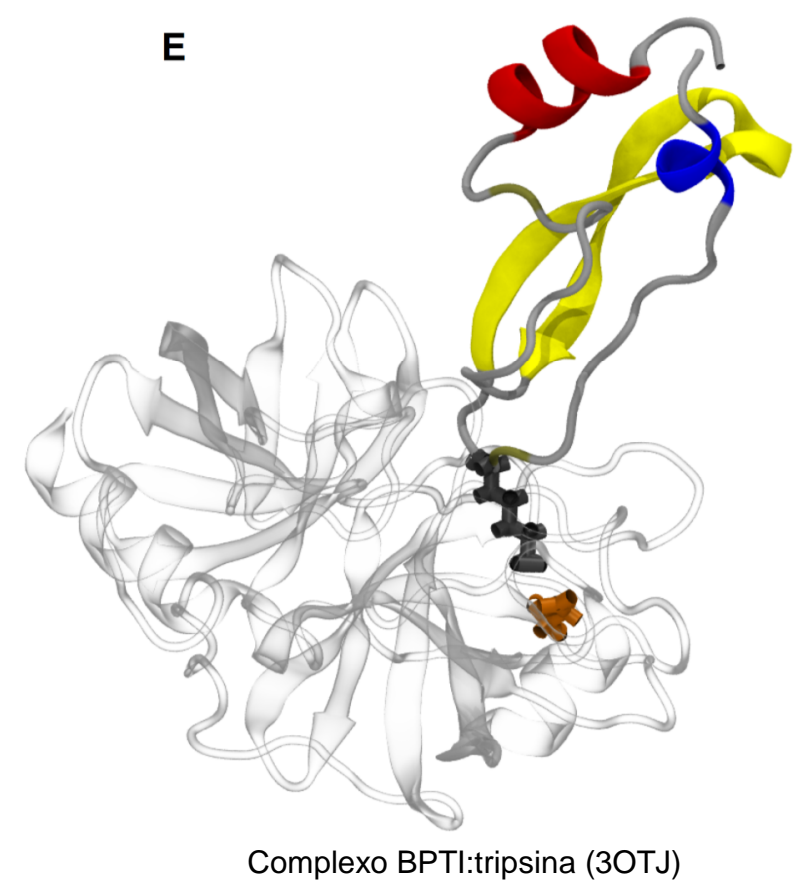

Figura 2.2. Estruturas tridimensionais de polipeptídeos isolados de animais venenosos e que apresentam o motivo estrutural tipo Kunitz (A-D) e o complexo BTPI:tripsina (E). (A) ShPI-1 (PDB 1SHP) da anênoma marinha Stoichactis helianthus; (B) conkunitzin-S1 (PDB 2CA7) do molusco marinho Conus striatus; (C) HWTX-XI (PDB 2JOT) da aranha Ornithoctonus huwena; (D) anntoxin (PDB 2KCR) do anfíbio Hyla annectans; (E) complexo BPTI:tripsina (PDB 3OTJ). As estruturas estão mostradas em diagramas de fita, onde as conformações em $\alpha$-hélice estão indicadas pela cor vermelha, as folhas- $\beta$ por amarelo, as hélices- $3_{10}$ por azul escuro, e as estruturas desordenadas por cinza. Em detalhe, o resíduo Lys na posição P1 (azul ciano de A-D). Em B, a posição alterada da Lys faz com que a conkunitzin-S1 não possua atividade inibidora de peptidase, apesar de apresentar o mesmo motivo estrutural dos demais KTIs. No complexo BPTI:tripsina, os resíduos em interação estão mostrados em cinza escuro para BPTI (Lys ${ }^{15}$ na posição S1) e laranja para tripsina (Asp ${ }^{189}$ na posição P1). A, C, D e E foram obtidos com o programa VMD (visual molecular dynamics), e a figura B foi obtida com o programa Discovery Studio 3.5 (Accelrys, Inc). Retirado de Mourão \& Schwartz (2013).

Com estrura semelhante à do BPTI, a toxina ShPI-1, da anêmona marinha Stichodactyla heliantus, teve sua estrutura determinada por RMN (PDB ID 1SHP) (Antuch 
et al., 1993) e também por cristalografia, em complexo com a tripsina (PDB ID: 3M7Q) (García-Fernández et al., 2012). Cerca de 40\% das interações totais na interface do complexo ShPI-1:tripsina são formadas pela Lys ${ }^{13}$ na posição P1 (Figura 2.2) com o Asp ${ }^{189}$ na posição S1 da tripsina. Contribuições adicionais para a estabilidade do complexo são dadas pelos resíduos $\operatorname{Arg}^{11}$ (sítio P3) e $1 l e^{32}$. O resídou Arg na posição P3 também está presente em outros inibidores de peptidase de anêmonas marinhas, como as kalicludinas (AsKC1 a AsKC3) e ShPI-2, além de outros KTIs de serpentes, escorpiões e aranhas (Figura 2.3). Sugere-se que a menor afinidade à tripsina pelas kalcicludinas, em comparação ao $\mathrm{BPTI}$, é devido à presença da $\operatorname{Pro}^{19}$ - equivalente à $\operatorname{Pro}^{21}$ nas dendrotoxinas (Skarżyński, 1992) -, a qual causa um desfavorecimento para a ligação da tripsina. O BPTI possui um resíduo lle na posição equivalente $\left({ }^{1} \mathrm{e}^{19}\right.$ ) (Schweitz et al., 1995). Em anêmonas marinhas, a maioria das toxinas possui, na posição P1, os resíduos Lys, Arg ou Thr (Isaeva et al., 2012; Mourão \& Schwartz, 2013), embora tenha sido mostrado que o resíduo Thr nessa posição forme menos interações com o sítio ativo da tripsina, levando a valores de $K_{\mathrm{i}}$ mais elevados (Gladkikh et al., 2012).

Na toxina de aranha HWTX-XI (PDB ID: 2JOT), o resíduo Lys ${ }^{14}$ (P1) também mostrouse essencial para a atividade contra tripsina (Yuan et al., 2008). A mutação K14N reduziu em cerca de $10^{5}$ vezes sua potência inibitória, enquanto a mutação K14A levou à ausência total de atividade. Propõe-se que a alta afinidade da toxina ( $K_{\mathrm{D}}$ de $\left.2,3 \times 10^{-10} \mathrm{M}\right)$ deve-se, entre outros fatores, à presença da $\mathrm{Ph}^{17}$, que possui maior cadeia lateral (grupo fenil) que a $l l e^{18}$ do BPTI (Figura 2.3), o que poderia aumentar a superfície hidrofóbica que interage com o bolsão hidrofóbico formado pela $\mathrm{Phe}^{41}$ e Lys ${ }^{60}$ da tripsina. Além disso, os grupos amino da longa cadeia lateral hidrofóbica da $\operatorname{Arg}^{12}$ da HWTX-XI tiveram um ótimo encaixe no bolsão positivo formado pelas hidroxilas dos resíduos Lys ${ }^{145}$, Ser ${ }^{146}$ e Gly ${ }^{148}$ da tripsina (Yuan et al., 2008). 
P00974|BPTI

Q9TWG0|AsKC1

Q9TWF9|AsKC2

Q9TWF8|AsKC3

P10280|SA5 II

P81547|AXPI-I

P81548|AXPI-II

P86862|APEKTX1

P16344 | Jn-IV

B2G331|APHCI

B1B5I8|SHTX-3

P31713|ShPI-1

P81129|ShPI-2

AEAPI

InhVJ

AFAPI-I

AFAPI-III

A8Y7N4 | CBPTI-1

A8Y7N5|CBPTI-2

A8Y7N6 |CBPTI-3

P00985|HHV II

P00986|NNV II

Q90WA1| textilinin-1

P00992|VACI

B7S4N9|TSPI

P25660|BF9

P20229|NNTI

Q5ZPJ7 |NACI

B6RLX2|OH-TCI

B4ESA2 | PILP-1

P00991|VATI I

P00984 | DTX-E

P0C8W3 |rHg1

P0DJ 46 | rLmKTT-1a

P0DJ45 | rLmKTT-1b

P0DJ48 | rLmKTT-1C

PODJ $49 \mid$ BmKTT - 1

P0DJ50|BmKTT-2

PODJ 4 | BmKTT-3

P68425|HWTX-XI

J9UVV9|KTPI

F8K9Q3|KSCI

COLNR2 | bicolin

G3LH89|Bi-KTI

D8KY58|Bt-KTI

Consensus/90\%

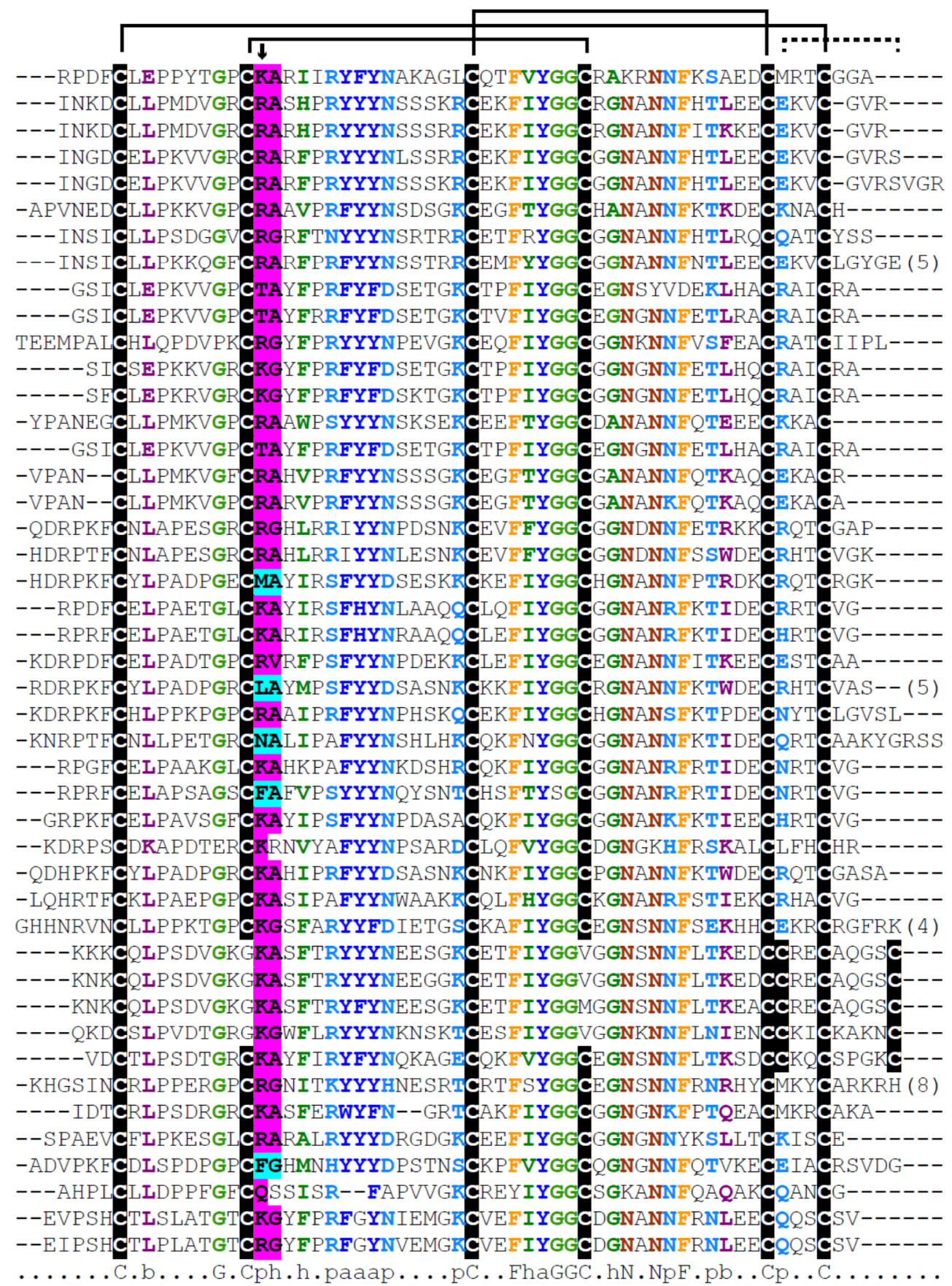

Figura 2.3. Alinhamento representativo de inibidores de serinopeptidases tipo Kunitz de animais venenosos. Organismos dos quais os PIs foram isolados são indicados pelas linhas coloridas à esquerda: azul, anêmonas marinhas; cinza, serpentes; vermelho, escorpiões; amarelo, aranhas; verde, anuros; roxo, himenópteros. O alinhamento foi gerado por ClustalW (Larkin et al., 2007) e a sequência consenso foi colorida usando Chroma (Goodstadt \& Ponting, 2001). Os resíduos-chave para a inibição de peptidase com maior especificidade para tripsina ou quimotripsina estão marcados em rosa ou azul ciano, respectivamente. O resíduo P1 está mostrado pela seta. Letras maiúsculas representam resíduos de aminoácidos. Letras minúsculas denotam: $b$, grande (big); $p$, polar; h, hidrofóbico; a, aromático. As pontes dissulfeto conservadas estão mostradas pelas linhas pretas. Linhas tracejadas mostram a formação de uma nova ponte dissulfeto nas toxinas de escorpiões (Chen et al., 2013b). 
Dentre as toxinas de escorpiões, as rLmKTT-1a, rLmKTT-1b, rLmKTT-1c e rBmKTT-1 se assemelham aos inibidores tipo Kunitz, mas, diferente desse motivo, possuem um padrão distinto das pontes dissulfeto. Nessas toxinas, as cisteínas responsáveis pela ponte $\mathrm{C}_{\| 1} \mathrm{C}_{\mathrm{IV}}$ estão ausentes, como na conkunitzin-S1, mas duas cisteínas adicionais na região Cterminal parecem formar um nova ponte dissulfeto (Chen et al., 2012a; Zhao et al., 2011). Por sua vez, a toxina rBmKTT-2 forma quatro pontes dissulfeto, e não três, como nos inibidores tipo Kunitz clássicos (Chen et al., 2012a) (Figura 2.3).

A elucidação da estrutura em solução da toxina rLmKTT-1a por RMN mostrou uma conformação típica dos KTI (Chen et al., 2013b). Esses dados corroboram que, apesar da baixa similaridade de sequência primária, resultante de uma diversidade molecular, os inibidores tipo Kunitz possuem um motivo estrutural conservado (Chen et al., 2013b). 0 mutante LmKTT-1a-C51A/C59A, com o mesmo padrão de pontes dissulfeto da conkunitzinS1, e preservando a estrutura secundária da LmKTT-1a, apresentou afinidade cinco vezes menor contra tripsina que a toxina nativa, embora tenha mantido a mesma atividade bloqueadora de canal $\mathrm{K}_{\mathrm{v}} 1.3$.

Simulações de dinâmica molecular com o modelo do complexo rLmKTT-1b:tripsina (Zhao et al., 2011), com base na interação do BPTI com a tripsina, mostraram as interações dos resíduos Lys ${ }^{12}$, Gly $^{13}$, Lys $^{14}$ e Ala $^{15}$ (Figura 2.3) com o bolsão S1 da tripsina. Nas proximidades do sítio ativo também havia fortes interações polares e apolares entre os resíduos. O resíduo $\mathrm{Phe}^{17}$ também parece contribuir para o aumento da afinidade. A cadeia lateral da Lys ${ }^{14}$, na posição P1 da rLmKTT-1b, projeta-se dentro do sítio S1 da tripsina, formando ligações de hidrogênio com os resíduos $\mathrm{Asp}^{176}$ e Ser ${ }^{192}$. Assim, sugere-se que, apesar de ter um padrão distinto das pontes dissulfeto, a rLmKTT-1b parece interagir com a tripsina de forma semelhante aos demais inibidores tipo Kunitz (Zhao et al., 2011).

Além dos inibidores com motivo estrutural tipo Kunitz, o motivo tipo Ascaris (ATI, do inglês Ascaris-type inhibitor) tem sido bastante identificado nas bibliotecas de cDNA da glândula de peçonha de escorpiões (Chen et al., 2013c). Membros dessa família apresentam cerca de 60 resíduos de aminoácidos e são caracterizados pela presença de cinco pontes dissulfeto e quatro cadeias- $\beta$ curtas organizadas em duas folhas- $\beta$ antiparalelas aproximadamente perpendiculares (Grasberger et al., 1994). Até o momento, foram identificados nove Pls tipo Ascaris da peçonha de escorpiões (Chen et al., 2013c; Liu 
et al., 2015; Song et al., 2014), mas apenas três tiveram suas atividades testadas contra peptidases. Suas estruturas tridimensionais ainda não foram elucidadas, de forma que a classificação foi feita com base na similaridade de sequência primária.

Dentre os inibidores de peptidases de animais venenosos, os PIs de anuros são os que mais apresentam variação em número de resíduos de aminoácidos e quantidade de pontes dissulfeto. Pelo menos seis classes podem ser identificadas (Mourão \& Schwartz, 2013):

1. PIs longos, consistindo de uma glicoproteína básica de cadeia única, com 22 a 60 kDa;

2. Inibidores do tipo Ascaris, com 56-61 resíduos de aminoácidos e cinco pontes dissulfeto;

3. Inibidores do tipo Kazal, com 52-78 resíduos de aminoácidos e três pontes dissulfeto;

4. Inibidores do tipo Kunitz, com 57-62 resíduos de aminoácidos e três pontes dissulfeto;

5. Inibidores com 60 resíduos de aminoácidos e apenas duas pontes dissulfeto;

6. Inibidores de peptidase de cadeia curta, com 17-18 resíduos de aminoácidos e uma única ponte dissulfeto.

Mesmo nos inibidores de cadeia curta, como o OGTI, do sapo Odorrana grahami, que possui 17 resíduos de aminoácidos e estrutura secundária predominantemente desordenada, a importância do resíduo Lys $^{13}$ para a inibição de tripsina foi confirmada pela inatividade do composto com a mutação K13A (Li et al., 2008). Estudos posteriores, porém, mostraram que a atividade inibitória do OGTI é reduzida com o tempo de incubação, devido a sua hidrólise pela tripsina, sendo sua atividade restrita a menos de 10 min de incubação com a enzima (Debowski et al., 2012). Outro inibidor de cadeia curta, o HV-BBI, isolado da secreção cutânea do sapo Huia versabilis, é composto por 18 resíduos de aminoácidos e possui uma ponte dissulfeto entre a $\mathrm{Cys}^{5} \mathrm{e} \mathrm{Cys}^{15}$, formando uma alça que é consistente com o motivo de inibidores de peptidase tipo Bowman-Birk (Song et al., 2008). A substituição da Lys $^{8}$ por Arg no HV-BBI levou a uma redução de três vezes na afinidade à tripsina, enquanto sua substituição por Phe levou à perda total de atividade contra tripsina, mas fez com que o peptídeo fosse ativo contra quimotripsina (Song et al., 2008). Tanto o HV-BBI como o OGTI apresentam também atividade antimicrobiana (Debowski et al., 2012). 
A estrutura cristalográfica de um análogo truncado do HV-BBI (resíduos 3-18) em complexo com a tripsina (resolução de $1 \AA$ ) mostra que a Lys ${ }^{8}$ projeta-se no bolsão S1 da enzima, e o inibidor assume, então, conformação semelhante à do substrato (Figura 2.4 A) (Grudnik et al., 2015). Os resíduos do loop de inibição de peptidase, altamente conservados nos inibidores Bowman-Birk (BBI) (Figura $2.4 \mathrm{~B}$ ), contribuem com a afinidade à tripsina formando ligações de hidrogênio com o bolsão S1, ou auxiliando na estabilização da estrutura em folha- $\beta$ do inibidor por meio de várias ligações de hidrogênio intramoleculares. Os resíduos fora do loop de ligação não são conservados na família BBI e fornecem menor contribuição para a interação do complexo enzima:inibidor, embora também contribuam para a afinidade do inibidor (Grudnik et al., 2015).

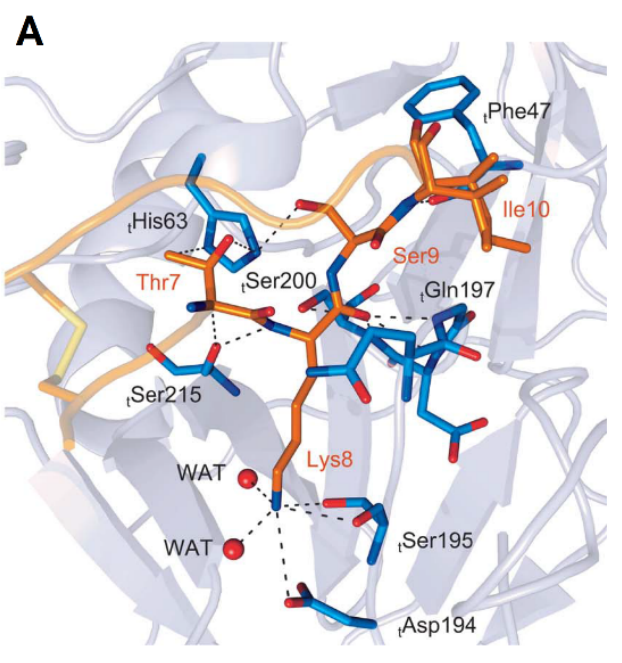

B

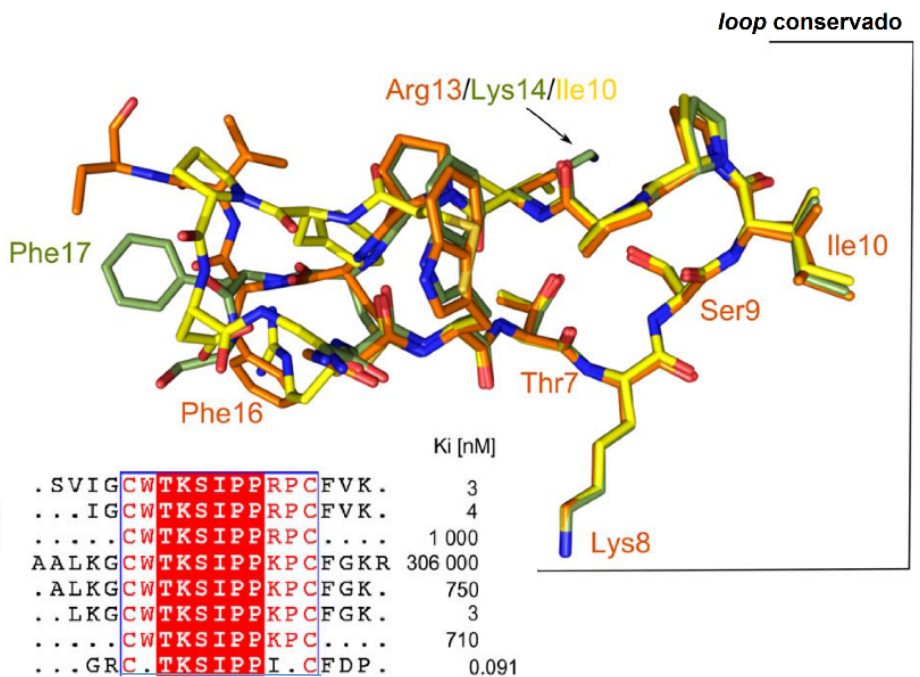

Figura 2.4. Estrutura tridimensional de inibidores do tipo Bowman-Birk. (A) Estrutura cristalográfica do HV-BBI(3-18) (laranja; apenas uma parte do loop do inibidor está representada) em complexo com a tripsina (azul). (B) Sobreposição da estrutura dos inibidores HV-BBI(3-18) (laranja), ORB-2 (verde) e SFTI-1 (amarelo), com destaque para o loop conservado. O alinhamento mostra que o loop de inibição de peptidases é estruturalmente conservado em inibidores do tipo Bowman-Birk. Adaptado de Grudnik et al. (2015).

A família de inibidores Bowman-Birk (BBI) compreende inibidores de serinopeptidases encontrados nas sementes de leguminosas e outras plantas. BBls de dicotiledôneas geralmente possuem cerca de 8 kDa e sua cadeia polipeptídica é composta por dois subdomínios homólogos, sendo chamados de inibidores de dupla cabeça. Cada subdomínio possui um sítio reativo independente localizado em um loop conservado exposto ao solvente (Figura 2.4 B), o qual contém nove resíduos de aminoácidos, com uma 
ponte dissulfeto entre os resíduos 1 e 9 . Assim, quando separados, cada subdomínio possui atividade inibidora de peptidase. No geral, o subdomínio N-terminal inibe tripsina (Lys/Arg na posição P1) e o C-terminal inibe quimotripsina (Phe/Trp/Leu/Met na posição P1), elastase (Ala na posição P1) ou tripsina (Laskowski \& Kato, 1980; Qi et al., 2005). O resíduo P1' nos dois subdomínios é uma Ser conservada (Figura 2.4 B). Por sua vez, BBIs de monocotiledôneas podem ser divididos em duas classes, uma com cerca de 8 kDa e apenas um sítio reativo (o outro teria sido perdido ao longo da evolução), e outra com cerca de 16 kDa e dois sítios reativos. A maioria dos BBIs de monocotiledôneas inibe tripsina. Os BBIs de dicotiledôneas têm sete pontes dissulfeto, enquanto os de monocotiledôneas com tamanho similar têm cinco pontes, em sua maioria. Em relação aos BBls de monocotiledôneas, os de dicotiledôneas apresentam uma maior especificidade para as enzimas inibidas. Esses inibidores parecem conferir resistência contra insetos e patógenos nas plantas, tendo sido estudados como agentes de defesa em plantas transgênicas. Além disso, têm sido estudados como agentes terapêuticos para a prevenção de câncer, dengue e desordens inflamatórias e alérgicas (Qi et al., 2005).

O loop reativo canônico de nove resíduos dos BBIs tem sido ainda mais explorado após a descoberta do inibidor de tripsina de girassol SFTI-1 (do inglês sunflower trypsin inhibitor), que é o menor membro de ocorrência natural da família. Com apenas 14 resíduos de aminoácidos ciclizados por meio de uma única ponte dissulfeto, o SFTI-1 é o mais potente inibidor de tripsina entre os BBls já caracterizados ( $K_{\mathrm{i}}$ de $110 \mathrm{pM}$ ) (Zablotna et al., 2002). SFTI-1 também inibe catepsina $\mathrm{G}(\mathrm{Ki}<0,15 \mathrm{nM})$ e, com menor afinidade, quimotripsina (Ki 7,4 $\mu \mathrm{M}$ ), elastase (Ki $105 \mu \mathrm{M})$ e trombina (Ki $136 \mu \mathrm{M})$, não apresentando efeito contra fator Xa (Luckett et al., 1999). Sua estrutura já foi determinada por RMN e cristalografia (PDB ID 1SFI) (Korsinczky et al., 2001; Luckett et al., 1999), propiciando um modelo ideal para o design de novas moléculas inibidoras específicas a suas respectivas peptidases.

Além dos motivos dos tipos Kunitz, Ascaris e Bowman-Birk, o motivo tipo Kazal também já foi descrito para outros organismos, dentre os quais anêmonas e anfíbios (Gebhard et al., 2004; Kolkenbrock \& Tschesche, 1987; Li et al., 2012; Tschesche et al., 1987). Essa família de Pls recebeu esse nome após a publicação, por Kazal e colaboradores (1948), do estudo de um inibidor de tripsina bovina pancreática que é secretado com os 
zimogênios no suco pancreático de vertebrados, posteriormente denominado de PSTI (pancreatic secretory trypsin inhibitor) ou SPINK1 (serine peptidase inhibitor Kazal type 1) (Wang \& Xu, 2010). O SPINK1 liga-se rapidamente à tripsina, inibindo sua atividade, o que levaria à proteção do pâncreas contra a ativação prematura do tripsinogênio, sendo, assim, um importante fator para o início da pancreatite. Outras atividades biológicas também foram descritas, assim como sua distribuição em vários órgãos e tecidos humanos e também em outros organismos (Shibata et al., 1987; Wang \& Xu, 2010). Inibidores do tipo Kazal são compostos tipicamente por um ou vários domínios, os quais consistem em 50-60 resíduos de aminoácidos e três pontes dissulfeto. Essa família possui diversos membros, dentre os quais os ovomucoides, proteínas abundantes em claras de ovos de aves, os quais consistem em três domínios Kazal homólogos, cada um com seu sítio reativo contra serinopeptidases (Bode et al., 1985; Kato et al., 1987; Laskowski et al., 1987).

Outros motivos estruturais de inibidores de peptidases são descritos também para os demais organismos (Krowarsch et al., 2003; Laskowski \& Kato, 1980; Shewry, 1999).

\subsubsection{BLOQUEIO dE CANAIS $K_{v}$ POR TOXINAS DE ESCORPIÕES}

Dentre as quatro famílias de KTxs escorpiônicas, a família $\alpha-K T x$ é a mais estudada e com maior número de toxinas descritas. Essas toxinas possuem tipicamente 30 a 40 resíduos de aminoácidos organizados em uma $\alpha$-hélice unida a uma folha- $\beta$ de duas fitas antiparalelas por três ou quatro pontes dissulfeto (estrutura $C S-\alpha / \beta$ ). A charybdotoxina, ou ChTx, é um exemplo bastante estudado dessa família, e bloqueia canais de $\mathrm{K}^{+}$ativados por $\mathrm{Ca}^{2+}\left(\mathrm{K}_{\mathrm{Ca}}\right)$ e canais $\mathrm{K}_{\mathrm{v}}$ 1.3. Recentemente, sua estrutura em complexo com um canal $\mathrm{K}_{\mathrm{v}}$ foi elucidada (Banerjee et al., 2013), sendo esta a primeira estrutura resolvida a partir da cristalização de uma toxina escorpiônica ligada a canais iônicos (Swartz, 2013). Mostrou-se que a porção helicoidal da toxina fica voltada para o lado oposto do canal, enquanto a face contendo os resíduos 25-29 da estrutura em folha- $\beta$ apontam para domínio do poro na porção extracelular do canal, bloqueando o fluxo iônico (Figura 2.5 A). Dentre esses resíduos, o grupo amino da cadeia lateral da Lys $^{27}$ interage diretamente com o filtro de seletividade, formando ligações de hidrogênio com os átomos de oxigênio das carbonilas na porção mais externa do filtro (sítio S1) (Figura 2.5 B). Sugere-se, assim, que um íon $\mathrm{K}^{+}$ seria desfavorável neste sítio tanto por repulsão eletrostática, devido à carga positiva do 
grupo amino da Lys, quanto pela indisponibilidade dos átomos de oxigênio que se ligariam ao $\mathrm{K}^{+}$no sítio S1. Essas observações complementam o que já havia sido mostrado antes por meio de mutações sítio-dirigidas e estudos de estrutura-função de diversas KTxs escorpiônicas, as quais frequentemente apresentam uma Lys na posição equivalente (Figura 2.5 C) (Banerjee et al., 2013).
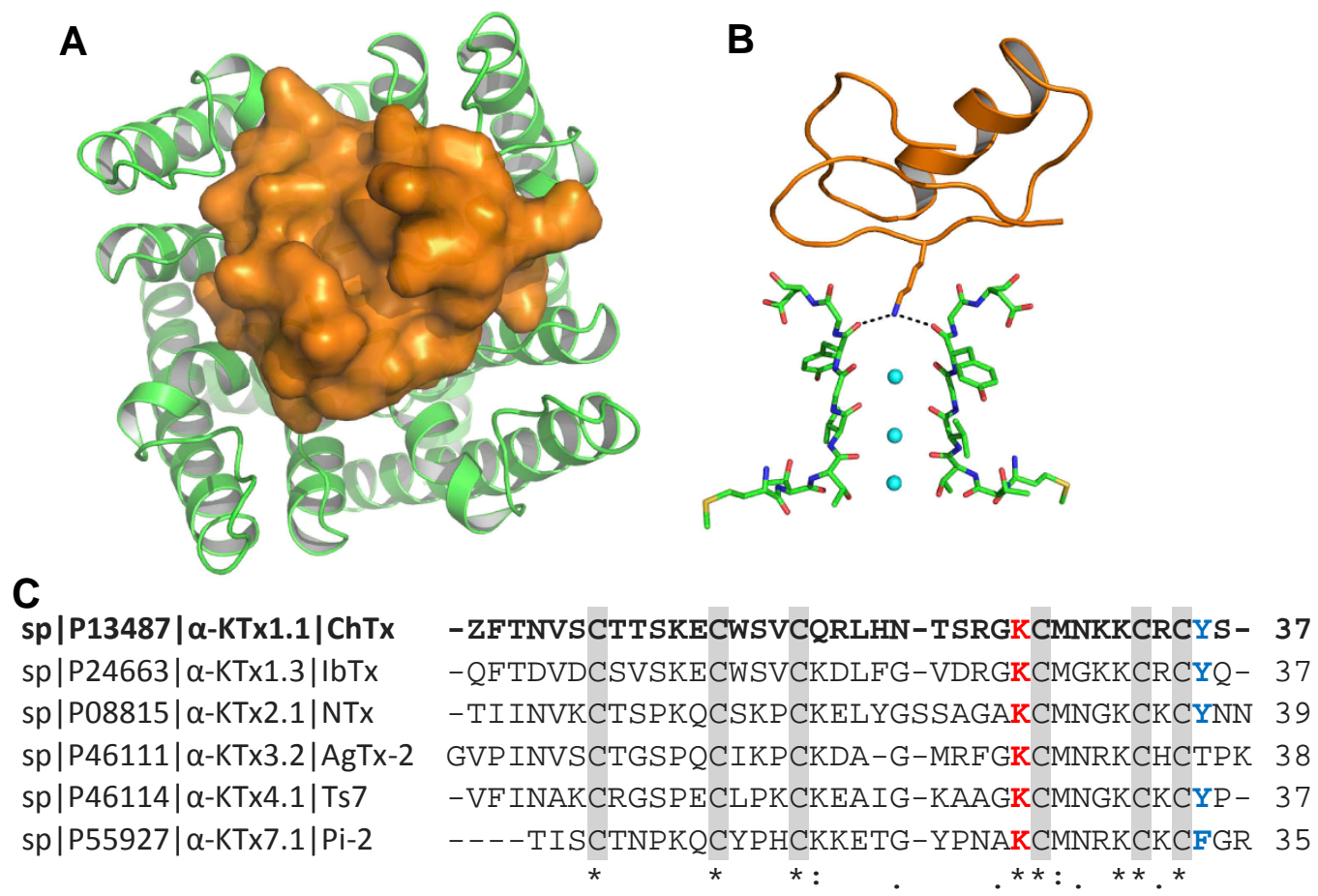

Figura 2.5. Estrutura do complexo charybdotoxina-canal $K_{v}$ e exemplos de $\alpha$-KTxs escorpiônicas. A estrutura da toxina em complexo com um mutante do canal $K_{v} 1.2$ de cérebro de rato (paddle chimera) foi determinada por cristalografia de raios-x. (A) Vista do lado extracelular, com a toxina (laranja) bloqueando o domínio do poro tetramérico (verde). (B) Filtro de seletividade do complexo toxina-canal. Os íons $\mathrm{K}^{+}$estão representados pelas esferas azuis. A toxina está mostrada em laranja, com o detalhe da cadeia lateral da Lys ${ }^{27}$ ligando-se (linhas tracejadas) aos oxigênios das carbonilas do filtro. (C) Alinhamento de sequências de KTxs escorpiônicas de diferentes famílias. Os resíduos de cisteína conservados estão mostrados em cinza, os resíduos de Lys conservados que interagem com o canal de $\mathrm{K}^{+}$estão em vermelho, e os resíduos Tyr ou Phe que são parte da díade funcional estão em azul. Adaptado de Banerjee et al. (2013).

A Lys ${ }^{27}$ em conjunto com um resíduo hidrofóbico, tipicamente a $\operatorname{Tyr}^{36}$ (posições em relação à $(\mathrm{hTx})$, Phe ou Leu, separados por uma distância de 5-7 $\AA$, constituem a denominada díade funcional para a atividade em canais da família $K_{v} 1$, estando presente em muitas neurotoxinas bloqueadoras de canais de potássio (Figura $2.5 \mathrm{C}$ ). Enquanto a Lys interage com o filtro de seletividade, o resíduo hidrofóbico (aromático ou alifático) interage com um grupo de resíduos hidrofóbicos do canal iônico (Mouhat et al., 2005). Na ChTx, por 
exemplo, o anel aromático da $\mathrm{Tyr}^{36}$ interage simultaneamente com os resíduos $\mathrm{Asp}^{375} \mathrm{e}$ $\mathrm{Val}^{377}$ do canal (Banerjee et al., 2013).

No entanto, o bloqueio de canais $K_{v} 1$ não depende exclusivamente da díade funcional. Na ausência desta, algumas toxinas reconhecem esses canais por meio de um anel formado por resíduos básicos, como é o caso da Tc32, do escorpião Tityus obscurus (Stehling et al., 2012), da Pi-1, do escorpião Pandinus imperator (Mouhat et al., 2004), e da KM-conotoxin RIIIK, de Conus radiatus (Verdier et al., 2005). Nesse modelo, o anel de cargas positivas da toxina é usado como uma âncora para os resíduos acídicos do vestíbulo externo do poro do canal, e o peptídeo bloqueia a região extracelular do poro como uma tampa, por meio de interações eletrostáticas.

Além dos modelos da díade funcional e do anel de resíduos básicos, estudos recentes parecem mostrar um terceiro mecanismo de bloqueio de canais $K_{v} 1$, no qual resíduos com carga negativa estariam alterando o mecanismo clássico de bloqueio do poro de canais $K_{v} 1$ pela Lys da díade funcional (Chen et al., 2015b; Chen et al., 2014). Na toxina BmKTX, do escorpião Mesobuthus martensii, o resíduo Asp ${ }^{33}$ encontra-se espacialmente adjacente ao resíduo conservado Lys ${ }^{26}$ (PDB ID: 1BKT). Devido à forte repulsão eletrostática da carga negativa do $\mathrm{Asp}^{33}$ com os resíduos acídicos do vestíbulo externo de canais de $\mathrm{K}^{+}$, essa proximidade impede com que a cadeia lateral da Lys $^{26}$ interaja com o filtro de seletividade do canal e bloqueie o poro. Essa repulsão eletrostática parece levar a uma reorientação da toxina, que passa, então, a usar o resíduo $\operatorname{Arg}^{23}$ para o bloqueio do poro. 


\subsection{OBJETIVOS}

\subsubsection{ObJetivo Geral}

Caracterizar a estrutura secundária e a estabilidade química e térmica do peptídeo ToPI1s. Identificar os principais resíduos de aminoácidos essenciais para a interação com tripsina, além de compreender o motivo para a ausência de atividade significativa em canais de $\mathrm{K}^{+}$do ToPI1s, a partir de experimentos realizados com dois peptídeos análogos do ToPI1, com resíduos de aminoácidos específicos alterados em relação ao peptídeo selvagem.

\subsubsection{OBJetIVOS ESPECÍFICOS}


2.3. MATERIAL E MÉTODOS 


\subsection{RESULTADOS}




\subsection{DISCUSSÃO}




\section{CONCLUSÃO E PERSPECTIVAS}




\section{REFERÊNCIAS BIBLIOGRÁFICAS}

Abbenante, G., Fairlie, D.P., 2005. Protease inhibitors in the clinic. Med Chem 1, 71-104.

Abdel-Rahman, M.A., Omran, M.A., Abdel-Nabi, I.M., Ueda, H., McVean, A., 2009. Intraspecific variation in the Egyptian scorpion Scorpio maurus palmatus venom collected from different biotopes. Toxicon 53, 349-359.

Aitken, A., Learmonth, M., 2008. Protein determination by UV absorption, in: Walker, J.M. (Ed.), The Protein Protocols Handbook. Humana Press, New Jersey, p. 809.

Antuch, W., Berndt, K.D., Chavez, M.A., Delfin, J., Wuthrich, K., 1993. The NMR solution structure of a Kunitz-type proteinase inhibitor from the sea anemone Stichodactyla helianthus. European journal of biochemistry / FEBS 212, 675-684.

Antz, C., Fakler, B., 1998. Fast inactivation of voltage-gated $\mathrm{K}^{+}$channels: from cartoon to structure. News in physiological sciences $13,177-182$.

Arcangeli, A., Becchetti, A., 2015. Novel perspectives in cancer therapy: Targeting ion channels. Drug resistance updates 21-22, 11-19.

Ardelt, W., Laskowski, M., Jr., 1983. Thermodynamics and kinetics of the hydrolysis and resynthesis of the reactive site peptide bond in turkey ovomucoid third domain by aspergillopeptidase B. Acta biochimica Polonica 30, 115-126.

Armstrong, W.B., Kennedy, A.R., Wan, X.S., Taylor, T.H., Nguyen, Q.A., Jensen, J., Thompson, W., Lagerberg, W., Meyskens, F.L., Jr., 2000. Clinical modulation of oral leukoplakia and protease activity by Bowman-Birk inhibitor concentrate in a phase lla chemoprevention trial. Clin Cancer Res 6, 4684-4691.

Armstrong, W.B., Taylor, T.H., Kennedy, A.R., Melrose, R.J., Messadi, D.V., Gu, M., Le, A.D., Perloff, M., Civantos, F., Goodwin, W.J., Wirth, L.J., Kerr, A.R., Meyskens, F.L., Jr., 2013. Bowman birk inhibitor concentrate and oral leukoplakia: a randomized phase Ilb trial. Cancer Prev Res (Phila) 6, 410-418.

Ascenzi, P., Bocedi, A., Bolognesi, M., Spallarossa, A., Coletta, M., De Cristofaro, R., Menegatti, E., 2003. The bovine basic pancreatic trypsin inhibitor (Kunitz inhibitor): a milestone protein. Current protein \& peptide science 4, 231-251.

Ascenzi, P., Ruoppolo, M., Amoresano, A., Pucci, P., Consonni, R., Zetta, L., Pascarella, S., Bortolotti, F., Menegatti, E., 1999. Characterization of low-molecular-mass trypsin isoinhibitors from oil-rape (Brassica napus var. oleifera) seed. European journal of biochemistry / FEBS 261, 275-284.

Asher, V., Sowter, H., Shaw, R., Bali, A., Khan, R., 2010. Eag and HERG potassium channels as novel therapeutic targets in cancer. World journal of surgical oncology 8,113 . 
Auguste, P., Hugues, M., Grave, B., Gesquiere, J.C., Maes, P., Tartar, A., Romey, G., Schweitz, H., Lazdunski, M., 1990. Leiurotoxin I (scyllatoxin), a peptide ligand for $\mathrm{Ca}^{2+}$-activated $\mathrm{K}^{+}$channels. Chemical synthesis, radiolabeling, and receptor characterization. The Journal of biological chemistry $265,4753-4759$.

Bajaj, M.S., Ogueli, G.I., Kumar, Y., Vadivel, K., Lawson, G., Shanker, S., Schmidt, A.E., Bajaj, S.P., 2011. Engineering kunitz domain 1 (KD1) of human tissue factor pathway inhibitor-2 to selectively inhibit fibrinolysis: properties of KD1-L17R variant. The Journal of biological chemistry 286, 4329-4340.

Banerjee, A., Lee, A., Campbell, E., Mackinnon, R., 2013. Structure of a pore-blocking toxin in complex with a eukaryotic voltage-dependent $\mathrm{K}^{+}$channel. eLife 2, e00594.

Barbosa, J.A., Teles, R.C., Forrer, V.P., Guimarães, B.G., Medrano, F.J., Ventura, M.M., Freitas, S.M., 2003. Crystallization, data collection and phasing of black-eyed pea trypsin/chymotrypsin inhibitor in complex with bovine beta-trypsin. Acta crystallographica. Section D, Biological crystallography 59, 1828-1830.

Bartok, A., Panyi, G., Varga, Z., 2014. Potassium channel blocking peptide toxins from scorpion venom, in: Gopalakrishnakone, P., Possani, L.D., F. Schwartz, E., Rodríguez de la Vega, R.C. (Eds.), Scorpion Venoms. Springer Netherlands, pp. 493-527.

Batista, C.V., del Pozo, L., Zamudio, F.Z., Contreras, S., Becerril, B., Wanke, E., Possani, L.D., 2004. Proteomics of the venom from the Amazonian scorpion Tityus cambridgei and the role of prolines on mass spectrometry analysis of toxins. Journal of chromatography. B, 803, 55-66.

Batista, C.V., Gomez-Lagunas, F., Lucas, S., Possani, L.D., 2000. Tc1, from Tityus cambridgei, is the first member of a new subfamily of scorpion toxin that blocks $\mathrm{K}^{+}$-channels. FEBS letters 486, 117-120.

Batista, C.V., Gómez-Lagunas, F., Rodríguez de la Vega, R.C., Hajdu, P., Panyi, G., Gáspár, R., Possani, L.D., 2002a. Two novel toxins from the Amazonian scorpion Tityus cambridgei that block Kv1.3 and Shaker B K+-channels with distinctly different affinities. Biochim Biophys Acta 1601, 123-131.

Batista, C.V., Zamudio, F.Z., Lucas, S., Fox, J.W., Frau, A., Prestipino, G., Possani, L.D., 2002b. Scorpion toxins from Tityus cambridgei that affect $\mathrm{Na}^{+}$-channels. Toxicon 40, 557-562.

Baugh, R.J., Trowbridge, C.G., 1972. Calorimetry of some trypsin-trypsin inhibitor reactions. The Journal of biological chemistry 247, 7498-7501.

Bayrhuber, M., Graf, R., Ferber, M., Zweckstetter, M., Imperial, J., Garrett, J.E., Olivera, B.M., Terlau, H., Becker, S., 2006. Production of recombinant Conkunitzin-S1 in Escherichia coli. Protein expression and purification 47, 640-644. 
Benkhadir, K., Kharrat, R., Cestele, S., Mosbah, A., Rochat, H., El Ayeb, M., Karoui, H., 2004. Molecular cloning and functional expression of the $\alpha$-scorpion toxin BotIII: pivotal role of the C-terminal region for its interaction with voltage-dependent sodium channels. Peptides 25, 151-161.

Benmosbah, M., Guegueniat, P., Mayence, C., Egmann, G., Narcisse, E., Gonon, S., Hommel, D., Kallel, H., 2013. Epidemiological and clinical study on scorpionism in French Guiana. Toxicon 73, 56-62.

Bergeron, Z.L., Bingham, J.P., 2012. Scorpion toxins specific for potassium ( $\left.\mathrm{K}^{+}\right)$channels: a historical overview of peptide bioengineering. Toxins 4, 1082-1119.

Berndt, K.D., Guntert, P., Orbons, L.P., Wuthrich, K., 1992. Determination of a high-quality nuclear magnetic resonance solution structure of the bovine pancreatic trypsin inhibitor and comparison with three crystal structures. Journal of molecular biology $227,757-775$.

Birnbaum, S.G., Varga, A.W., Yuan, L.L., Anderson, A.E., Sweatt, J.D., Schrader, L.A., 2004. Structure and function of $\mathrm{K}_{\mathrm{v}} 4$-family transient potassium channels. Physiological reviews $84,803-833$.

Blanc, E., Sabatier, J.M., Kharrat, R., Meunier, S., el Ayeb, M., Van Rietschoten, J., Darbon, H., 1997. Solution structure of maurotoxin, a scorpion toxin from Scorpio maurus, with high affinity for voltage-gated potassium channels. Proteins 29, 321-333.

Bode, W., Epp, O., Huber, R., Laskowski, M., Jr., Ardelt, W., 1985. The crystal and molecular structure of the third domain of silver pheasant ovomucoid (OMSVP3). European journal of biochemistry / FEBS 147, 387-395.

Bohm, G., Muhr, R., Jaenicke, R., 1992. Quantitative analysis of protein far UV circular dichroism spectra by neural networks. Protein engineering 5, 191-195.

Bontems, F., Roumestand, C., Gilquin, B., Menez, A., Toma, F., 1991. Refined structure of charybdotoxin: common motifs in scorpion toxins and insect defensins. Science 254, 1521-1523.

Borch, J., Roepstorff, P., 2004. Screening for enzyme inhibitors by surface plasmon resonance combined with mass spectrometry. Analytical chemistry 76, 5243-5248.

Borgono, C.A., Diamandis, E.P., 2004. The emerging roles of human tissue kallikreins in cancer. Nature reviews. Cancer 4, 876-890.

Brazón, J., D'Suze, G., D'Errico, M.L., Arocha-Piñango, C.L., Guerrero, B., 2009. Discreplasminin, a plasmin inhibitor isolated from Tityus discrepans scorpion venom. Archives of toxicology 83, 669-678. 
Caliskan, F., García, B.I., Coronas, F.I., Batista, C.V., Zamudio, F.Z., Possani, L.D., 2006. Characterization of venom components from the scorpion Androctonus crassicauda of Turkey: peptides and genes. Toxicon 48, 12-22.

Camargos, T.S., Restano-Cassulini, R., Possani, L.D., Peigneur, S., Tytgat, J., Schwartz, C.A., Alves, E.M., de Freitas, S.M., Schwartz, E.F., 2011. The new K-KTx 2.5 from the scorpion Opisthacanthus cayaporum. Peptides 32, 1509-1517.

Carvalho, R.M.d., Rath, S., Kubota, L.T., 2003. SPR: Uma nova ferramenta para biossensores. Química Nova 26, 97-104.

Castro, M.J., Anderson, S., 1996. Alanine point-mutations in the reactive region of bovine pancreatic trypsin inhibitor: effects on the kinetics and thermodynamics of binding to $\beta$-trypsin and $\alpha$-chymotrypsin. Biochemistry 35, 11435-11446.

Cathcart, J., Pulkoski-Gross, A., Cao, J., 2015. Targeting Matrix Metalloproteinases in Cancer: Bringing New Life to Old Ideas. Genes \& Diseases 2, 26-34.

Cekanova, M., Rathore, K., 2014. Animal models and therapeutic molecular targets of cancer: utility and limitations. Drug design, development and therapy 8, 1911-1921.

Chabner, B.A., Allegra, C.J., 2011. Antifolates, in: Chabner, B.A., Longo, D.L. (Eds.), Cancer Chemotherapy and Biotherapy: Principles and Practice, 5 ed. Wolters Kluwer: Lipincott Williams \& Wilkins, Philadelphia, USA, p. 848.

Chang, L., Chung, C., Huang, H.B., Lin, S., 2001. Purification and characterization of a chymotrypsin inhibitor from the venom of Ophiophagus hannah (King Cobra). Biochemical and biophysical research communications 283, 862-867.

Chen, C., Hsu, C.H., Su, N.Y., Lin, Y.C., Chiou, S.H., Wu, S.H., 2001. Solution structure of a Kunitz-type chymotrypsin inhibitor isolated from the elapid snake Bungarus fasciatus. The Journal of biological chemistry 276, 45079-45087.

Chen, J., Zhang, C., Yang, W., Cao, Z., Li, W., Chen, Z., Wu, Y., 2015a. SjAPI-2 is the first member of a new neurotoxin family with Ascaris-type fold and KCNQ1 inhibitory activity. International journal of biological macromolecules 79, 504-510.

Chen, P.C., Kuyucak, S., 2012. Developing a comparative docking protocol for the prediction of peptide selectivity profiles: investigation of potassium channel toxins. Toxins 4, 110138.

Chen, X., Wang, Q., Ni, F., Ma, J., 2010. Structure of the full-length Shaker potassium channel $\mathrm{K}_{\mathrm{v}} 1.2$ by normal-mode-based X-ray crystallographic refinement. Proceedings of the National Academy of Sciences of the United States of America 107, 11352-11357. 
Chen, Y.W., Huang, S.C., Lin-Shiau, S.Y., Lin, J.K., 2005. Bowman-Birk inhibitor abates proteasome function and suppresses the proliferation of MCF7 breast cancer cells through accumulation of MAP kinase phosphatase-1. Carcinogenesis 26, 1296-1306.

Chen, Z., Cao, Z., Li, W., Wu, Y., 2013a. Cloning and characterization of a novel Kunitz-type inhibitor from scorpion with unique cysteine framework. Toxicon 72, 5-10.

Chen, Z., Hu, Y., Hong, J., Hu, J., Yang, W., Xiang, F., Yang, F., Xie, Z., Cao, Z., Li, W., Lin, D., $\mathrm{Wu}, \mathrm{Y} ., 2015 \mathrm{~b}$. Toxin acidic residue evolutionary function-guided design of de novo peptide drugs for the immunotherapeutic target, the $K_{v} 1.3$ channel. Scientific reports $5,9881$.

Chen, Z., Hu, Y., Hu, J., Yang, W., Sabatier, J.M., De Waard, M., Cao, Z., Li, W., Han, S., Wu, Y., 2014. Unusual binding mode of scorpion toxin BmKTX onto potassium channels relies on its distribution of acidic residues. Biochemical and biophysical research communications $447,70-76$.

Chen, Z., Luo, F., Feng, J., Yang, W., Zeng, D., Zhao, R., Cao, Z., Liu, M., Li, W., Jiang, L., Wu, Y., 2013b. Genomic and structural characterization of Kunitz-type peptide LmKTT-1a highlights diversity and evolution of scorpion potassium channel toxins. PloS one 8 , e60201.

Chen, Z., Wang, B., Hu, J., Yang, W., Cao, Z., Zhuo, R., Li, W., Wu, Y., 2013c. SjAPI, the first functionally characterized Ascaris-type protease inhibitor from animal venoms. PloS one 8 , e57529.

Chen, Z.Y., Hu, Y.T., Yang, W.S., He, Y.W., Feng, J., Wang, B., Zhao, R.M., Ding, J.P., Cao, Z.J., Li, W.X., Wu, Y.L., 2012a. Hg1, novel peptide inhibitor specific for Kv1.3 channels from first scorpion Kunitz-type potassium channel toxin family. The Journal of biological chemistry 287, 13813-13821.

Chen, Z.Y., Zeng, D.Y., Hu, Y.T., He, Y.W., Pan, N., Ding, J.P., Cao, Z.J., Liu, M.L., Li, W.X., Yi, H., Jiang, L., Wu, Y.L., 2012b. Structural and functional diversity of acidic scorpion potassium channel toxins. PloS one 7, e35154.

Chhatwal, G.S., Habermann, E., 1981. Neurotoxins, protease inhibitors and histamine releasers in the venom of the Indian red scorpion (Buthus tamulus): isolation and partial characterization. Toxicon 19, 807-823.

Chippaux, J.P., Goyffon, M., 2008. Epidemiology of scorpionism: a global appraisal. Acta tropica 107, 71-79.

Choe, S., 2002. Potassium channel structures. Nature reviews. Neuroscience 3, 115-121.

Ciechanover, A., 2005. Proteolysis: from the lysosome to ubiquitin and the proteasome.

Nature reviews. Molecular cell biology 6, 79-87. 
Clement, H., Flores, V., Diego-Garcia, E., Corrales-Garcia, L., Villegas, E., Corzo, G., 2015. A comparison between the recombinant expression and chemical synthesis of a short cysteine-rich insecticidal spider peptide. The journal of venomous animals and toxins including tropical diseases $21,19$.

Conlon, J.M., Kim, J.B., 2000. A protease inhibitor of the Kunitz family from skin secretions of the tomato frog, Dyscophus guineti (Microhylidae). Biochemical and biophysical research communications 279 , 961-964.

Cooper, E.C., Milroy, A., Jan, Y.N., Jan, L.Y., Lowenstein, D.H., 1998. Presynaptic localization of Kv1.4-containing A-type potassium channels near excitatory synapses in the hippocampus. The Journal of neuroscience 18, 965-974.

Cooper, M.A., 2002. Optical biosensors in drug discovery. Nature reviews. Drug discovery 1, 515-528.

Copeland, R.A., 2000. Enzymes: a practical introduction to structure, mechanism, and data analysis, 2nd ed. Wiley-VCH, Inc.

Copeland, R.A., 2005. Evaluation of enzyme inhibitors in drug discovery. A guide for medicinal chemists and pharmacologists. Methods of biochemical analysis 46, 1-265.

Copeland, R.A., 2013. Evaluation of Enzyme Inhibitors in Drug Discovery: A Guide for Medicinal Chemists and Pharmacologists, 2 ed. Wiley.

Cui, J., 2016. Voltage-Dependent Gating: Novel Insights from KCNQ1 Channels. Biophysical journal 110, 14-25.

Czapinska, H., Otlewski, J., Krzywda, S., Sheldrick, G.M., Jaskolski, M., 2000. High-resolution structure of bovine pancreatic trypsin inhibitor with altered binding loop sequence. Journal of molecular biology 295, 1237-1249.

da Silva, A.V., De Souza, B.M., Dos Santos Cabrera, M.P., Dias, N.B., Gomes, P.C., Neto, J.R., Stabeli, R.G., Palma, M.S., 2014. The effects of the C-terminal amidation of mastoparans on their biological actions and interactions with membrane-mimetic systems. Biochimica et biophysica acta 1838, 2357-2368.

Dardevet, L., Rani, D., Aziz, T.A., Bazin, I., Sabatier, J.M., Fadl, M., Brambilla, E., De Waard, M., 2015. Chlorotoxin: a helpful natural scorpion peptide to diagnose glioma and fight tumor invasion. Toxins 7, 1079-1101.

Dauplais, M., Gilquin, B., Possani, L.D., Gurrola-Briones, G., Roumestand, C., Menez, A., 1995. Determination of the three-dimensional solution structure of noxiustoxin: analysis of structural differences with related short-chain scorpion toxins. Biochemistry 34, 16563-16573. 
Day, Y.S., Baird, C.L., Rich, R.L., Myszka, D.G., 2002. Direct comparison of binding equilibrium, thermodynamic, and rate constants determined by surface- and solution-based biophysical methods. Protein science 11, 1017-1025.

de Freitas, S.M., Ikemoto, H., Ventura, M.M., 1999. Thermodynamics of the binding of chymotrypsin with the black-eyed pea trypsin and chymotrypsin inhibitor (BTCI). Journal of protein chemistry $18,307-313$.

De Sousa, L., Borges, A., Vasquez-Suarez, A., Op den Camp, H.J., Chadee-Burgos, R.I., Romero-Bellorin, M., Espinoza, J., De Sousa-Insana, L., Pino-Garcia, O., 2010. Differences in venom toxicity and antigenicity between females and males Tityus nororientalis (Buthidae) scorpions. Journal of venom research 1, 61-70.

De Veer, S.J., Swedberg, J.E., Akcan, M., Rosengren, K.J., Brattsand, M., Craik, D.J., Harris, J.M., 2015. Engineered protease inhibitors based on sunflower trypsin inhibitor-1 (SFTI-1) provide insights into the role of sequence and conformation in Laskowski mechanism inhibition. The Biochemical journal 469(2), 243-53.

Debowski, D., Lukajtis, R., Legowska, A., Karna, N., Pikula, M., Wysocka, M., Maliszewska, I., Sienczyk, M., Lesner, A., Rolka, K., 2012. Inhibitory and antimicrobial activities of OGTI and HV-BBI peptides, fragments and analogs derived from amphibian skin. Peptides 35, 276-284.

Deinum, J., Gustavsson, L., Gyzander, E., Kullman-Magnusson, M., Edstrom, A., Karlsson, R., 2002. A thermodynamic characterization of the binding of thrombin inhibitors to human thrombin, combining biosensor technology, stopped-flow spectrophotometry, and microcalorimetry. Analytical biochemistry 300, 152-162.

Deisenhofer, J., Steigemann, W., 1975. Crystallographic refinement of the structure of bovine pancreatic trypsin inhibitor at I.5 A resolution. Acta Crystallographica Section B 31, 238-250.

Demeure, K., Gabelica, V., De Pauw, E.A., 2010. New advances in the understanding of the in-source decay fragmentation of peptides in MALDI-TOF-MS. Journal of the American Society for Mass Spectrometry 21, 1906-1917.

Deu, E., Verdoes, M., Bogyo, M., 2012. New approaches for dissecting protease functions to improve probe development and drug discovery. Nature structural \& molecular biology 19, 9-16.

Di Cera, E., 2009. Serine proteases. IUBMB life 61, 510-515.

Ding, F., Xiao, H., Wang, M., Xie, X., Hu, F., 2014. The role of the ubiquitin-proteasome pathway in cancer development and treatment. Front Biosci (Landmark Ed) 19, 886895. 
Ding, L., Wang, X., Liu, H., San, M., Xu, Y., Li, J., Li, S., Cao, Z., Li, W., Wu, Y., Chen, Z., 2015. A new Kunitz-type plasmin inhibitor from scorpion venom. Toxicon 106, 7-13.

Doorty, K.B., Bevan, S., Wadsworth, J.D., Strong, P.N., 1997. A novel small conductance Ca ${ }^{2+}$ activated $\mathrm{K}^{+}$channel blocker from Oxyuranus scutellatus taipan venom. Re-evaluation of taicatoxin as a selective $\mathrm{Ca}^{2+}$ channel probe. The Journal of biological chemistry 272 , 19925-19930.

Dunaevsky, Y.E., Elpidina, E.N., Vinokurov, K.S., Belozersky, M.A., 2005. Protease inhibitors in improvement of plant resistance to pathogens and insects. Mol Biol 39, 608-613.

Easson, L.H., Stedman, E., 1936. The absolute activity of choline-esterase. Proceedings of the Royal Society of London B 121, 142-164.

Edgington, L.E., Bogyo, M., 2013. In vivo imaging and biochemical characterization of protease function using fluorescent activity-based probes. Current protocols in chemical biology 5, 25-44.

Ellem, S.J., De-Juan-Pardo, E.M., Risbridger, G.P., 2014. In vitro modeling of the prostate cancer microenvironment. Advanced drug delivery reviews 79-80, 214-221.

Fahrney, D.E., Gold, A.M., 1963. Sulfonyl fluorides as inhibitors of esterases. I. Rates of reaction with acetylcholinesterase, $\alpha$-chymotrypsin, and trypsin. Journal of the American Chemical Society 85, 997-1000.

Fergusson, D.A., Hebert, P.C., Mazer, C.D., Fremes, S., MacAdams, C., Murkin, J.M., Teoh, K., Duke, P.C., Arellano, R., Blajchman, M.A., Bussieres, J.S., Cote, D., Karski, J., Martineau, R., Robblee, J.A., Rodger, M., Wells, G., Clinch, J., Pretorius, R., 2008. A comparison of aprotinin and lysine analogues in high-risk cardiac surgery. The New England journal of medicine 358, 2319-2331.

Fiedler, F., 1987. Effects of secondary interactions on the kinetics of peptide and peptide ester hydrolysis by tissue kallikrein and trypsin. European journal of biochemistry / FEBS 163, 303-312.

Flight, S.M., Johnson, L.A., Du, Q.S., Warner, R.L., Trabi, M., Gaffney, P.J., Lavin, M.F., de Jersey, J., Masci, P.P., 2009. Textilinin-1, an alternative anti-bleeding agent to aprotinin: Importance of plasmin inhibition in controlling blood loss. British journal of haematology 145, 207-211.

Fonovic, M., Turk, B., 2014. Cysteine cathepsins and extracellular matrix degradation. Biochimica et biophysica acta 1840, 2560-2570.

Friedl, P., Wolf, K., 2008. Tube travel: the role of proteases in individual and collective cancer cell invasion. Cancer research 68, 7247-7249. 
Gao, B., Harvey, P.J., Craik, D.J., Ronjat, M., De Waard, M., Zhu, S., 2013. Functional evolution of scorpion venom peptides with an inhibitor cystine knot fold. Bioscience reports 33.

Gao, J., Yin, D.H., Yao, Y., Sun, H., Qin, Z., Schoneich, C., Williams, T.D., Squier, T.C., 1998. Loss of conformational stability in calmodulin upon methionine oxidation. Biophysical journal 74, 1115-1134.

García-Fernández, R., Pons, T., Perbandt, M., Valiente, P.A., Talavera, A., González-González, Y., Rehders, D., Chávez, M.A., Betzel, C., Redecke, L., 2012. Structural insights into serine protease inhibition by a marine invertebrate BPTI Kunitz-type inhibitor. Journal of structural biology 180, 271-279.

Gasparini, S., Danse, J.M., Lecoq, A., Pinkasfeld, S., Zinn-Justin, S., Young, L.C., de Medeiros, C.C., Rowan, E.G., Harvey, A.L., Menez, A., 1998. Delineation of the functional site of $\alpha$-dendrotoxin. The functional topographies of dendrotoxins are different but share a conserved core with those of other Kv1 potassium channel-blocking toxins. The Journal of biological chemistry 273, 25393-25403.

Gasymov, O.K., Abduragimov, A.R., Glasgow, B.J., 2014. Probing tertiary structure of proteins using single Trp mutations with circular dichroism at low temperature. The journal of physical chemistry. B 118, 986-995.

Gatehouse, J.A., 2011. Prospects for using proteinase inhibitors to protect transgenic plants against attack by herbivorous insects. Current protein \& peptide science 12, 409-416.

Gati, C.D., Mortari, M.R., Schwartz, E.F., 2012. Towards therapeutic applications of arthropod venom $\mathrm{K}^{+}$-channel blockers in CNS neurologic diseases involving memory acquisition and storage. Journal of toxicology 2012, 756358.

Gebhard, L.G., Carrizo, F.U., Stern, A.L., Burgardt, N.I., Faivovich, J., Lavilla, E., Ermacora, M.R., 2004. A Kazal prolyl endopeptidase inhibitor isolated from the skin of Phyllomedusa sauvagii. European journal of biochemistry / FEBS 271, 2117-2126.

Gill, P., Moghadam, T.T., Ranjbar, B., 2010. Differential scanning calorimetry techniques: applications in biology and nanoscience. Journal of biomolecular techniques 21,167 193.

Gladkikh, I., Monastyrnaya, M., Leychenko, E., Zelepuga, E., Chausova, V., Isaeva, M., Anastyuk, S., Andreev, Y., Peigneur, S., Tytgat, J., Kozlovkaya, E., 2012. Atypical reactive center Kunitz-type inhibitor from the sea anemone Heteractis crispa. Marine drugs 10, 1545-1565.

GLOBOCAN, 2012. Cancer Incidence and Mortality Worldwide, v.10 ed. IARC CancerBase, Disponível em http://globocan.iarc.fr. 
Goldstein, S.A., Pheasant, D.J., Miller, C., 1994. The charybdotoxin receptor of a Shaker K+ channel: peptide and channel residues mediating molecular recognition. Neuron 12 , 1377-1388.

González-González, Y., Hernández-Zanuy, A., Araujo, M.S., Oliva, M.L.V., Planes, M.A.C., Sampaio, C.A.M., 2003. Screening of serine proteinase inhibitors from marine organisms. Biotecnología Aplicada 20, 111-114.

Goodrich, J.A., Kugel, J.F., 2007. Binding and Kinetics for Molecular Biologists. Cold Spring Harbor Laboratory Press.

Goodstadt, L., Ponting, C.P., 2001. CHROMA: consensus-based colouring of multiple alignments for publication. Bioinformatics 17, 845-846.

Grasberger, B.L., Clore, G.M., Gronenborn, A.M., 1994. High-resolution structure of Ascaris trypsin inhibitor in solution: direct evidence for a $\mathrm{pH}$-induced conformational transition in the reactive site. Structure 2, 669-678.

Greenfield, N.J., 2006. Using circular dichroism spectra to estimate protein secondary structure. Nature protocols 1, 2876-2890.

Grudnik, P., Debowski, D., Legowska, A., Malicki, S., Golik, P., Karna, N., Rolka, K., Dubin, G., 2015. Atomic resolution crystal structure of HV-BBI protease inhibitor from amphibian skin in complex with bovine trypsin. Proteins 83, 582-589.

Grzesiak, A., Helland, R., Smalas, A.O., Krowarsch, D., Dadlez, M., Otlewski, J., 2000a. Substitutions at the $\mathrm{P}_{1}{ }^{\prime}$ position in BPTI strongly affect the association energy with serine proteinases. Journal of molecular biology 301, 205-217.

Grzesiak, A., Krokoszynska, I., Krowarsch, D., Buczek, O., Dadlez, M., Otlewski, J., 2000b. Inhibition of six serine proteinases of the human coagulation system by mutants of bovine pancreatic trypsin inhibitor. The Journal of biological chemistry 275 , 3334633352.

Guerrero-Vargas, J.A., Mourão, C.B., Quintero-Hernández, V., Possani, L.D., Schwartz, E.F., 2012. Identification and phylogenetic analysis of Tityus pachyurus and Tityus obscurus novel putative $\mathrm{Na}^{+}$-channel scorpion toxins. PloS one 7, e30478.

Guo, C.T., McClean, S., Shaw, C., Rao, P.F., Ye, M.Y., Bjourson, A.J., 2013. Trypsin and chymotrypsin inhibitor peptides from the venom of Chinese Daboia russellii siamensis. Toxicon 63, 154-164.

Gurevitz, M., Gordon, D., Barzilai, M., Kahn, R., Cohen, L., Moran, Y., Zilberberg, N., Froy, O., Altman-Gueta, H., Turkov, M., Dong, K., Karbat, I., 2014. Molecular description of scorpion toxin interaction with voltage-gated sodium channels, in: Gopalakrishnakone, P. (Ed.), Toxinology. Springer Netherlands, pp. 1-19. 
Gutman, G.A., Chandy, K.G., Grissmer, S., Lazdunski, M., McKinnon, D., Pardo, L.A., Robertson, G.A., Rudy, B., Sanguinetti, M.C., Stuhmer, W., Wang, X., 2005. International Union of Pharmacology. LIII. Nomenclature and molecular relationships of voltage-gated potassium channels. Pharmacological reviews 57, 473-508.

Han, Z., Harris, P.K., Jones, D.E., Chugani, R., Kim, T., Agarwal, M., Shen, W., Wildman, S.A., Janetka, J.W., 2014. Inhibitors of HGFA, Matriptase, and Hepsin Serine Proteases: A Nonkinase Strategy to Block Cell Signaling in Cancer. ACS medicinal chemistry letters 5, 1219-1224.

Hanahan, D., Weinberg, R.A., 2011. Hallmarks of cancer: the next generation. Cell 144, 646674.

Hardy, J.F., Desroches, J., 1992. Natural and synthetic antifibrinolytics in cardiac surgery. Canadian journal of anaesthesia 39, 353-365.

Harvey, A.L., 1997. Recent studies on dendrotoxins and potassium ion channels. General pharmacology 28, 7-12.

Harvey, A.L., 2001. Twenty years of dendrotoxins. Toxicon 39, 15-26.

Harvey, A.L., Robertson, B., 2004. Dendrotoxins: structure-activity relationships and effects on potassium ion channels. Current medicinal chemistry 11, 3065-3072.

Harvey, A.L., Rowan, E.G., Vatanpour, H., Engstrom, A., Westerlund, B., Karlsson, E., 1997. Changes to biological activity following acetylation of dendrotoxin I from Dendroaspis polylepis (black mamba). Toxicon 35, 1263-1273.

Hedstrom, L., 2002. Serine protease mechanism and specificity. Chemical reviews 102, 45014524.

Herndon, T.M., Deisseroth, A., Kaminskas, E., Kane, R.C., Koti, K.M., Rothmann, M.D., Habtemariam, B., Bullock, J., Bray, J.D., Hawes, J., Palmby, T.R., Jee, J., Adams, W., Mahayni, H., Brown, J., Dorantes, A., Sridhara, R., Farrell, A.T., Pazdur, R., 2013. U.s. Food and Drug Administration approval: carfilzomib for the treatment of multiple myeloma. Clinical cancer research 19, 4559-4563.

Honma, T., Kawahata, S., Ishida, M., Nagai, H., Nagashima, Y., Shiomi, K., 2008. Novel peptide toxins from the sea anemone Stichodactyla haddoni. Peptides 29, 536-544.

Honma, T., Shiomi, K., 2006. Peptide toxins in sea anemones: structural and functional aspects. Mar Biotechnol (NY) 8, 1-10.

Hopkins, W.F., 1998. Toxin and subunit specificity of blocking affinity of three peptide toxins for heteromultimeric, voltage-gated potassium channels expressed in Xenopus oocytes. The Journal of pharmacology and experimental therapeutics 285, 10511060. 
Hoshi, T., Heinemann, S., 2001. Regulation of cell function by methionine oxidation and reduction. The Journal of physiology 531, 1-11.

INCA, 2016. Instituto Nacional do Câncer, Disponível em <http://www2.inca.gov.br/wps/wcm/connect/tiposdecancer/site/home>.

Irigaray, P., Newby, J.A., Clapp, R., Hardell, L., Howard, V., Montagnier, L., Epstein, S., Belpomme, D., 2007. Lifestyle-related factors and environmental agents causing cancer: an overview. Biomedicine \& pharmacotherapy 61, 640-658.

Isaeva, M.P., Chausova, V.E., Zelepuga, E.A., Guzev, K.V., Tabakmakher, V.M., Monastyrnaya, M.M., Kozlovskaya, E.P., 2012. A new multigene superfamily of Kunitz-type protease inhibitors from sea anemone Heteractis crispa. Peptides 34, 88-97.

Iwanaga, S., Yamasaki, N., Kimura, M., Kouzuma, Y., 2005. Contribution of conserved Asn residues to the inhibitory activities of Kunitz-type protease inhibitors from plants. Bioscience, biotechnology, and biochemistry 69, 220-223.

Jehle, J., Schweizer, P.A., Katus, H.A., Thomas, D., 2011. Novel roles for hERG K ${ }^{+}$channels in cell proliferation and apoptosis. Cell death \& disease 2, e193.

Jelesarov, I., 2010. Energetics of protein-protein interactions, in: Zacharias, M. (Ed.), ProteinProtein Complexes: Analysis, Modeling and Drug Design. Imperial College Press, London, p. 401.

Jenkinson, D.H., 2006. Potassium channels--multiplicity and challenges. British journal of pharmacology 147 Suppl 1, S63-71.

Jimenez-Garduno, A.M., Mitkovski, M., Alexopoulos, I.K., Sanchez, A., Stuhmer, W., Pardo, L.A., Ortega, A., 2014. Kv10.1 Kt-channel plasma membrane discrete domain partitioning and its functional correlation in neurons. Biochimica et biophysica acta 1838, 921-931.

Jimenez-Vargas, J.M., Restano-Cassulini, R., Quintero-Hernandez, V., Gurrola, G.B., Possani, L.D., 2011. Recombinant expression of the toxic peptide ErgTx1 and role of Met35 on its stability and function. Peptides 32, 560-567.

Jin, L., Wu, Y., 2011. Molecular mechanism of ?-dendrotoxin-potassium channel recognition explored by docking and molecular dynamic simulations. Journal of molecular recognition $24,101-107$.

Joanitti, G.A., Azevedo, R.B., Freitas, S.M., 2010. Apoptosis and lysosome membrane permeabilization induction on breast cancer cells by an anticarcinogenic Bowman-Birk protease inhibitor from Vigna unguiculata seeds. Cancer Lett 293, 73-81.

Johnson, C.M., 2013. Differential scanning calorimetry as a tool for protein folding and stability. Archives of biochemistry and biophysics 531, 100-109. 
Johnson, D.E., 2015. The ubiquitin-proteasome system: opportunities for therapeutic intervention in solid tumors. Endocrine-related cancer 22, T1-17.

Johnson, J.I., Decker, S., Zaharevitz, D., Rubinstein, L.V., Venditti, J.M., Schepartz, S., Kalyandrug, S., Christian, M., Arbuck, S., Hollingshead, M., Sausville, E.A., 2001. Relationships between drug activity in $\mathrm{NCl}$ preclinical in vitro and in vivo models and early clinical trials. British journal of cancer 84, 1424-1431.

Johnsson, B., Lofas, S., Lindquist, G., 1991. Immobilization of proteins to a carboxymethyldextran-modified gold surface for biospecific interaction analysis in surface plasmon resonance sensors. Analytical biochemistry 198, 268-277.

Joutovsky, A., Hadzi-Nesic, J., Nardi, M.A., 2004. HPLC retention time as a diagnostic tool for hemoglobin variants and hemoglobinopathies: a study of 60000 samples in a clinical diagnostic laboratory. Clinical chemistry 50, 1736-1747.

Ju, M., Wray, D., 2002. Molecular identification and characterisation of the human eag2 potassium channel. FEBS letters 524, 204-210.

Kato, I., Schrode, J., Kohr, W.J., Laskowski, M., Jr., 1987. Chicken ovomucoid: determination of its amino acid sequence, determination of the trypsin reactive site, and preparation of all three of its domains. Biochemistry 26, 193-201.

Kawamura, K., Yamada, T., Kurihara, K., Tamada, T., Kuroki, R., Tanaka, I., Takahashi, H., Niimura, N., 2011. X-ray and neutron protein crystallographic analysis of the trypsinBPTI complex. Acta crystallographica. Section D, Biological crystallography 67,140 148.

Kazal, L.A., Spicer, D.S., Brahinsky, R.A., 1948. Isolation of a crystalline trypsin inhibitoranticoagulant protein from pancreas. J Am Chem Soc 70, 3034-3040.

Kelly, S.M., Jess, T.J., Price, N.C., 2005. How to study proteins by circular dichroism. Biochimica et biophysica acta 1751, 119-139.

Kennedy, A.R., 1998. Chemopreventive agents: protease inhibitors. Pharmacology \& therapeutics 78, 167-209.

Kobayashi, H., 2013. Prevention of cancer and inflammation by soybean protease inhibitors. Front Biosci (Elite Ed) 5, 966-973.

Koblinski, J.E., Ahram, M., Sloane, B.F., 2000. Unraveling the role of proteases in cancer. Clinica chimica acta 291, 113-135.

Kolkenbrock, H., Tschesche, H., 1987. A new inhibitor of elastase from the sea anemone (Anemonia sulcata). Biological chemistry Hoppe-Seyler 368, 93-99.

Koltai, T., 2015. Nelfinavir and other protease inhibitors in cancer: mechanisms involved in anticancer activity. F1000Research 4(9), 1-19. 
Korsinczky, M.L., Schirra, H.J., Rosengren, K.J., West, J., Condie, B.A., Otvos, L., Anderson, M.A., Craik, D.J., 2001. Solution structures by ${ }^{1} \mathrm{H}$ NMR of the novel cyclic trypsin inhibitor SFTI-1 from sunflower seeds and an acyclic permutant. Journal of molecular biology 311, 579-591.

Krowarsch, D., Cierpicki, T., Jelen, F., Otlewski, J., 2003. Canonical protein inhibitors of serine proteases. Cellular and molecular life sciences 60, 2427-2444.

Kumar, S.K., LaPlant, B., Roy, V., Reeder, C.B., Lacy, M.Q., Gertz, M.A., Laumann, K., Thompson, M.A., Witzig, T.E., Buadi, F.K., Rivera, C.E., Mikhael, J.R., Bergsagel, P.L., Kapoor, P., Hwa, L., Fonseca, R., Stewart, A.K., Chanan-Khan, A., Rajkumar, S.V., Dispenzieri, A., 2015. Phase 2 trial of ixazomib in patients with relapsed multiple myeloma not refractory to bortezomib. Blood cancer journal 5, e338.

Kunitz, M., Northrop, J.H., 1936. Isolation from beef pancreas of crystalline trypsinogen, trypsin, a trypsin Inhibitor, and an inhibitor-trypsin compound. The Journal of general physiology 19, 991-1007.

Kunz-Schughart, L.A., Freyer, J.P., Hofstaedter, F., Ebner, R., 2004. The use of 3-D cultures for high-throughput screening: the multicellular spheroid model. Journal of biomolecular screening 9, 273-285.

Larkin, M.A., Blackshields, G., Brown, N.P., Chenna, R., McGettigan, P.A., McWilliam, H., Valentin, F., Wallace, I.M., Wilm, A., Lopez, R., Thompson, J.D., Gibson, T.J., Higgins, D.G., 2007. Clustal W and Clustal X version 2.0. Bioinformatics 23, 2947-2948.

Laskowski, M., Jr., Kato, I., 1980. Protein inhibitors of proteinases. Annual review of biochemistry 49, 593-626.

Laskowski, M., Jr., Kato, I., Ardelt, W., Cook, J., Denton, A., Empie, M.W., Kohr, W.J., Park, S.J., Parks, K., Schatzley, B.L., et al., 1987. Ovomucoid third domains from 100 avian species: isolation, sequences, and hypervariability of enzyme-inhibitor contact residues. Biochemistry 26, 202-221.

Lauffer, M.A., 1975. Entropy-driven processes in biology. Polymerization of Tobacco Mosaic Virus Protein and Similar Reactions. Molecular biology, biochemistry, and biophysics 1-264.

Lee, M.V., Topper, S.E., Hubler, S.L., Hose, J., Wenger, C.D., Coon, J.J., Gasch, A.P., 2011. A dynamic model of proteome changes reveals new roles for transcript alteration in yeast. Molecular systems biology 7, 514.

Li, J., Wu, J., Wang, Y., Xu, X., Liu, T., Lai, R., Zhu, H., 2008. A small trypsin inhibitor from the frog of Odorrana grahami. Biochimie 90, 1356-1361. 
Li, M.H., Zhang, N.X., Chen, X.Q., Wu, G., Wu, H.M., Hu, G.Y., 2003. BmKK4, a novel toxin from the venom of Asian scorpion Buthus martensii Karsch, inhibits potassium currents in rat hippocampal neurons in vitro. Toxicon 42, 199-205.

Li, R., Wang, H., Jiang, Y., Yu, Y., Wang, L., Zhou, M., Zhang, Y., Chen, T., Shaw, C., 2012. A novel Kazal-type trypsin inhibitor from the skin secretion of the Central American redeyed leaf frog, Agalychnis callidryas. Biochimie 94, 1376-1381.

Lichtenstein, G.R., Deren, J.J., Katz, S., Lewis, J.D., Kennedy, A.R., Ware, J.H., 2008. BowmanBirk inhibitor concentrate: a novel therapeutic agent for patients with active ulcerative colitis. Digestive diseases and sciences 53, 175-180.

Lingaraju, M.H., Gowda, L.R., 2008. A Kunitz trypsin inhibitor of Entada scandens seeds: another member with single disulfide bridge. Biochimica et biophysica acta 1784, 850855.

Liu, H., Chen, J., Wang, X., Yan, S., Xu, Y., San, M., Tang, W., Yang, F., Cao, Z., Li, W., Wu, Y., Chen, Z., 2015. Functional characterization of a new non-Kunitz serine protease inhibitor from the scorpion Lychas mucronatus. International journal of biological macromolecules $72,158-162$.

Lopes, J.L., Valadares, N.F., Moraes, D.I., Rosa, J.C., Araujo, H.S., Beltramini, L.M., 2009. Physico-chemical and antifungal properties of protease inhibitors from Acacia plumosa. Phytochemistry 70, 871-879.

Lopez-Otin, C., Matrisian, L.M., 2007. Emerging roles of proteases in tumour suppression. Nature reviews. Cancer 7, 800-808.

Löser, R., Pietzsch, J., 2015. Cysteine cathepsins: their role in tumor progression and recent trends in the development of imaging probes. Frontiers in chemistry 3, 37.

Lourenço, W.R., Leguin, E.A., 2008. The true identity of Scorpio (Atreus) obscurus Gervais, 1843 (Scorpiones, Buthidae), Euscorpius. Marshall University, Huntington, WV.

Lourenço, W.R., Von Eickstedt, R.D., 2009. Escorpiões de importância médica, in: Cardoso, J.L.C., França, F.O.S., Wen, F.H., Málaque, C.M.S.A., Haddad Jr, V. (Eds.), Animais peçonhentos no Brasil: Biologia, clínica e terapêutica dos acidentes, 2 ed. Sarvier, São Paulo, pp. 198-213.

Luckett, S., Garcia, R.S., Barker, J.J., Konarev, A.V., Shewry, P.R., Clarke, A.R., Brady, R.L., 1999. High-resolution structure of a potent, cyclic proteinase inhibitor from sunflower seeds. Journal of molecular biology 290, 525-533.

Ma, Y., He, Y., Zhao, R., Wu, Y., Li, W., Cao, Z., 2012. Extreme diversity of scorpion venom peptides and proteins revealed by transcriptomic analysis: implication for proteome evolution of scorpion venom arsenal. Journal of proteomics 75, 1563-1576. 
Macedo, M.L., de Sa, C.M., Freire, M.D., Parra, J.R., 2004. A Kunitz-type inhibitor of coleopteran proteases, isolated from Adenanthera pavonina $\mathrm{L}$. seeds and its effect on Callosobruchus maculatus. Journal of agricultural and food chemistry 52, 2533-2540.

MacKinnon, R., 2003. Potassium channels. FEBS letters 555, 62-65.

Maestri Neto, A., Guedes, A.B., Carmo, S.d.F., Chalkidis, H.d.M., Souza Coelho, J., Pardal, P.P.d.O., 2008. Aspectos do Escorpionismo no Estado do Pará-Brasil. Revista Paraense de Medicina 22, 49-55.

Makhatadze, G.I., Kim, K.S., Woodward, C., Privalov, P.L., 1993. Thermodynamics of BPTI folding. Protein science 2, 2028-2036.

Malkowicz, S.B., McKenna, W.G., Vaughn, D.J., Wan, X.S., Propert, K.J., Rockwell, K., Marks, S.H., Wein, A.J., Kennedy, A.R., 2001. Effects of Bowman-Birk inhibitor concentrate (BBIC) in patients with benign prostatic hyperplasia. The Prostate 48, 16-28.

Marini, S., Fiorucci, L., Fioretti, E., Giardina, B., Ascoli, F., 1991. Monoclonal antibodies against protease inhibitors: the case of the bovine pancreatic trypsin inhibitor. Annali dell'Istituto superiore di sanita 27, 161-165.

Markey, F., 1999. What is SPR anyway? BIA journal 1, 14-17.

Martins, M.A., Barrada, L., Silva, R.H.V., Pardal, P.P.O., 2002. Estudo clínico e epidemiológico dos acidentes por escorpiões atendidos no Hospital Universitário João de Barros Barreto, período de janeiro a dezembro de 1996. Revista Paraense de Medicina 16, 34-38.

Masters, J.R., 2002. HeLa cells 50 years on: the good, the bad and the ugly. Nature reviews. Cancer 2, 315-319.

McGrath, M.E., Mirzadegan, T., Schmidt, B.F., 1997. Crystal structure of phenylmethanesulfonyl fluoride-treated human chymase at 1.9 A. Biochemistry 36, 14318-14324.

Mebs, D., Gebauer, E., 1980. Isolation of proteinase inhibitory, toxic and hemolytic polypeptides from a sea anemone, Stoichactis sp. Toxicon 18, 97-106.

Mitsudo, K., Jayakumar, A., Henderson, Y., Frederick, M.J., Kang, Y., Wang, M., El-Naggar, A.K., Clayman, G.L., 2003. Inhibition of serine proteinases plasmin, trypsin, subtilisin A, cathepsin G, and elastase by LEKTI: a kinetic analysis. Biochemistry 42, 3874-3881.

Moin, K., Sameni, M., Victor, B.C., Rothberg, J.M., Mattingly, R.R., Sloane, B.F., 2012. 3D/4D functional imaging of tumor-associated proteolysis: impact of microenvironment. Methods in enzymology 506, 175-194.

Moro, N., Mauch, C., Zigrino, P., 2014. Metalloproteinases in melanoma. European journal of cell biology $93,23-29$. 
Morrison, J.F., 1969. Kinetics of the reversible inhibition of enzyme-catalysed reactions by tight-binding inhibitors. Biochimica et biophysica acta 185, 269-286.

Mosmann, T., 1983. Rapid colorimetric assay for cellular growth and survival: application to proliferation and cytotoxicity assays. J Immunol Methods 65, 55-63.

Mouhat, S., De Waard, M., Sabatier, J.M., 2005. Contribution of the functional dyad of animal toxins acting on voltage-gated $K_{v} 1$-type channels. Journal of peptide science $11,65-$ 68.

Mouhat, S., Mosbah, A., Visan, V., Wulff, H., Delepierre, M., Darbon, H., Grissmer, S., De Waard, M., Sabatier, J.M., 2004. The 'functional' dyad of scorpion toxin Pi1 is not itself a prerequisite for toxin binding to the voltage-gated $\mathrm{K}_{\mathrm{v}} 1.2$ potassium channels. The Biochemical journal 377, 25-36.

Mourão, C.B., Oliveira, F.N., e Carvalho, A.C., Arenas, C.J., Duque, H.M., Gonçalves, J.C., Macedo, J.K., Galante, P., Schwartz, C.A., Mortari, M.R., Almeida Santos Mde, F., Schwartz, E.F., 2013. Venomic and pharmacological activity of Acanthoscurria paulensis (Theraphosidae) spider venom. Toxicon 61, 129-138.

Mourão, C.B., Schwartz, E.F., 2013. Protease inhibitors from marine venomous animals and their counterparts in terrestrial venomous animals. Marine drugs 11, 2069-2112.

MS, 2009. Secretaria de Vigilância em Saúde: Departamento de Vigilância Epidemiológica: Manual de controle de escorpiões. Ministério da Saúde, Brasília.

Mukherjee, A.K., Mackessy, S.P., Dutta, S., 2014. Characterization of a Kunitz-type protease inhibitor peptide (Rusvikunin) purified from Daboia russelii russelii venom. International journal of biological macromolecules $67,154-162$.

Murgia, A.R., Batista, C.V., Prestipino, G., Possani, L.D., 2004. Amino acid sequence and function of a new alpha-toxin from the Amazonian scorpion Tityus cambridgei. Toxicon $43,737-740$.

Murphy, D.J., 2004. Determination of accurate $K_{I}$ values for tight-binding enzyme inhibitors: an in silico study of experimental error and assay design. Analytical biochemistry 327, 61-67.

Myers, D.K., 1952. Studies on cholinesterase. 7. Determination of the molar concentration of pseudo-cholinesterase in serum. The Biochemical journal 51, 303-311.

Myszka, D.G., He, X., Dembo, M., Morton, T.A., Goldstein, B., 1998. Extending the range of rate constants available from BIACORE: interpreting mass transport-influenced binding data. Biophysical journal 75, 583-594.

Nabi, G., Ahmad, N., Ullah, S., Dr., G., Khan, S., 2014. Therapeutic Applications of Scorpion Venom in Cancer: Mini Review. Journal of Biology and Life Science 6 (1), 57-66. 
Nascimento, D.G., Rates, B., Santos, D.M., Verano-Braga, T., Barbosa-Silva, A., Dutra, A.A., Biondi, I., Martin-Eauclaire, M.F., De Lima, M.E., Pimenta, A.M., 2006. Moving pieces in a taxonomic puzzle: venom $2 \mathrm{D}-\mathrm{LC} / \mathrm{MS}$ and data clustering analyses to infer phylogenetic relationships in some scorpions from the Buthidae family (Scorpiones). Toxicon 47, 628-639.

Navaneetham, D., Sinha, D., Walsh, P.N., 2010. Mechanisms and specificity of factor Xla and trypsin inhibition by protease nexin 2 and basic pancreatic trypsin inhibitor. Journal of biochemistry $148,467-479$.

Navaneetham, D., Wu, W., Li, H., Sinha, D., Tuma, R.F., Walsh, P.N., 2013. P1 and P2' site mutations convert protease nexin-2 from a factor Xla inhibitor to a plasmin inhibitor. Journal of biochemistry 153, 221-231.

Nelson, D.L., Cox, M.M., 2006. Lehninger princípios de bioquímica, 4 ed. Sarvier, São Paulo.

$\mathrm{NIH}, 2010$. What you need to know about melanoma and other skin cancers. National Institutes of Health.

Nomura, D.K., Dix, M.M., Cravatt, B.F., 2010. Activity-based protein profiling for biochemical pathway discovery in cancer. Nature reviews. Cancer 10, 630-638.

O'Shannessy, D.J., Brigham-Burke, M., Soneson, K.K., Hensley, P., Brooks, I., 1993. Determination of rate and equilibrium binding constants for macromolecular interactions using surface plasmon resonance: use of nonlinear least squares analysis methods. Analytical biochemistry 212, 457-468.

Ohta, K., Makinen, K.K., Loesche, W.J., 1986. Purification and characterization of an enzyme produced by Treponema denticola capable of hydrolyzing synthetic trypsin substrates. Infection and immunity 53, 213-220.

Olamendi-Portugal, T., Gomez-Lagunas, F., Gurrola, G.B., Possani, L.D., 1998. Two similar peptides from the venom of the scorpion Pandinus imperator, one highly effective blocker and the other inactive on $\mathrm{K}^{+}$channels. Toxicon 36, 759-770.

Oliveira, F.N., Mortari, M.R., Carneiro, F.P., Guerrero-Vargas, J.A., Santos, D.M., Pimenta, A.M., Schwartz, E.F., 2013. Another record of significant regional variation in toxicity of Tityus serrulatus venom in Brazil: a step towards understanding the possible role of sodium channel modulators. Toxicon $73,33-46$.

Ortiz, E., Gurrola, G.B., Schwartz, E.F., Possani, L.D., 2015. Scorpion venom components as potential candidates for drug development. Toxicon 93, 125-135.

Otlewski, J., Jaskolski, M., Buczek, O., Cierpicki, T., Czapinska, H., Krowarsch, D., Smalas, A.O., Stachowiak, D., Szpineta, A., Dadlez, M., 2001. Structure-function relationship of serine protease-protein inhibitor interaction. Acta biochimica Polonica 48, 419-428. 
Otlewski, J., Jelen, F., Zakrzewska, M., Oleksy, A., 2005. The many faces of protease-protein inhibitor interaction. The EMBO journal 24, 1303-1310.

Ovsepian, S.V., LeBerre, M., Steuber, V., O'Leary, V.B., Leibold, C., Oliver Dolly, J., 2016. Distinctive role of $\mathrm{K}_{\mathrm{v}} 1.1$ subunit in the biology and functions of low threshold $\mathrm{K}^{+}$ channels with implications for neurological disease. Pharmacology \& therapeutics $159,93-101$.

Owen, D.G., Hall, A., Stephens, G., Stow, J., Robertson, B., 1997. The relative potencies of dendrotoxins as blockers of the cloned voltage-gated K+ channel, mK 1.1 (MK-1), when stably expressed in Chinese hamster ovary cells. British journal of pharmacology 120 , 1029-1034.

Page, M.J., Di Cera, E., 2008. Serine peptidases: classification, structure and function. Cellular and molecular life sciences 65, 1220-1236.

Paluncic, J., Kovacevic, Z., Jansson, P.J., Kalinowski, D., Merlot, A., Huang, M.L., Lok, H., Sahni, S., Lane, D.J., Richardson, D.R., 2016. Roads to melanoma: Key pathways and emerging players in melanoma progression and oncogenic signaling. Biochimica et biophysica acta $1863(4), 770-84$.

Pardal, P.P., 2014. Contribuição ao conhecimento do escorpionismo e do escorpião Tityus obscurus Gervais, 1843 (Scorpiones: Buthidae) de duas regiões distintas no estado do Pará na Amazônia brasileira, Núcleo de Medicina Tropical. Programa de PósGraduação em Doenças Tropicais. Tese de Doutorado. Universidade Federal do Pará, p. 93.

Pardal, P.P., Ishikawa, E.A., Vieira, J.L., Coelho, J.S., Dorea, R.C., Abati, P.A., Quiroga, M.M., Chalkidis, H.M., 2014. Clinical aspects of envenomation caused by Tityus obscurus (Gervais, 1843) in two distinct regions of Pará state, Brazilian Amazon basin: a prospective case series. The journal of venomous animals and toxins including tropical diseases 20, 3.

Pardal, P.P.O., Castro, L.C., Jennings, E., Pardal, J.S.O., Monteiro, M.R., 2003. [Epidemiological and clinical aspects of scorpion envenomation in the region of Santarém, Pará, Brazil]. Rev Soc Bras Med Trop 36, 349-353.

Pardo-Lopez, L., Zhang, M., Liu, J., Jiang, M., Possani, L.D., Tseng, G.N., 2002. Mapping the binding site of a human ether-a-go-go-related gene-specific peptide toxin (ErgTx) to the channel's outer vestibule. The Journal of biological chemistry 277, 16403-16411.

Pardo, L.A., Stuhmer, W., 2014. The roles of $\mathrm{K}^{+}$channels in cancer. Nature reviews. Cancer $14,39-48$. 
Park, C.S., Miller, C., 1992. Mapping function to structure in a channel-blocking peptide: electrostatic mutants of charybdotoxin. Biochemistry 31, 7749-7755.

Peigneur, S., Billen, B., Derua, R., Waelkens, E., Debaveye, S., Beress, L., Tytgat, J., 2011. A bifunctional sea anemone peptide with Kunitz type protease and potassium channel inhibiting properties. Biochemical pharmacology 82, 81-90.

Polis, G.A., 1990. The Biology of Scorpions. Stanford University Press, Stanford, CA, 1990. xxvi, 587 pp. Science 249, 1176-1177.

Powers, J.C., Asgian, J.L., Ekici, O.D., James, K.E., 2002. Irreversible inhibitors of serine, cysteine, and threonine proteases. Chemical reviews 102, 4639-4750.

Prasad, E.R., Merzendorfer, H., Madhurarekha, C., Dutta-Gupta, A., Padmasree, K., 2010. Bowman-Birk proteinase inhibitor from Cajanus cajan seeds: purification, characterization, and insecticidal properties. Journal of agricultural and food chemistry 58, 2838-2847.

Prasad, S., Cantwell, A.M., Bush, L.A., Shih, P., Xu, H., Di Cera, E., 2004. Residue Asp-189 controls both substrate binding and the monovalent cation specificity of thrombin. The Journal of biological chemistry 279, 10103-10108.

Prendini, L., 2011. Order Scorpiones C.L. Koch, 1850, in: Zhang, Z.-Q.E. (Ed.), Animal biodiversity: An outline of higher-level classification and survey of taxonomic richness. Zootaxa, pp. 115-117.

Pucca, M.B., Amorim, F.G., Cerni, F.A., Bordon Kde, C., Cardoso, I.A., Anjolette, F.A., Arantes, E.C., 2014a. Influence of post-starvation extraction time and prey-specific diet in Tityus serrulatus scorpion venom composition and hyaluronidase activity. Toxicon 90, 326336.

Pucca, M.B., Oliveira, F.N., Schwartz, E.F., Arantes, E.C., Lira-da-Silva, R.M., 2014b. Scorpionism and Dangerous Species of Brazil, in: Gopalakrishnakone, P., Possani, L.D., F. Schwartz, E., Rodríguez de la Vega, R.C. (Eds.), Scorpion Venoms. Springer Netherlands, pp. 299-324.

Puente, X.S., Sanchez, L.M., Gutierrez-Fernandez, A., Velasco, G., Lopez-Otin, C., 2005. A genomic view of the complexity of mammalian proteolytic systems. Biochemical Society transactions $33,331-334$.

Qi, R.F., Song, Z.W., Chi, C.W., 2005. Structural features and molecular evolution of BowmanBirk protease inhibitors and their potential application. Acta biochimica et biophysica Sinica 37, 283-292. 
Rajic, A., Kweifio-Okai, G., Macrides, T., Sandeman, R.M., Chandler, D.S., Polya, G.M., 2000. Inhibition of serine proteases by anti-inflammatory triterpenoids. Planta medica 66, 206-210.

Ranjan, R., Khazen, G., Gambazzi, L., Ramaswamy, S., Hill, S.L., Schurmann, F., Markram, H., 2011. Channelpedia: an integrative and interactive database for ion channels. Frontiers in neuroinformatics 5, 36.

Rawlings, N.D., Barrett, A.J., Bateman, A., 2011. Asparagine peptide lyases: a seventh catalytic type of proteolytic enzymes. The Journal of biological chemistry 286, 3832138328.

Rich, R.L., Myszka, D.G., 2000. Advances in surface plasmon resonance biosensor analysis. Current opinion in biotechnology 11, 54-61.

Robbins, C.A., Tempel, B.L., 2012. $\mathrm{K}_{\mathrm{v}} 1.1$ and $\mathrm{K}_{\mathrm{v}} 1.2$ : similar channels, different seizure models. Epilepsia 53 Suppl 1, 134-141.

Rodríguez de la Vega, R.C., Merino, E., Becerril, B., Possani, L.D., 2003. Novel interactions between $\mathrm{K}^{+}$channels and scorpion toxins. Trends in pharmacological sciences $24,222-$ 227.

Rodriguez de la Vega, R.C., Possani, L.D., 2005. Overview of scorpion toxins specific for $\mathrm{Na}^{+}$ channels and related peptides: biodiversity, structure-function relationships and evolution. Toxicon 46, 831-844.

Rodríguez de la Vega, R.C., Possani, L.D., 2004. Current views on scorpion toxins specific for $\mathrm{K}^{+}$-channels. Toxicon 43, 865-875.

Ruddon, R.W., 2007. Cancer Biology. Oxford University Press, USA.

Ruhlmann, A., Kukla, D., Schwager, P., Bartels, K., Huber, R., 1973. Structure of the complex formed by bovine trypsin and bovine pancreatic trypsin inhibitor. Crystal structure determination and stereochemistry of the contact region. Journal of molecular biology 77, 417-436.

Sahdev, S., Khattar, S.K., Saini, K.S., 2008. Production of active eukaryotic proteins through bacterial expression systems: a review of the existing biotechnology strategies. Molecular and cellular biochemistry 307, 249-264.

Schechter, I., Berger, A., 1967. On the size of the active site in proteases. I. Papain. Biochemical and biophysical research communications 27, 157-162.

Scheidig, A.J., Hynes, T.R., Pelletier, L.A., Wells, J.A., Kossiakoff, A.A., 1997. Crystal structures of bovine chymotrypsin and trypsin complexed to the inhibitor domain of Alzheimer's amyloid ?-protein precursor (APPI) and basic pancreatic trypsin inhibitor (BPTI): engineering of inhibitors with altered specificities. Protein science 6, 1806-1824. 
Schimer, J., Pavova, M., Anders, M., Pachl, P., Sacha, P., Cigler, P., Weber, J., Majer, P., Rezacova, P., Krausslich, H.G., Muller, B., Konvalinka, J., 2015. Triggering HIV polyprotein processing by light using rapid photodegradation of a tight-binding protease inhibitor. Nature communications 6, 6461.

Schubert, F., Zettl, H., Hafner, W., Krauss, G., Krausch, G., 2003. Comparative thermodynamic analysis of DNA - protein interactions using surface plasmon resonance and fluorescence correlation spectroscopy. Biochemistry 42, 10288-10294.

Schwartz, E.F., Diego-Garcia, E., Rodríguez de la Vega, R.C., Possani, L.D., 2007. Transcriptome analysis of the venom gland of the Mexican scorpion Hadrurus gertschi (Arachnida: Scorpiones). BMC genomics 8, 119.

Schweitz, H., Bruhn, T., Guillemare, E., Moinier, D., Lancelin, J.M., Beress, L., Lazdunski, M., 1995. Kalicludines and kaliseptine. Two different classes of sea anemone toxins for voltage sensitive $\mathrm{K}^{+}$channels. The Journal of biological chemistry 270, 25121-25126.

Shadrin, N., Shapira, M.G., Khalfin, B., Uppalapati, L., Parola, A.H., Nathan, I., 2015. Serine protease inhibitors interact with IFN- $\gamma$ through up-regulation of FasR; a novel therapeutic strategy against cancer. Experimental cell research 330, 233-239.

Shewry, P., 1999. Enzyme inhibitors of seeds: types and properties, in: Shewry, P., Casey, R. (Eds.), Seed Proteins. Springer Netherlands, pp. 587-615.

Shibata, T., Ogawa, M., Takata, N., Matsuda, K., Niinobu, T., Uda, K., Wakasugi, C., Mori, T., 1987. Distribution of pancreatic secretory trypsin inhibitor in various human tissues and its inactivation in the gastric mucosa. Research communications in chemical pathology and pharmacology 55, 243-248.

Shields, D.J., Niessen, S., Murphy, E.A., Mielgo, A., Desgrosellier, J.S., Lau, S.K., Barnes, L.A., Lesperance, J., Bouvet, M., Tarin, D., Cravatt, B.F., Cheresh, D.A., 2010. RBBP9: a tumorassociated serine hydrolase activity required for pancreatic neoplasia. Proceedings of the National Academy of Sciences of the United States of America 107, 2189-2194.

Skarzynski, T., 1992. Crystal structure of $\alpha$-dendrotoxin from the green mamba venom and its comparison with the structure of bovine pancreatic trypsin inhibitor. Journal of molecular biology 224, 671-683.

Skarżyński, T., 1992. Crystal structure of $\alpha$-dendrotoxin from the green mamba venom and its comparison with the structure of bovine pancreatic trypsin inhibitor. Journal of molecular biology 224, 671-683.

Sloane, B.F., Sameni, M., Podgorski, I., Cavallo-Medved, D., Moin, K., 2006. Functional imaging of tumor proteolysis. Annual review of pharmacology and toxicology 46, 301315. 
Smith, L.A., Reid, P.F., Wang, F.C., Parcej, D.N., Schmidt, J.J., Olson, M.A., Dolly, J.O., 1997. Site-directed mutagenesis of dendrotoxin $K$ reveals amino acids critical for its interaction with neuronal $\mathrm{K}^{+}$channels. Biochemistry 36, 7690-7696.

Soding, J., Biegert, A., Lupas, A.N., 2005. The HHpred interactive server for protein homology detection and structure prediction. Nucleic acids research 33, W244-248.

Song, G., Zhou, M., Chen, W., Chen, T., Walker, B., Shaw, C., 2008. HV-BBI -- a novel amphibian skin Bowman-Birk-like trypsin inhibitor. Biochemical and biophysical research communications 372, 191-196.

Song, Y., Gong, K., Yan, H., Hong, W., Wang, L., Wu, Y., Li, W., Cao, Z., 2014. Sj7170, a unique dual-function peptide with a specific $\alpha$-chymotrypsin inhibitory activity and a potent tumor-activating effect from scorpion venom. The Journal of biological chemistry 289, 11667-11680.

Sperotto, L.S., Yamano, E.Y.S., Knowles, B.M., Camilo, F.S., Silva, M.A., Sousa, R.D., Zanelato, E., Pardal, P.P.O., 2001. Estudo clínico e epidemiológico de 27 casos de escorpionismo em Brasil Novo/Altamira-PA. Período de fevereiro a setembro de 2000. Revista da Sociedade Brasileira de Medicina Tropical 34, 381.

Sreerama, N., Manning, M.C., Powers, M.E., Zhang, J.X., Goldenberg, D.P., Woody, R.W., 1999. Tyrosine, phenylalanine, and disulfide contributions to the circular dichroism of proteins: circular dichroism spectra of wild-type and mutant bovine pancreatic trypsin inhibitor. Biochemistry 38, 10814-10822.

Sreerama, N., Woody, R.W., 2000. Estimation of protein secondary structure from circular dichroism spectra: comparison of CONTIN, SELCON, and CDSSTR methods with an expanded reference set. Analytical biochemistry 287, 252-260.

Stassen, J.M., Lambeir, A.M., Matthyssens, G., Ripka, W.C., Nystrom, A., Sixma, J.J., Vermylen, J., 1995. Characterisation of a novel series of aprotinin-derived anticoagulants. I. In vitro and pharmacological properties. Thrombosis and haemostasis $74,646-654$.

Stehling, E.G., Sforca, M.L., Zanchin, N.I., Oyama, S., Jr., Pignatelli, A., Belluzzi, O., Polverini, E., Corsini, R., Spisni, A., Pertinhez, T.A., 2012. Looking over toxin-K+ $\mathrm{K}^{+}$channel interactions. Clues from the structural and functional characterization of $\alpha-K T x$ toxin Tc32, a Kv1.3 channel blocker. Biochemistry 51, 1885-1894.

Stoscheck, C.M., 1990a. Quantification of protein., in: DEUTSCHER, M.P.E. (Ed.), Methods in Enzymology. New York: Academic Press Inc., pp. 50-68.

Stoscheck, C.M., 1990b. Quantitation of protein. Methods in enzymology 182, 50-68. 
Straus, O.H., Goldstein, A., 1943. Zone behavior of enzymes : Illustrated by the effect of dissociation constant and dilution on the system cholinesterase-physostigmine. The Journal of general physiology 26, 559-585.

Strelow, J., Dewe, W., Iversen, P.W., Brooks, H.B., Radding, J.A., McGee, J., Weidner, J., 2004. Mechanism of action assays for enzymes, in: Sittampalam, G.S., Coussens, N.P., Nelson, H., Arkin, M., Auld, D., Austin, C., Bejcek, B., Glicksman, M., Inglese, J., Iversen, P.W., Li, Z., McGee, J., McManus, O., Minor, L., Napper, A., Peltier, J.M., Riss, T., Trask, O.J., Jr., Weidner, J. (Eds.), Assay Guidance Manual, Bethesda (MD).

Stricher, F., Martin, L., Vita, C., 2006. Design of miniproteins by the transfer of active sites onto small-size scaffolds. Methods Mol Biol 340, 113-149.

Swartz, K.J., 2013. The scorpion toxin and the potassium channel. elife 2, e00873.

Takayama, M., 2001. In-source decay characteristics of peptides in matrix-assisted laser desorption/ionization time-of-flight mass spectrometry. Journal of the American Society for Mass Spectrometry 12, 420-427.

Tenenholz, T.C., Rogowski, R.S., Collins, J.H., Blaustein, M.P., Weber, D.J., 1997. Solution structure for Pandinus toxin K- $\alpha$ (PiTX-K $\alpha$ ), a selective blocker of A-type potassium channels. Biochemistry 36, 2763-2771.

Thomas, D., Karle, C.A., Kiehn, J., 2006. The cardiac $h E R G / I_{k r}$ potassium channel as pharmacological target: structure, function, regulation, and clinical applications. Current pharmaceutical design 12, 2271-2283.

Thouta, S., Sokolov, S., Abe, Y., Clark, S.J., Cheng, Y.M., Claydon, T.W., 2014. Proline scan of the HERG channel S6 helix reveals the location of the intracellular pore gate. Biophysical journal 106, 1057-1069.

Tomlinson, S.E., Tan, S.V., Kullmann, D.M., Griggs, R.C., Burke, D., Hanna, M.G., Bostock, H., 2010. Nerve excitability studies characterize $\mathrm{K}_{\mathrm{v}} 1.1$ fast potassium channel dysfunction in patients with episodic ataxia type 1. Brain 133, 3530-3540.

Tschesche, H., Kolkenbrock, H., Bode, W., 1987. The covalent structure of the elastase inhibitor from Anemonia sulcata - a "non-classical" Kazal-type protein. Biological chemistry Hoppe-Seyler 368, 1297-1304.

Turk, B., 2006. Targeting proteases: successes, failures and future prospects. Nature reviews. Drug discovery 5, 785-799.

Tytgat, J., Vandenberghe, I., Ulens, C., Van Beeumen, J., 2001. New polypeptide components purified from mamba venom. FEBS letters 491, 217-221.

Uhland, K., 2006. Matriptase and its putative role in cancer. Cellular and molecular life sciences 63, 2968-2978. 
Urrego, D., Tomczak, A.P., Zahed, F., Stuhmer, W., Pardo, L.A., 2014. Potassium channels in cell cycle and cell proliferation. Philosophical transactions of the Royal Society of London. Series B 369, 20130094.

Vakorina, T.I., Gladkikh, I.N., Monastyrnaia, M.M., Kozlovskaia, E.P., 2011. [Conformational stability of serine proteinase inhibitor from the sea anemone Heteractis crispa]. Bioorganicheskaia khimiia 37, 310-318.

Van Nostrand, W.E., Schmaier, A.H., Siegel, R.S., Wagner, S.L., Raschke, W.C., 1995. Enhanced plasmin inhibition by a reactive center lysine mutant of the Kunitz-type protease inhibitor domain of the amyloid ?-protein precursor. The Journal of biological chemistry $270,22827-22830$.

Vandenberg, J.I., Perry, M.D., Perrin, M.J., Mann, S.A., Ke, Y., Hill, A.P., 2012. hERG K' channels: structure, function, and clinical significance. Physiological reviews 92, 13931478.

Vandendriessche, T., Kopljar, I., Jenkins, D.P., Diego-Garcia, E., Abdel-Mottaleb, Y., Vermassen, E., Clynen, E., Schoofs, L., Wulff, H., Snyders, D., Tytgat, J., 2012. Purification, molecular cloning and functional characterization of HelaTx1 (Heterometrus laoticus): the first member of a new K-KTX subfamily. Biochem Pharmacol 83, 1307-1317.

Verdier, L., Al-Sabi, A., Rivier, J.E., Olivera, B.M., Terlau, H., Carlomagno, T., 2005. Identification of a novel pharmacophore for peptide toxins interacting with $\mathrm{K}^{+}$ channels. The Journal of biological chemistry 280, 21246-21255.

Vincent, J.P., Lazdunski, M., 1972. Trypsin-pancreatic trypsin inhibitor association. Dynamics of the interaction and role of disulfide bridges. Biochemistry 11, 2967-2977.

Vincent, J.P., Lazdunski, M., 1973. The interaction between $\alpha$-chymotrypsin and pancreatic trypsin inhibitor (Kunitz inhibitor). Kinetic and thermodynamic properties. European journal of biochemistry / FEBS 38, 365-372.

Vogel, C., Marcotte, E.M., 2012. Insights into the regulation of protein abundance from proteomic and transcriptomic analyses. Nature reviews. Genetics 13, 227-232.

Vranken, W.F., 2014. NMR structure validation in relation to dynamics and structure determination. Progress in nuclear magnetic resonance spectroscopy 82, 27-38.

Waddell, W.J., 1956. A simple ultraviolet spectrophotometric method for the determination of protein. The Journal of laboratory and clinical medicine 48, 311-314.

Wagner, G., Braun, W., Havel, T.F., Schaumann, T., Go, N., Wuthrich, K., 1987. Protein structures in solution by nuclear magnetic resonance and distance geometry. The 
polypeptide fold of the basic pancreatic trypsin inhibitor determined using two different algorithms, DISGEO and DISMAN. Journal of molecular biology 196, 611-639.

Wang, F.C., Bell, N., Reid, P., Smith, L.A., McIntosh, P., Robertson, B., Dolly, J.O., 1999. Identification of residues in dendrotoxin $\mathrm{K}$ responsible for its discrimination between neuronal $\mathrm{K}^{+}$channels containing $\mathrm{K}_{\mathrm{v}} 1.1$ and 1.2 a subunits. European journal of biochemistry / FEBS 263, 222-229.

Wang, G.P., Xu, C.S., 2010. Pancreatic secretory trypsin inhibitor: More than a trypsin inhibitor. World journal of gastrointestinal pathophysiology 1, 85-90.

Wang, I., Wu, S.H., Chang, H.K., Shieh, R.C., Yu, H.M., Chen, C., 2002. Solution structure of a $\mathrm{K}^{+}$-channel blocker from the scorpion Tityus cambridgei. Protein science 11, 390-400.

Wang, Y., Chen, X., Zhang, N., Wu, G., Wu, H., 2005. The solution structure of BmTx3B, a member of the scorpion toxin subfamily $\alpha-K T \times 16$. Proteins $58,489-497$.

Warmke, J.W., Ganetzky, B., 1994. A family of potassium channel genes related to eag in Drosophila and mammals. Proceedings of the National Academy of Sciences of the United States of America 91, 3438-3442.

Wee, C.L., Bemporad, D., Sands, Z.A., Gavaghan, D., Sansom, M.S., 2007. SGTx1, a Kv channel gating-modifier toxin, binds to the interfacial region of lipid bilayers. Biophysical journal 92, L07-09.

Whitmore, L., Wallace, B.A., 2004. DICHROWEB, an online server for protein secondary structure analyses from circular dichroism spectroscopic data. Nucleic acids research 32, W668-673.

Williams, J.W., Morrison, J.F., 1979. The kinetics of reversible tight-binding inhibition. Methods in enzymology 63, 437-467.

Wilson, W.D., 2002. Analyzing biomolecular interactions. Science 295, 2103-2105.

Wulff, H., Zhorov, B.S., 2008. $\mathrm{K}^{+}$channel modulators for the treatment of neurological disorders and autoimmune diseases. Chemical reviews 108, 1744-1773.

Yang, W., Feng, J., Wang, B., Cao, Z., Li, W., Wu, Y., Chen, Z., 2014. BF9, the first functionally characterized snake toxin peptide with Kunitz-type protease and potassium channel inhibiting properties. Journal of biochemical and molecular toxicology $28,76-83$.

Yin, D., Sun, H., Weaver, R.F., Squier, T.C., 1999. Nonessential role for methionines in the productive association between calmodulin and the plasma membrane Ca-ATPase. Biochemistry 38, 13654-13660.

Yu, K., Fu, W., Liu, H., Luo, X., Chen, K.X., Ding, J., Shen, J., Jiang, H., 2004. Computational simulations of interactions of scorpion toxins with the voltage-gated potassium ion channel. Biophysical journal 86, 3542-3555. 
Yuan, C.H., He, Q.Y., Peng, K., Diao, J.B., Jiang, L.P., Tang, X., Liang, S.P., 2008. Discovery of a distinct superfamily of Kunitz-type toxin (KTT) from tarantulas. PloS one 3, e3414.

Zablotna, E., Kazmierczak, K., Jaskiewicz, A., Stawikowski, M., Kupryszewski, G., Rolka, K., 2002. Chemical synthesis and kinetic study of the smallest naturally occurring trypsin inhibitor SFTI-1 isolated from sunflower seeds and its analogues. Biochemical and biophysical research communications 292, 855-859.

Zeng, X.C., Peng, F., Luo, F., Zhu, S.Y., Liu, H., Li, W.X., 2001. Molecular cloning and characterization of four scorpion $\mathrm{K}^{+}$-toxin-like peptides: a new subfamily of venom peptides ( $\alpha$-KTx14) and genomic analysis of a member. Biochimie 83, 883-889.

Zhang, N., Chen, X., Li, M., Cao, C., Wang, Y., Wu, G., Hu, G., Wu, H., 2004. Solution structure of BmKK4, the first member of subfamily $\alpha-K T \times 17$ of scorpion toxins. Biochemistry 43, 12469-12476.

Zhao, R., Dai, H., Qiu, S., Li, T., He, Y., Ma, Y., Chen, Z., Wu, Y., Li, W., Cao, Z., 2011. SdPI, the first functionally characterized Kunitz-type trypsin inhibitor from scorpion venom. PLoS One 6, e27548.

Zhijian, C., Feng, L., Yingliang, W., Xin, M., Wenxin, L., 2006. Genetic mechanisms of scorpion venom peptide diversification. Toxicon 47, 348-355.

Zhu, S., Huys, I., Dyason, K., Verdonck, F., Tytgat, J., 2004. Evolutionary trace analysis of scorpion toxins specific for K-channels. Proteins 54, 361-370.

Zupunski, V., Kordis, D., Gubensek, F., 2003. Adaptive evolution in the snake venom Kunitz/BPTI protein family. FEBS letters 547, 131-136. 


\section{APÊNDICE}

Apêndice I. Mourão, C.B., Schwartz, E.F., 2013. Protease inhibitors from marine venomous animals and their counterparts in terrestrial venomous animals. Marine drugs 11, 2069-2112. 